\title{
Phosphorescent Bismoviologens for Electrophosphorochromism and Visible Light-Induced Cross-Dehydrogenative Coupling
}

\author{
Wenqiang Ma, ${ }^{\dagger}$ Letian Xu, ${ }^{\dagger}$ Sikun Zhang, ${ }^{\dagger}$ Guoping $\mathrm{Li},{ }^{\dagger}$ Tianyu $\mathrm{Ma},{ }^{\perp}$ Bin Rao, ${ }^{\ddagger}$ Mingming Zhang ${ }^{\S}$ \\ and Gang $\mathrm{He}^{*}, \dagger$
}

tFrontier Institute of Science and Technology, State Key Laboratory for Strength and Vibration of Mechanical Structures, Key Laboratory of Shaanxi Province for Craniofacial Precision Medicine Research, College of Stomatology, Xi'an Jiaotong University, Xi'an, Shaanxi 710054, P. R. China.

${ }^{\perp}$ Frontier Institute of Science and Technology, Xi'an Jiaotong University, Xi'an, Shaanxi 710054, P. R. China. ‡School of Chemistry, Xi'an Key Laboratory of Sustainable Energy Materials Chemistry, Xi'an Jiaotong University, Xi'an, Shaanxi 710049, P. R. China.

§School of Materials Science and Engineering, Xi'an Jiaotong University, Xi'an, Shaanxi 710049, P. R. China.

\begin{abstract}
A series of novel bismuth-bridged viologen analogues, bismoviologens $\left(\mathrm{BiV}^{2+}\right)$, synthesized through a combination of bismuth atom and viologen skeleton is reported. Their optical and electrochemical properties were fine-tuned through the $\mathrm{N}$-arylation or $\mathrm{N}$-alkylation reactions. Bismolviologens not only showed good redox properties but also exhibited phosphorescence under ambient conditions (in air at room temperature). This phenomenon makes $\mathrm{BiV}^{2+}$ the first examples of phosphorescent viologen analogues reported to date. On the basis of the excellent and unique redox and optical properties of $\mathrm{BiV}^{2+}$, their electrophosphorochromic devices were fabricated. Furthermore, the $\mathrm{BiV}^{2+}$ was used for the first time as both a photocatalyst and electron mediator in visible light-induced cross-dehydrogenative coupling reactions.
\end{abstract}




\section{Table of Contents}

1. Materials and instrumentation S3

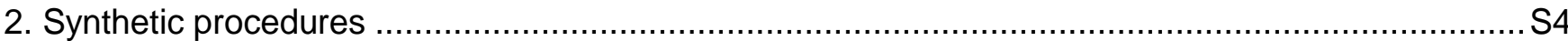

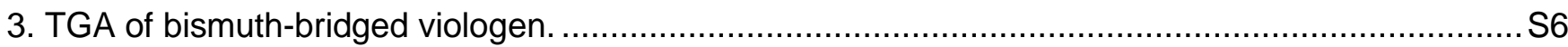

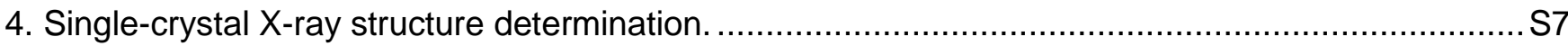

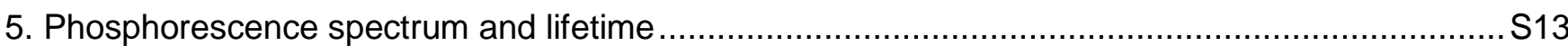

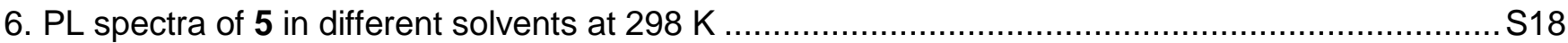

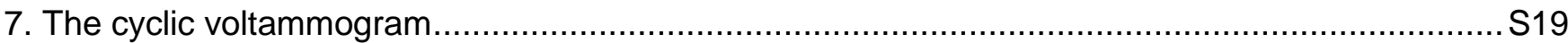

8. Electrostatic potential surfaces of bismoviologens dications and radical species........................S2 1

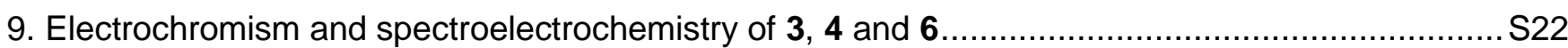

10. Optical stability test for electrochromic switching of $\mathbf{5}$ and $\mathbf{5}+\mathrm{FeCp}_{2}$ complex ........................S24

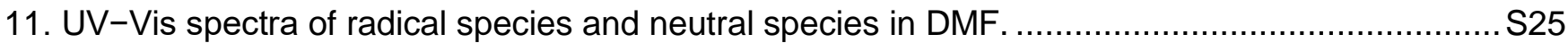

12. Photoluminescence spectrum of radical species and neutral species......................................S26

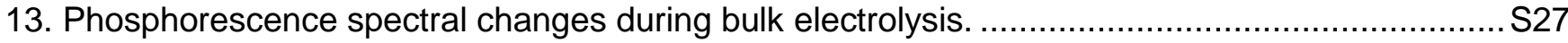

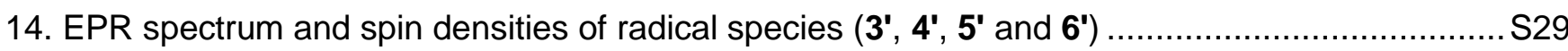

15. Visible light-induced cross-dehydrogenative coupling reactions ............................................. 330

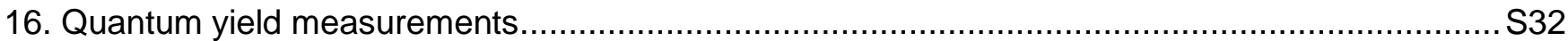

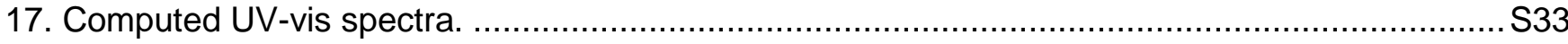

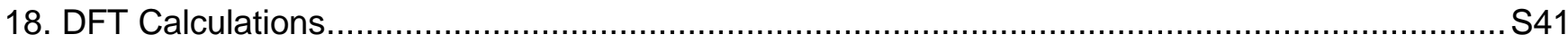

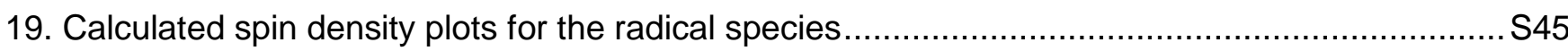

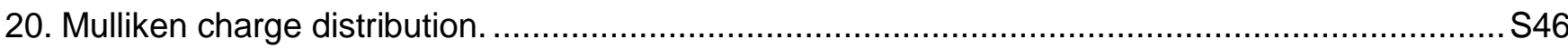

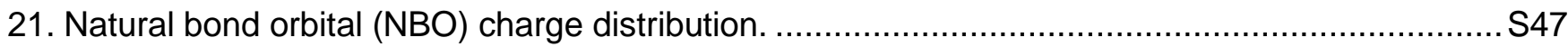

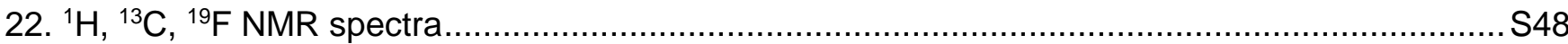

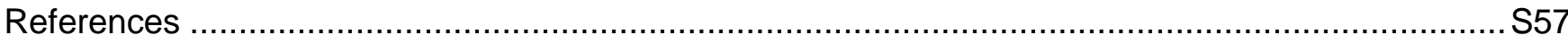




\section{Experimental Procedures}

\section{Materials and instrumentation}

General. All reactions were performed using standard Schlenk and glovebox (Vigor) techniques under argon atmosphere. $\mathrm{Et}_{2} \mathrm{O}, \mathrm{THF}$ were distilled from sodium/benzophenone prior to use. Dry DMF, Anhydrous Cu(OAc) 2 (97\%), Benzene (99\%), Thiophene (99\%), 3Chloroperoxybenzoic acid (85\%), $I_{2}(99.8 \%)$, lodobenzene (98\%) were purchased from Energy Chemical Inc. p-Toluenesulfonic acid monohydrate (98\%), 1,2,3,4-Tetrahydroisoquinoline (96\%) was purchased from Bide Pharmatech Ltd. Diphenyl iodonium triflate ${ }^{1}$ and dithienyl iodonium triflate ${ }^{2}$ were synthesized according to the references. $\mathrm{PhBiCl}_{2}$ were synthesized according to the references. ${ }^{3} \mathrm{~N}$ phenyl-tetrahydroisoquinolines 7 needed for CDC reactions were prepared by using the reported procedure. ${ }^{4}$ If no other special indicated, other reagents and solvents were used as commercially available without further purification. Column chromatographic purification of products was accomplished using 200-300 mesh silica gel.

NMR spectra were measured on a Bruker Avance-400 spectrometer in the solvents indicated; chemical shifts are reported in units (ppm) by assigning TMS resonance in the ${ }^{1} \mathrm{H}$ spectrum as $0.00 \mathrm{ppm}$, DMSO- $d 6$ resonance in the ${ }^{13} \mathrm{C}$ spectrum as $39.50 \mathrm{ppm}$. Coupling constants are reported in $\mathrm{Hz}$ with multiplicities denoted as $\mathrm{s}$ (singlet), d (doublet), $\mathrm{t}$ (triplet), q (quartet) and $\mathrm{m}$ (multiplet). UV-vis measurements were performed using DH-2000-BAL Scan spectrophotometer. The cyclic voltammetry (CV) in solution were measured using CHI660E B157216, with a polished gold electrode as the working electrode, a Pt-net as counter electrode, and an Ag wire as reference electrode, using ferrocene/ferrocenium $(\mathrm{Fc} / \mathrm{Fc}+)$ as internal standard. EPR for $\mathbf{3}$ and $\mathbf{4}$ were measured using a Bruker EMX PLUS6/1 instrument at room temperature in dry degassed DMF. EPR for $\mathbf{5}$ and $\mathbf{6}$ were carried out at room temperature using a Bruker ELEXSYS E500 EPR spectrometer. Scans were performed with magnetic field modulation amplitude of $0.1 \mathrm{G}$ at room temperature in dry degassed DMF. Thermogravimetric analysis (TGA) measurements were carried out in the temperature range of $30-700{ }^{\circ} \mathrm{C}$ by using of a Mettler-Toledo TGA1 thermal analyzer in air, at a heating rate of $10 \mathrm{~K} \cdot \mathrm{min}-1$. High-resolution mass spectra (HRMS) were collected on a Bruker maxis UHR-TOF mass spectrometer in an ESI positive mode. photoluminescence spectra were measured using Horiba PL spectrometer (Fluorolog-3). The phosphorescence quantum efficiency, time-resolved phosphorescence spectra and lifetime were obtained using Edinburgh FLSP980 fluorescence spectrophotometer equipped with a xenon lamp (Xe900), a picosecond pulsed laser (EPL-375), a microsecond flash-lamp ( $\mu \mathrm{F} 900)$ and an integrating sphere, respectively. Single crystal X-ray diffraction analysis was carried out on a Bruker Apex Duo instrument. Photographs were taken using a Nikon D5100 digital camera.

All the computational calculations reported in this work were performed using the Gaussian 09 code. To simulate the experimental UVVis in N,N-dimethylformamide (DMF), the Polarizable Continuum Model (PCM) ${ }^{5}$ as a self-consistent reaction field (SCRF) was used for the calculation of equilibrium geometries, vibrational frequencies and excited state calculations. The geometries for the ground state of these compounds in the DMF solution were optimized at the B3LYP level ${ }^{6}$ with the LANL08(d) basis set ${ }^{7}$ applied for the Bi atom and 6-31G(d) basis set for all other atoms. It should be pointed out that the structures of all stationary points in DMF solvent were fully optimized, and frequency calculations were performed at the same level. The frequency calculations confirmed the nature of all revealed equilibrium geometries: there were no imaginary frequencies.

The simulated UV-Vis spectra for optimized molecules were performed at the time dependent density functional theory (TD-DFT) at the ground-state equilibrium geometries in DMF solution, both low-lying singlet and triplet states were determined using the B3LYP, in association with the LANL08(d) basis set applied for the Bi atom and 6-311G(d,p) basis set for all other atoms. ${ }^{8}$

In the solution-based ECD, Indium tin oxide (ITO)-coated glass ( $15 \Omega / \mathrm{sq})$ was utilized as the electrodes and $\mathbf{3 , 4 , 5}$ and $\mathbf{6}$ was used as active component. The two pieces of ITO glass were sealed together with a UV-cured gasket with $50 \mu \mathrm{m}$-thick intervals introduced by Baumgartner group. ${ }^{9}$ 


\section{Synthetic procedures}

\section{Synthesis of bismobipyridine 2.}

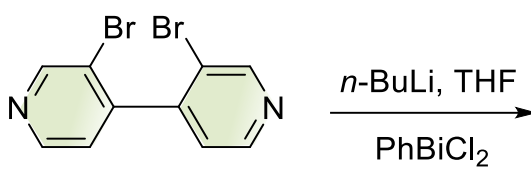

1

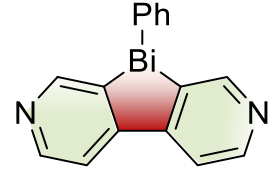

2

3,3'-dibromo-4,4'-bipyridine ${ }^{10}(628 \mathrm{mg}, 2.0 \mathrm{mmol})$ in dry THF $(50 \mathrm{~mL})$ was cooled to $-85^{\circ} \mathrm{C}$, and the a solution of $n$-BuLi $(2.5 \mathrm{M}$ in hexanes, $1.7 \mathrm{~mL}, 4.2 \mathrm{mmol}$ ) was added dropwise. The mixture was stirred for $90 \mathrm{~min}$ at $-85^{\circ} \mathrm{C}$, followed by the addition of $\mathrm{PhBiCl}_{2}(2.4$ $\mathrm{mmol}$ in $10 \mathrm{~mL}$ of THF) ${ }^{3}$. The mixture was allowed to warm to room temperature and stirred overnight. The volatiles were removed under reduced pressure and the solid was dissolved in the mixed solution of water and ethyl acetate. The organic phase was separated, and the aqueous phase was extracted with ethyl acetate $(50 \mathrm{~mL} \times 3)$. The combined organic phase were dried over anhydrous sodium sulfate and concentrated, which was separated by column chromatography $\left(\mathrm{SiO}_{2}\right.$, petroleum/acetone $\left.=3: 1\right)$ to give 2 as a white solid. Yield: $353.1 \mathrm{mg}(40.1 \%)$.

${ }^{1} \mathrm{H}$ NMR (400 MHz, DMSO-d6 ) $\delta 9.03(\mathrm{~s}, 2 \mathrm{H}), 8.75$ (d, $\left.J=5.2 \mathrm{~Hz}, 2 \mathrm{H}\right), 8.05$ (d, $\left.J=5.2 \mathrm{~Hz}, 2 \mathrm{H}\right), 7.74(\mathrm{~d}, J=6.4 \mathrm{~Hz}, 2 \mathrm{H}), 7.22(\mathrm{t}, J=$ $7.3 \mathrm{~Hz}, 2 \mathrm{H}$ ), 7.12 (t, $J=7.3 \mathrm{~Hz}, 1 \mathrm{H}) ;{ }^{13} \mathrm{C}$ NMR (100 MHz, DMSO-d6) $\delta 163.90,163.26,157.56,150.55,148.38,136.94,130.04,127.02$ 121.14; HRMS $\left(E S I^{+}\right) \mathrm{m} / \mathrm{z}:[\mathrm{M}+\mathrm{H}]+$ calcd for $\mathrm{C}_{16} \mathrm{H}_{12} \mathrm{BiN}_{2} 441.0799$; found 441.0802 .

\section{Synthesis of methylbismoviologen 3.}

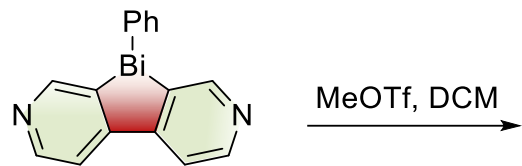

2

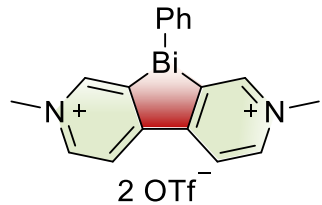

3

Bismobipyridine $2(220 \mathrm{mg}, 0.5 \mathrm{mmol})$ was dissolved in dichloromethane $(5 \mathrm{~mL})$ and the solution was cooled to $0^{\circ} \mathrm{C}$, followed by methyl triflate $(0.28 \mathrm{~mL}, 2.5 \mathrm{mmol})$ was added dropwise. The reaction mixture was stirred at $0^{\circ} \mathrm{C}$ for $5 \mathrm{~min}$, then it was allowed to warm to room temperature and stirred for $5 \mathrm{~h}$. The yellow precipitate was collected via vacuum filtration, washed with dichlorometh ane and diethyl ether, and dried at $40^{\circ} \mathrm{C}$ under a vacuum: Yield: $276.8 \mathrm{mg}(72.1 \%)$.

${ }^{1} \mathrm{H}$ NMR (400 MHz, DMSO-d6) $\delta 9.20$ (d, J = 4.8 Hz, 4H), 8.96 (d, J=6.5 Hz, 2H), 7.90 (d, J = 7.3 Hz, 2H), $7.34(\mathrm{t}, J=7.4 \mathrm{~Hz}, 2 \mathrm{H})$, 7.20 (t, $J=7.6 \mathrm{~Hz}, 1 \mathrm{H}), 4.40$ (s, 6H); ${ }^{13} \mathrm{C} N M R(100 \mathrm{MHz}$, DMSO-d6) $\delta 177.10,167.17,165.55,152.27,144.67,137.63,130.82,127.54$, 126.37,122.05, 119.05, 47.90; ${ }^{19} \mathrm{~F}$ NMR (376 MHz, DMSO-d6) $\delta-77.74 ;$ HRMS (ESI+) m/z: [M-2OTf] calcd for $\mathrm{C}_{18} \mathrm{H}_{17} \mathrm{BiN}_{2} 470.1190$ found $470.1194 ; \mathrm{Mp}\left({ }^{\circ} \mathrm{C}\right): 194.4{ }^{\circ} \mathrm{C}-196.2^{\circ} \mathrm{C}$.

\section{Synthesis of benzylbismoviologen 4 .}<smiles></smiles>

a) $\mathrm{BnBr}, 60^{\circ} \mathrm{C}$

b) MeOTf, DCM<smiles></smiles>

4

Bismobipyridine 2 (101.2 mg, $0.23 \mathrm{mmol}$ ) and benzyl bromide ( $2 \mathrm{~mL}$, excess) were combined in a $10 \mathrm{~mL}$ of Schlenk tube and heated at $60^{\circ} \mathrm{C}$ for $72 \mathrm{~h}$ while stirring. The reaction was allowed to cool to room temperature and the precipitate was isolated via vacuum filtration and washed with dichloromethane. The precipitate was collected to obtain a dark red solid (111.5 mg, 68.7\%).

To a suspension of dark red solid $(70.5 \mathrm{mg}, 0.1 \mathrm{mmol})$ in dichloromethane at $0^{\circ} \mathrm{C}$ was added dropwise methyl triflate $(26 \mathrm{uL}, 0.23$ $\mathrm{mmol})$. The mixture was stirred at room temperature until the reaction underwent a significant color change. The yellow precipitate was 
collected via vacuum filtration, washed with dichloromethane and diethyl ether, and dried at $40^{\circ} \mathrm{C}$ under a vacuum. Yield: $63.6 \mathrm{mg}$ (47.5\%).

${ }^{1} \mathrm{H}$ NMR (400 MHz, DMSO-d6) $\delta 9.47$ (d, J = 6.3 Hz, 2H), 9.31 (s, 2H), 9.02 (d, J=6.4 Hz, 2H), 7.77 (d, J = 7.4 Hz, 2H), $7.46-7.52$ $(\mathrm{m}, 10 \mathrm{H}), 7.27$ (t, $J=7.3 \mathrm{~Hz}, 2 \mathrm{H}), 7.16(\mathrm{t}, J=7.2 \mathrm{~Hz}, 1 \mathrm{H}), 5.93(\mathrm{~s}, 4 \mathrm{H}) ;{ }^{13} \mathrm{C}$ NMR $(100 \mathrm{MHz}$, DMSO-d6) $\delta 178.63,168.42,166.13$, 151.07, 144.22, 137.50, 134.50, 130.75, 129.43, 129.33, 128.86, 127.44, 127.05, 122.26, 119.05, 63.20; ${ }^{19} \mathrm{~F} \mathrm{NMR} \mathrm{(376} \mathrm{MHz,} \mathrm{DMSO-}$ d6) $\delta$-77.74; HRMS (ESI+) m/z: [M-2OTf] ${ }^{+}$calcd for $\mathrm{C}_{30} \mathrm{H}_{25} \mathrm{BiN}_{2} 622.1816$; found $622.1809 ; \mathrm{Mp}\left({ }^{\circ} \mathrm{C}\right): 186.0^{\circ} \mathrm{C}-187.5^{\circ} \mathrm{C}$.

\section{Synthesis of phenylbismoviologen 5 .}

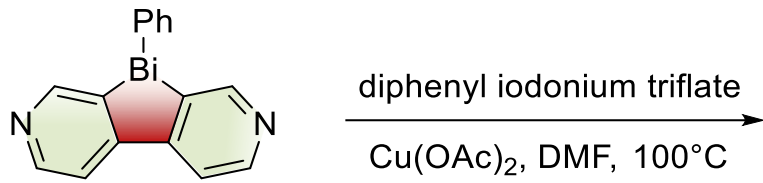

2

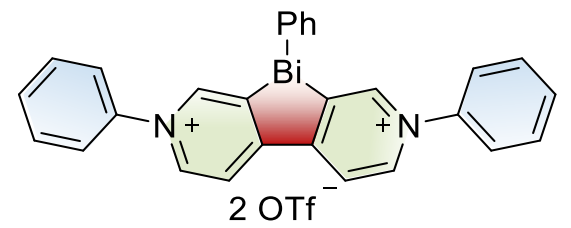

5

Bismobipyridine 2 (44 mg, $0.1 \mathrm{mmol}$,), diphenyl iodonium triflate (129.1 mg, $0.3 \mathrm{mmol}$,) and anhydrous $\mathrm{Cu}(\mathrm{OAc})_{2}(1 \mathrm{mg}, 0.005 \mathrm{mmol}$,) were dissolved in degassed DMF $(4 \mathrm{~mL})$. The reaction mixture was stirred for $8 \mathrm{~h}$ at $100^{\circ} \mathrm{C}$. The volatiles were removed under reduced pressure, the dark brown oil was taken up in acetone/chloroform/diethyl ether (1:1:1), and filtered. The resulting residue was taken up in chloroform/acetone $(5: 1 ; 300 \mathrm{~mL})$ and vigorously stirred for $2 \mathrm{~h}$, followed by the dark yellow solid was collected via vacuum filtration, washed with cold water and diethyl ether, and dried at $40^{\circ} \mathrm{C}$ under a vacuum. Yield: $45.5 \mathrm{mg}(51.0 \%)$.

${ }^{1} \mathrm{H}$ NMR (400 MHz, DMSO-d6 ) $\delta 9.65$ (d, $\left.J=6.7 \mathrm{~Hz}, 2 \mathrm{H}\right), 9.63(\mathrm{~s}, 2 \mathrm{H}), 9.31$ (d, J = 6.6 Hz, 2H), 8.02 (d, $\left.J=7.5 \mathrm{~Hz}, 2 \mathrm{H}\right), 7.98-7.96$ $(\mathrm{m}, 4 \mathrm{H}), 7.83-7.80(\mathrm{~m}, 6 \mathrm{H}), 7.39(\mathrm{t}, J=7.4 \mathrm{~Hz}, 2 \mathrm{H}), 7.22(\mathrm{t}, J=7.4 \mathrm{~Hz}, 1 \mathrm{H}) ;{ }^{13} \mathrm{C}$ NMR $(100 \mathrm{MHz}, \mathrm{DMSO}-d 6) \delta 177.20,167.75,166.59$, $151.01,144.25,142.82,137.82,131.47,131.03,130.48,127.66,127.08,124.61,122.24,119.04 ;{ }^{19} \mathrm{~F} \mathrm{NMR}$ (376 MHz, DMSO-d6) $\delta$ 77.73; HRMS (ESI+) m/z: [M-2OTf] ${ }^{+}$calcd for $\mathrm{C}_{28} \mathrm{H}_{21} \mathrm{BiN}_{2}$ 594.1503; found 594.1502; $\mathrm{Mp}\left({ }^{\circ} \mathrm{C}\right): 217.2-218.6{ }^{\circ} \mathrm{C}$.

Synthesis of thienylbismoviologen 6 .<smiles>c1ccc(-c2ccncc2[Bi](c2ccccc2)c2ccncc2)cc1</smiles>

2 dithienyl iodonium triflate

$\mathrm{Cu}(\mathrm{OAc})_{2}, \mathrm{DMF}, 40^{\circ} \mathrm{C}$<smiles>Nc1cccs1</smiles>

20<smiles></smiles>

6

Bismobipyridine 2 (44 mg, $0.1 \mathrm{mmol})$, dithienyl iodonium triflate $(221.1 \mathrm{mg}, 0.5 \mathrm{mmol})$ and anhydrous $\mathrm{Cu}(\mathrm{OAc})_{2}(1.8 \mathrm{mg}, 0.01 \mathrm{mmol})$ were dissolved in degassed DMF ( $6 \mathrm{~mL}$ ). The reaction mixture was stirred at $40^{\circ} \mathrm{C}$ for $36 \mathrm{~h}$. The volatiles were removed under reduced pressure, the red residue was taken up in THF $(5 \mathrm{~mL})$ and a mixture of dichloromethane /diethyl ether $(1: 1 ; 10 \mathrm{~mL})$ was added. The precipitated dark green solid was collected via vacuum filtration, washed with dichloromethane and diethyl ether, and dried at $40^{\circ} \mathrm{C}$ under a vacuum. Yield: $69.0 \mathrm{mg}(76.3 \%)$.

${ }^{1} \mathrm{H}$ NMR $\left(400 \mathrm{MHz}, \mathrm{CH}_{3} \mathrm{CN}-\mathrm{d} 3\right) \delta 9.44(\mathrm{~s}, 2 \mathrm{H}), 9.20$ (d, J=6.6 Hz, 2H), $8.84(\mathrm{~d}, J=6.6 \mathrm{~Hz}, 2 \mathrm{H}), 7.98(\mathrm{~d}, J=7.5 \mathrm{~Hz}, 2 \mathrm{H}), 7.75(\mathrm{~d}, J$ $=5.3 \mathrm{~Hz}, 2 \mathrm{H}), 7.71(\mathrm{~d}, J=3.9 \mathrm{~Hz}, 2 \mathrm{H}), 7.43(\mathrm{t}, J=7.2 \mathrm{~Hz}, 2 \mathrm{H}), 7.31-7.27(\mathrm{~m}, 3 \mathrm{H}) ;{ }^{13} \mathrm{C} \mathrm{NMR}(100 \mathrm{MHz}, \mathrm{CH} 3 \mathrm{CN}-d 3) \delta 176.04,168.09$, 152.18, 144.62, 144.05, 139.27, 132.41, 129.90, 129.45, 128.87, 128.79, 126.31; $\left.{ }^{19} \mathrm{~F} \mathrm{NMR} \mathrm{(376} \mathrm{MHz,} \mathrm{CH}_{3} \mathrm{CN}-d 3\right) \delta-79.26$; HRMS (ESI) $\mathrm{m} / \mathrm{z}$ : [M-2OTf]+ calcd for $\mathrm{C}_{24} \mathrm{H}_{17} \mathrm{BiN}_{2} \mathrm{~S}_{2} 606.0632$; found $606.0619 ; \mathrm{Mp}\left({ }^{\circ} \mathrm{C}\right):>300^{\circ} \mathrm{C}$. 
3. TGA of bismuth-bridged viologen.

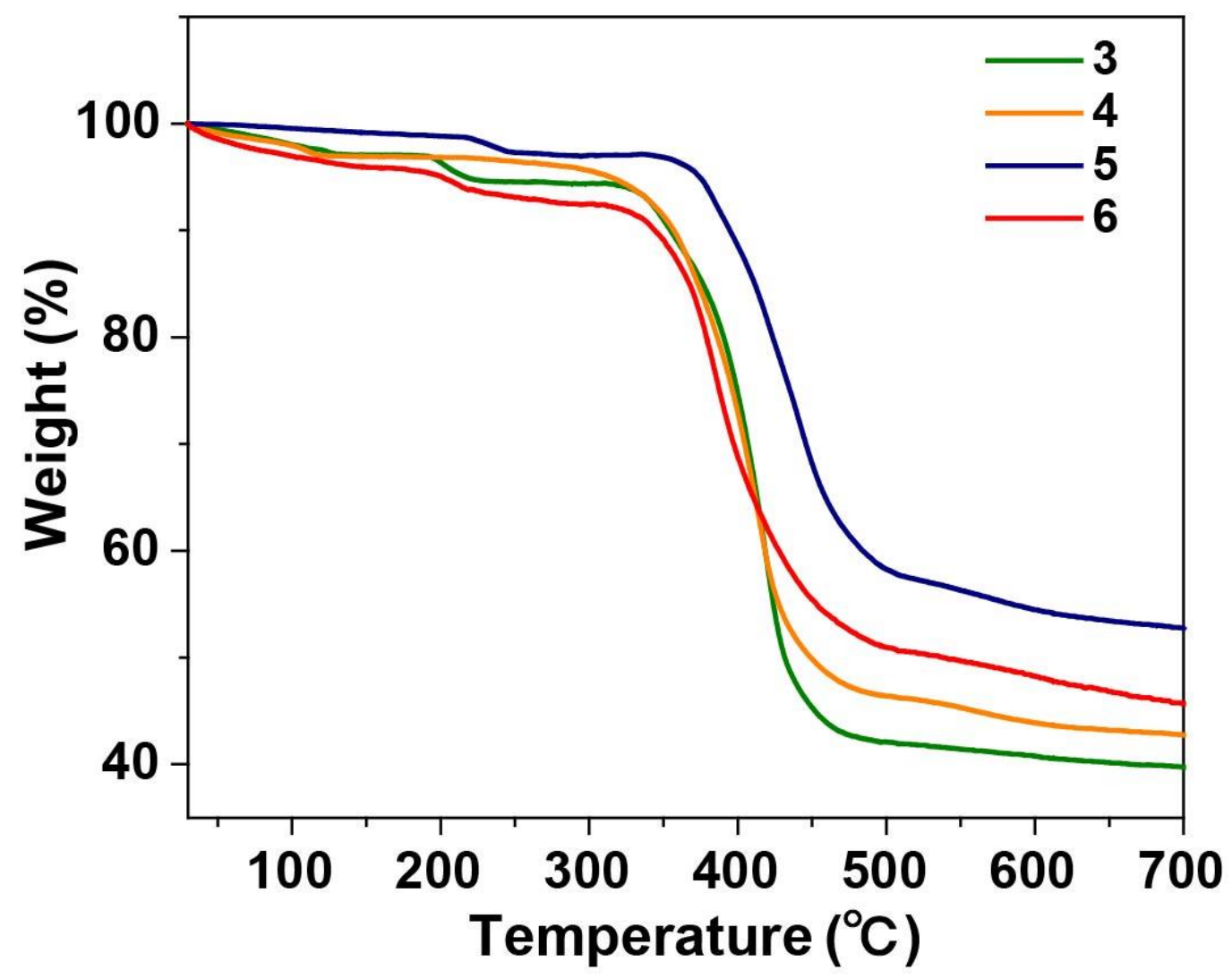

Figure S1. TGA of compounds 3, 4, 5 and 6 . 


\section{Single-crystal X-ray structure determination.}

X-ray Crystallography. Crystals of appropriate quality for X-ray diffraction studies were removed from a vial (in a glove box) and immediately covered with a thin layer of hydrocarbon oil (Paratone- $N$ ). A suitable crystal was then selected, attached to a glass fiber, and quickly placed in a glass vial. All data were collected using a Bruker APEX II CCD detector/D8 diffractometer using Mo/Cu Ka radiation. The data were corrected for absorption through Gaussian integration from indexing of the crystal faces. Structures were solved using the direct methods programs SHELXS-97, and refinements were completed using the program SHELXL-97.
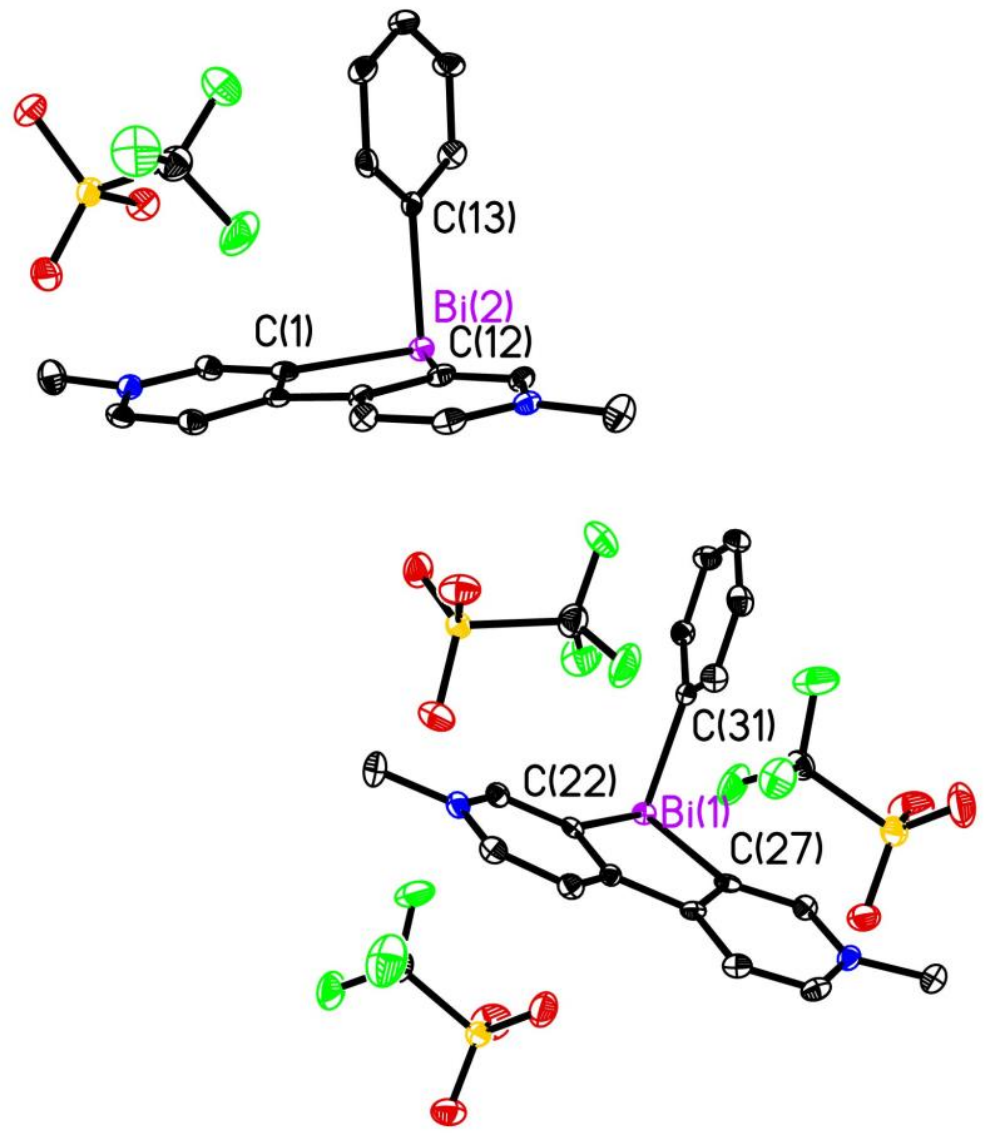

Figure S2. Molecular Structure of 3 with thermal ellipsoids presented at a 50\% probability level. All hydrogen atoms have been omitted for clarity. Selected bond lengths (Å): $\mathrm{Bi}(1)-\mathrm{C}(22), 2.267(6) ; \mathrm{Bi}(1)-\mathrm{C}(27), 2.271(6) ; \mathrm{Bi}(1)-\mathrm{C}(31), 2.258(6) ; \mathrm{Bi}(2)-\mathrm{C}(1), 2.277(6)$; $\mathrm{Bi}(2)-\mathrm{C}(12), 2.287(6) ; \mathrm{Bi}(2)-\mathrm{C}(13), 2.262(6)$; Bond angles (deg): C(22)-Bi(1)-C(27), 75.9(2); C(31)-Bi(1)-C(22), 89.2(2); C(31)-Bi(1)$C(27), 94.0(2) ; C(1)-B i(2)-C(12), 75.5(2) ; C(13)-B i(2)-C(1), 92.7(2) ; C(13)-B i(2)-C(12), 93.0(2)$. 
Table S1. Crystal data and structure refinement for compound 3 (CCDC 2043490)..

Empirical formula

Formula weight

Temperature

Wavelength

Crystal system, space group

Unit cell dimensions

Volume

Z, Calculated density

Absorption coefficient

$F(000)$

Crystal size

Theta range for data collection

Limiting indices

Reflections collected / unique

Completeness to theta $=26.72$

Max. and min. transmission

Refinement method

Data / restraints / parameters

Goodness-of-fit on $\mathrm{F}^{\wedge} 2$

Final $R$ indices [l>2sigma(I)]

$R$ indices (all data)

Largest diff. peak and hole
$\mathrm{C}_{40} \mathrm{H}_{42} \mathrm{Bi}_{2} \mathrm{~F}_{12} \mathrm{~N}_{4} \mathrm{O}_{16} \mathrm{~S}_{4}$

1608.98

$296.15 \mathrm{~K}$

$0.71073 \AA$

Monoclinic, P121/n1

$a=17.628(14) \AA \quad \alpha=90 \mathrm{deg}$.

$b=15.700(12) \AA \quad \beta=97.887(10)$ deg.

$C=19.843(15) \AA \quad \gamma=90 \mathrm{deg}$.

$5440(7) \AA \wedge$

4, $1.964 \mathrm{Mg} / \mathrm{m}^{\wedge} 3$

$6.723 \mathrm{~mm}^{\wedge}-1$

3104

$0.2 \times 0.2 \times 0.2 \mathrm{~mm}$

1.45 to $26.72 \mathrm{deg}$.

$-21<=\mathrm{h}<=21,-19<=\mathrm{k}<=19,-24<=\mathrm{l}<=25$

$56901 / 11238[R($ int $)=0.0686]$

$97.6 \%$

0.3466 and 0.3466

Full-matrix least-squares on $\mathrm{F}^{\wedge} 2$

11238 / 0 / 719

1.054

$\mathrm{R} 1=0.0398, w R 2=0.0838$

$\mathrm{R} 1=0.0653, \mathrm{wR} 2=0.0930$

2.765 and -0.977 e. $A^{\wedge}-3$ 

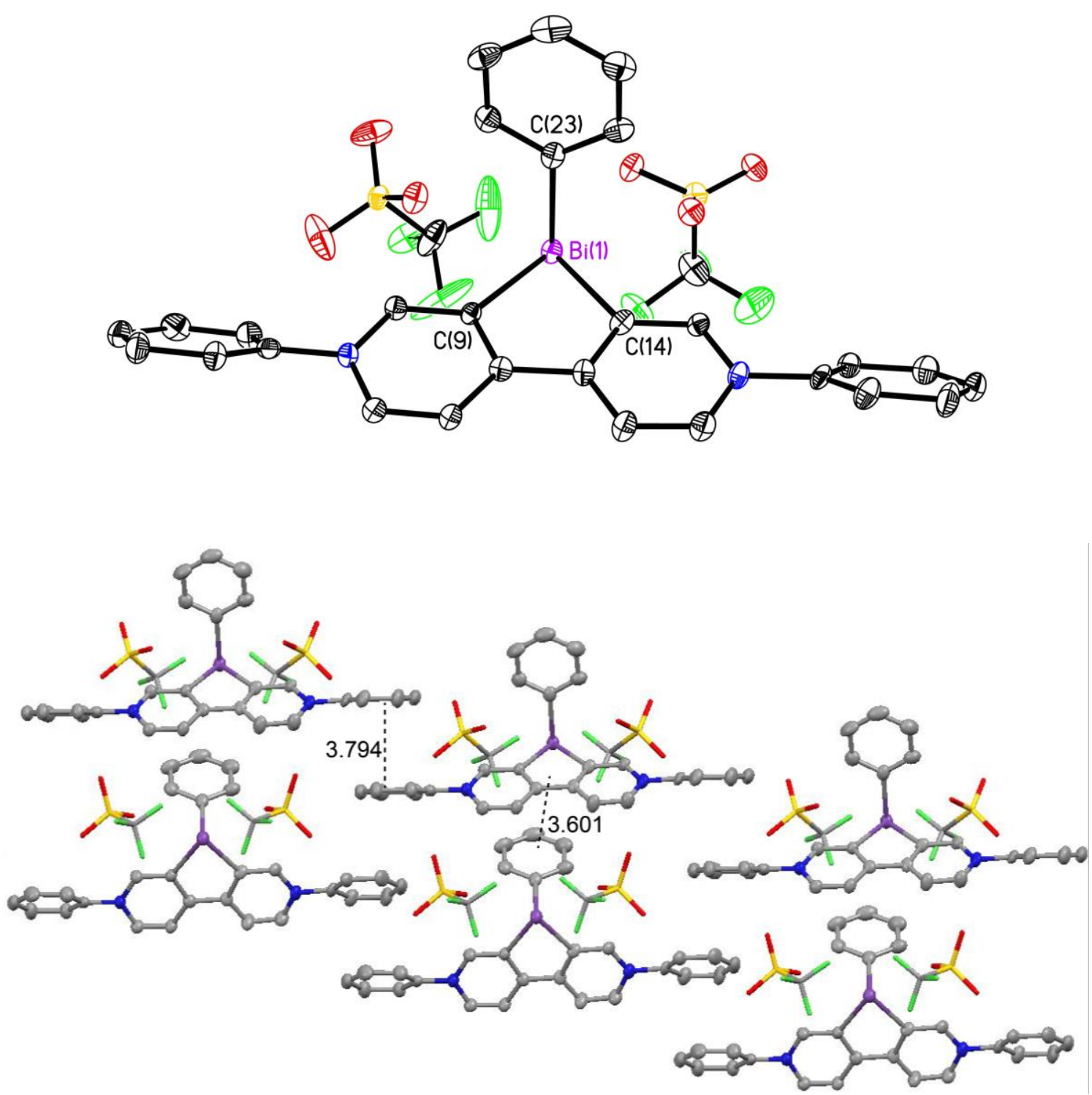

Figure S3. Molecular Structure of 5 with thermal ellipsoids presented at a 50\% probability level. All hydrogen atoms have been omitted for clarity. Selected bond lengths (Å): $\mathrm{Bi}(1)-\mathrm{C}(9), 2.268(8)$; $\mathrm{Bi}(1)-\mathrm{C}(14), 2.268(8) ; \mathrm{Bi}(1)-\mathrm{C}(23), 2.260(9)$; Bond angles (deg): $\mathrm{C}(9)-\mathrm{Bi}(1)-\mathrm{C}(14), 75.3(3) ; \mathrm{C}(23)-\mathrm{Bi}(1)-\mathrm{C}(9), 91.8(3)$; $\mathrm{C}(23)-\mathrm{Bi}(1)-\mathrm{C}(14), 93.4(3) .$. 
Table S2. Crystal data and structure refinement for compound 5 (CCDC 2043493)..

Empirical formula

Formula weight

Temperature

Wavelength

Crystal system, space group

Unit cell dimensions

Volume

Z, Calculated density

Absorption coefficient

$\mathrm{F}(000)$

Crystal size

Theta range for data collection

Limiting indices

Reflections collected / unique

Completeness to theta $=26.58$

Absorption correction

Max. and min. transmission

Refinement method

Data / restraints / parameters

Goodness-of-fit on $\mathrm{F}^{\wedge} 2$

Final $\mathrm{R}$ indices [l>2sigma(l)]

$\mathrm{R}$ indices (all data)

Largest diff. peak and hole
$\mathrm{C}_{32} \mathrm{H}_{24} \mathrm{BiF}_{6} \mathrm{~N}_{3} \mathrm{O}_{6} \mathrm{~S}_{2}$

933.64

$296.15 \mathrm{~K}$

$0.71073 \AA$

Monoclinic, P121/c1

$a=13.658(5) \AA \quad \alpha=90 \mathrm{deg}$.

$b=17.056(6) \AA \quad \beta=98.946(4)$ deg .

$\mathrm{C}=14.691(5) \AA \quad \gamma=90 \mathrm{deg}$.

3381(2) $A^{\wedge} 3$

4, $1.834 \mathrm{Mg} / \mathrm{m}^{\wedge} 3$

$5.420 \mathrm{~mm}^{\wedge}-1$

1816

$0.3 \times 0.2 \times 0.2 \mathrm{~mm}$

1.51 to $26.58 \mathrm{deg}$.

$-17<=\mathrm{h}<=17,-21<=\mathrm{k}<=21,-18<=\mathrm{k}<=18$

$33634 / 6943$ [R(int) $=0.0960]$

$98.1 \%$

Semi-empirical from equivalents

0.7454 and 0.3606

Full-matrix least-squares on $\mathrm{F}^{\wedge} 2$

6943 / 42 / 489

1.044

$\mathrm{R} 1=0.0545, \mathrm{wR} 2=0.1309$

$\mathrm{R} 1=0.0882, \mathrm{wR} 2=0.1515$

5.111 and -2.016 e. $A^{\wedge}-3$ 

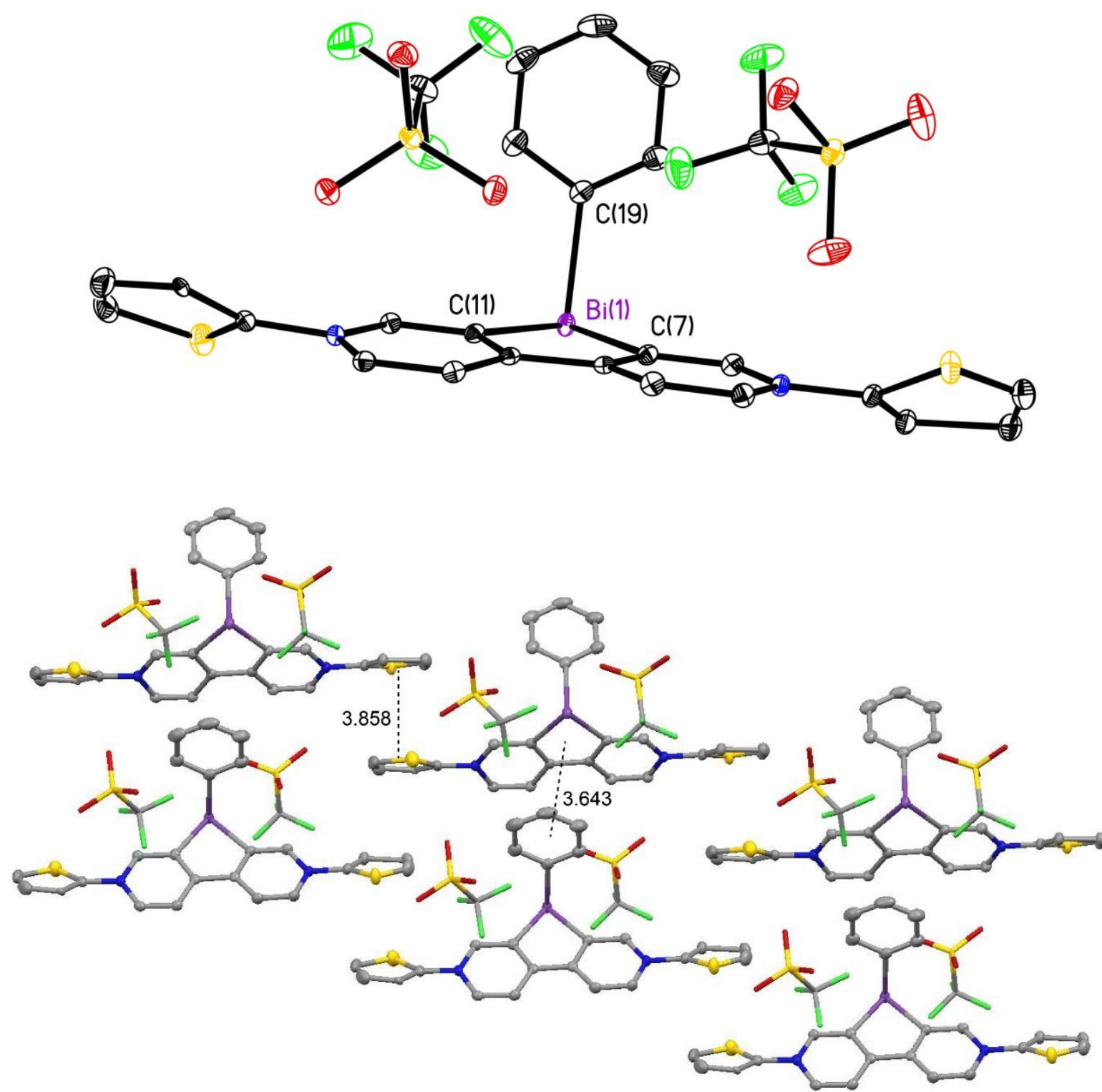

Figure S4. Molecular Structure of 6 with thermal ellipsoids presented at a 50\% probability level. All hydrogen atoms have been omitted for clarity. Selected bond lengths $(\AA)$ : $B i(1)-C(19), 2.259(4) ; B i(1)-C(11), 2.291(3) ; B i(1)-C(7), 2.279(3)$; Bond angles (deg): $C(19)-B i(1)-C(11), 90.98(12) ; C(19)-B i(1)-C(7), 91.26(13) ; C(7)-B i(1)-C(11), 75.59(12) .$. 
Table S3. Crystal data and structure refinement for compound 6 (CCDC 2043494)..

Empirical formula

Formula weight

Temperature

Wavelength

Crystal system, space group

Unit cell dimensions

Volume

Z, Calculated density

Absorption coefficient

$F(000)$

Crystal size

Theta range for data collection

Limiting indices

Reflections collected / unique

Completeness to theta $=26.78$

Absorption correction

Max. and min. transmission

Refinement method

Data / restraints / parameters

Goodness-of-fit on $\mathrm{F}^{\wedge} 2$

Final $R$ indices [l>2sigma(I)]

$R$ indices (all data)

Largest diff. peak and hole
$\mathrm{C}_{28} \mathrm{H}_{20} \mathrm{BiF}_{6} \mathrm{~N}_{3} \mathrm{O}_{6} \mathrm{~S}_{4}$

945.69

$296.15 \mathrm{~K}$

$0.71073 \AA$

Monoclinic, P121/c1

$a=12.9686(15) \AA \quad \alpha=90$ deg.

$b=17.018(2) \AA \quad \beta=99.641(2)$ deg.

$C=14.8907(17) \AA \quad \gamma=90 \mathrm{deg}$.

$3240.0(7) \mathrm{A}^{\wedge} 3$

4, $1.939 \mathrm{Mg} / \mathrm{m}^{\wedge} 3$

$5.781 \mathrm{~mm}^{\wedge}-1$

1832

$0.2 \times 0.2 \times 0.2 \mathrm{~mm}$

1.83 to 26.78 deg.

$-16<=h<=16,-21<=k<=21,-18<=\mid<=18$

$34706 / 6877[\mathrm{R}(\mathrm{int})=0.0296]$

$99.3 \%$

Semi-empirical from equivalents

0.7454 and 0.5749

Full-matrix least-squares on $\mathrm{F}^{\wedge} 2$

$6877 / 30 / 453$

1.055

$\mathrm{R} 1=0.0235, \mathrm{wR} 2=0.0557$

$\mathrm{R} 1=0.0310, w R 2=0.0584$

0.861 and -0.613 e. $A^{\wedge}-3$ 
5. Phosphorescence spectrum and lifetime
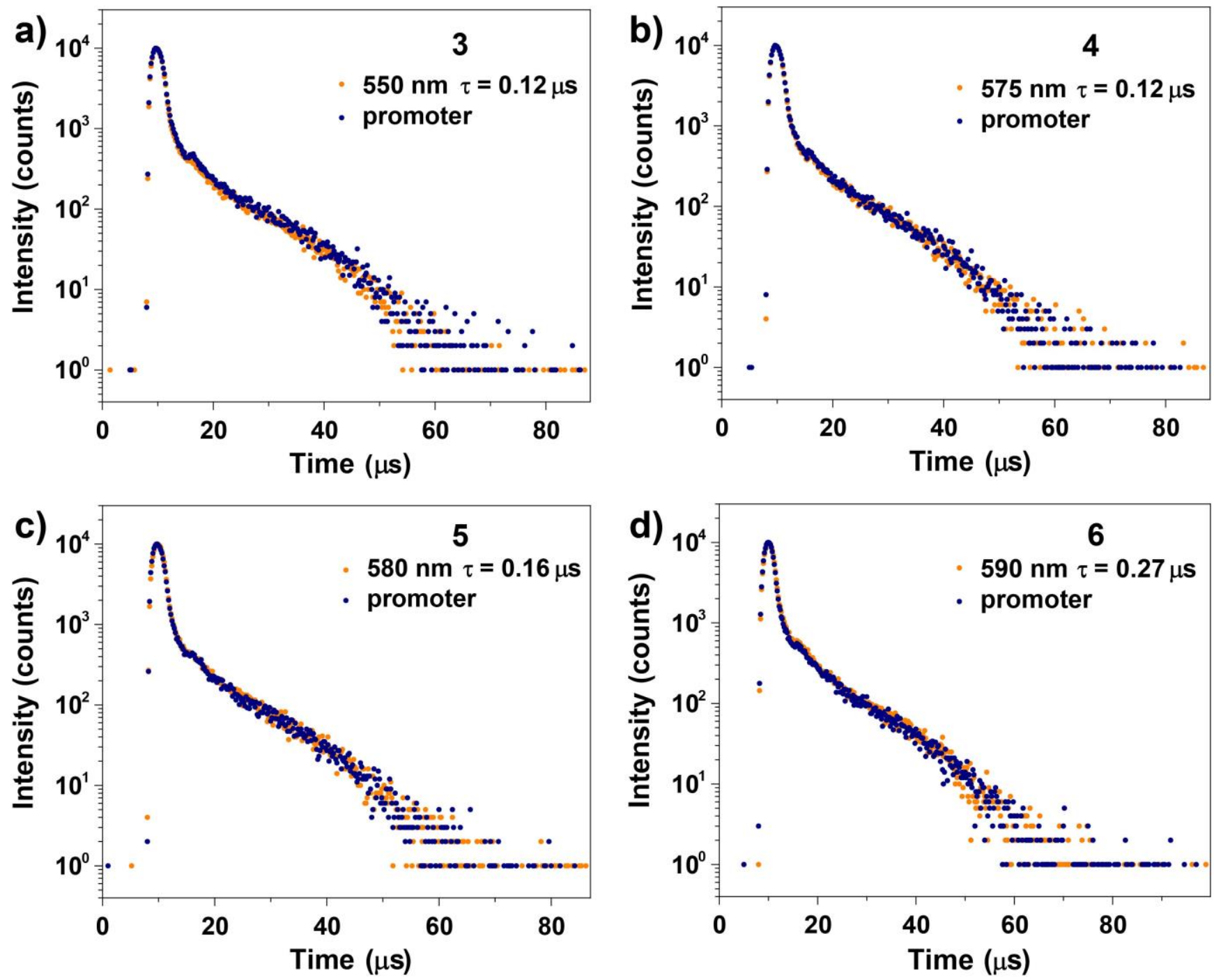

Figure S5. Lifetime decay profiles of phosphorescence bands of $3,4,5$ and 6 in acetonitrile $\left(C=10^{-3} \mathrm{M}\right)$ under ambient conditions.

Table S4. Phosphorescence Properties of Bismoviologens under ambient conditions .

\begin{tabular}{|c|c|c|c|c|c|}
\hline Compound & $\lambda_{\max }(\mathrm{nm})$ & $\Phi(\%)$ & $\tau(\mu s)$ & $k_{r}^{[a]}\left(10^{5} s^{-1}\right)$ & $k_{n r}^{[b]}\left(10^{5} \mathrm{~s}^{-1}\right)$ \\
\hline 3 & 550 & 2.45 & 0.12 & 2.0 & 81.3 \\
\hline 4 & 575 & 4.50 & 0.12 & 3.8 & 79.5 \\
\hline 5 & 580 & 2.27 & 0.16 & 1.4 & 61.1 \\
\hline 6 & 590 & 2.06 & 0.27 & 0.8 & 36.2 \\
\hline
\end{tabular}

[a] Obtain from $k_{r}=\Phi / \tau$. [b]. Obtain from $k_{n r}=1 / \tau-k_{r}$ 


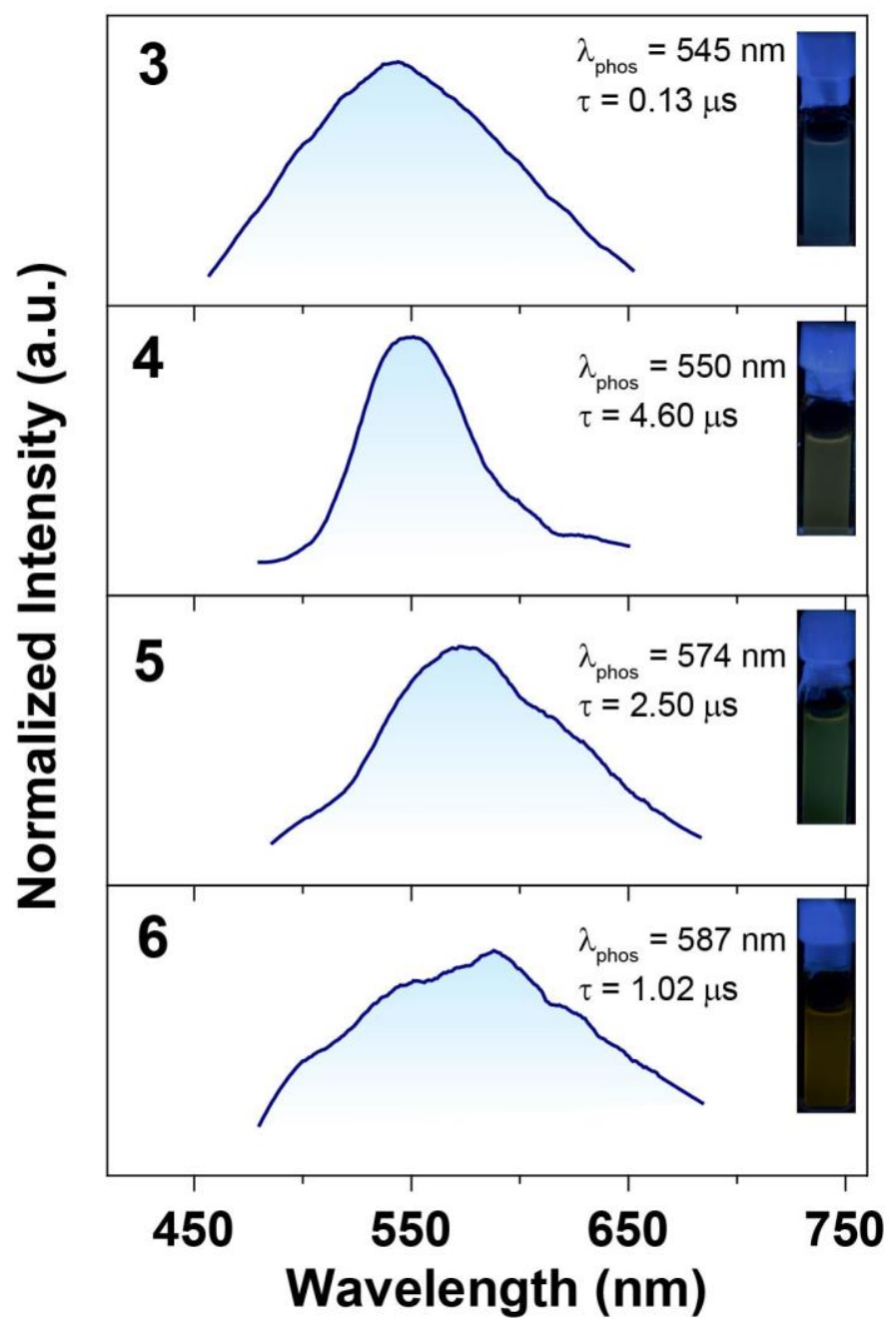

Figure S6. Phosphorescence spectra of 3, 4, 5 and $\mathbf{6}$ at room temperature in acetonitrile $\left(\mathrm{C}=10^{-3} \mathrm{M}\right)$ under argon atmosphere.

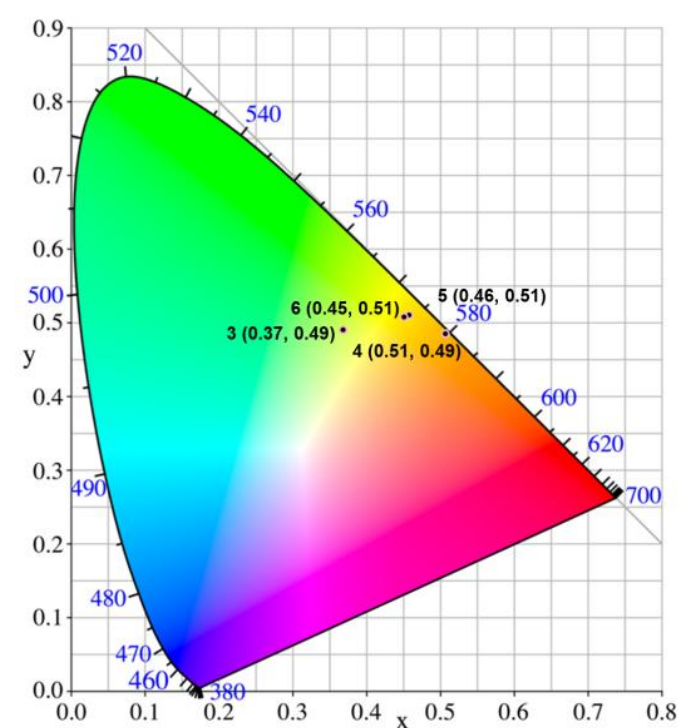

Figure S7. Phosphorescence color coordinates for bismoviologens plotted in the CIE 1931 chromaticity diagram in acetonitrile $(\mathrm{c}=$ $\left.10^{-3} \mathrm{M}\right)$ under argon atmosphere. 

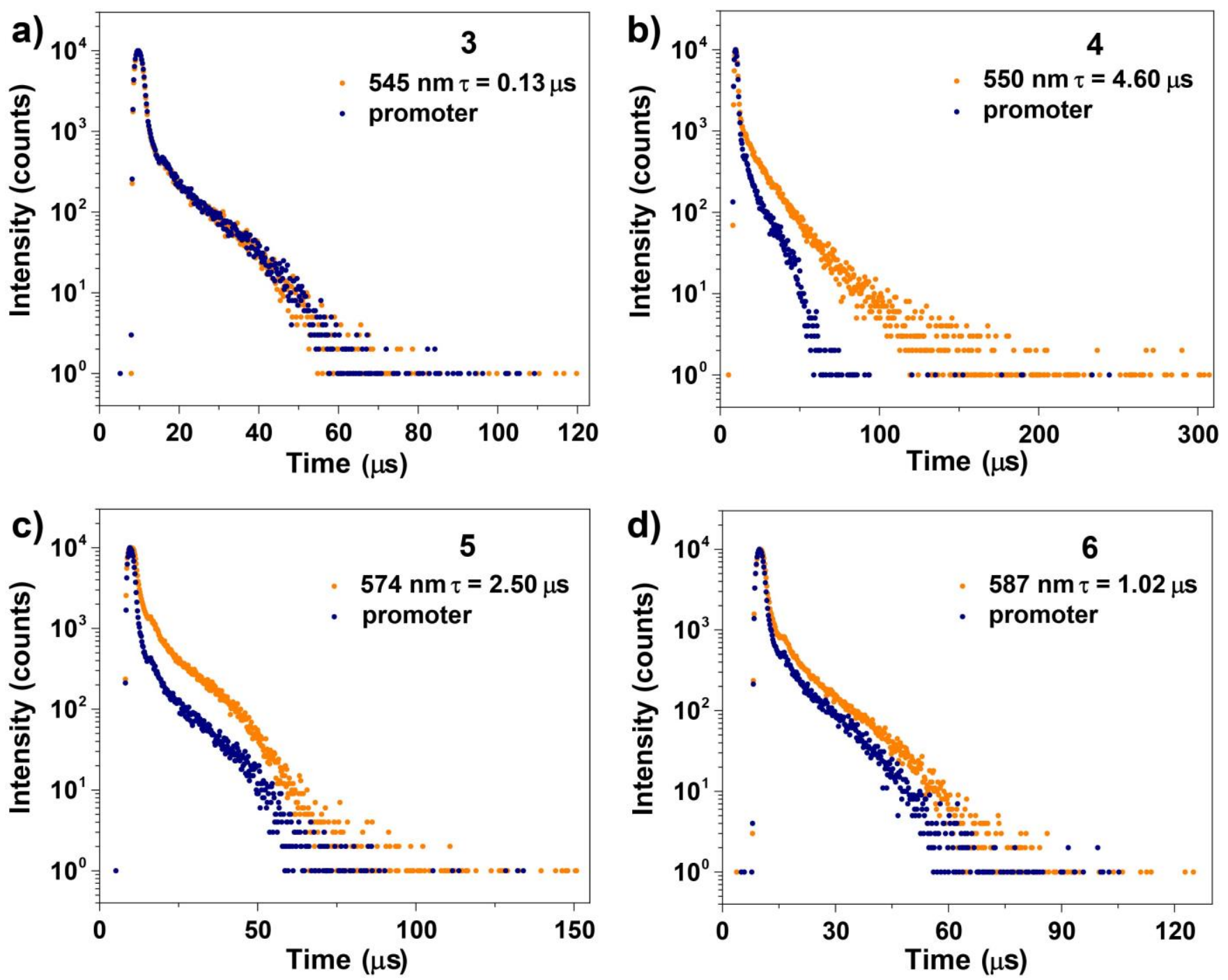

Figure S8. Lifetime decay profiles of phosphorescence bands of 3, 4, 5 and $\mathbf{6}$ at room temperature in acetonitrile $\left(\mathrm{c}=10^{-3} \mathrm{M}\right)$ under argon atmosphere. 


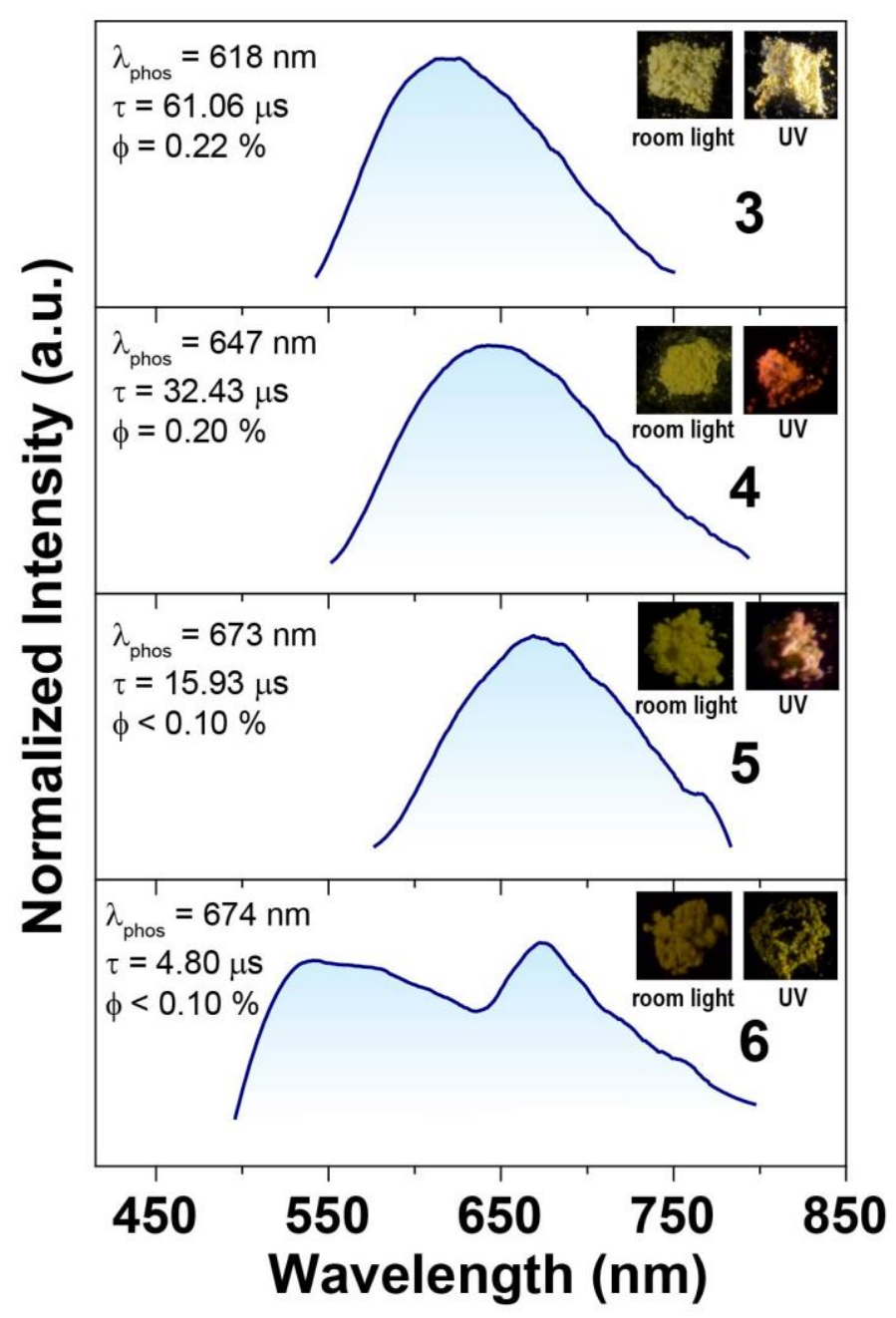

Figure S9. Phosphorescence spectra of 3, 4, 5 and 6 solid powders under ambient conditions.

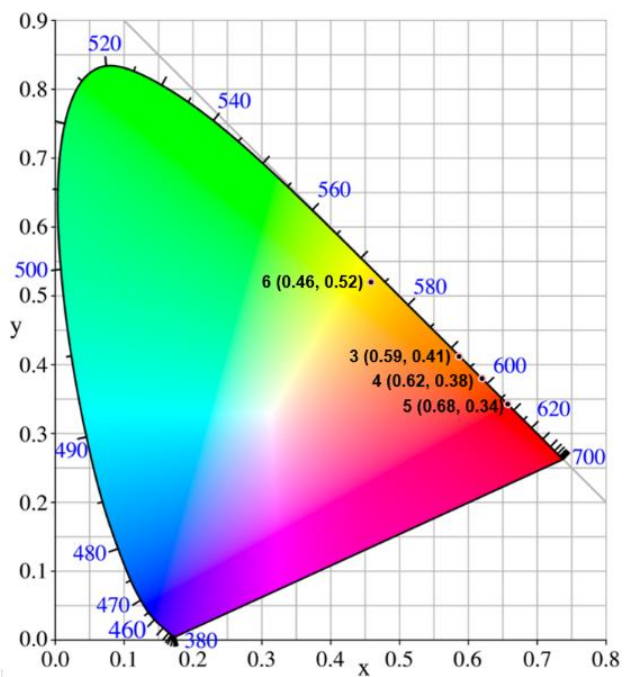

Figure S10. Phosphorescence color coordinates for bismoviologens solid powders plotted in the CIE 1931 chromaticity diagram under ambient conditions. 

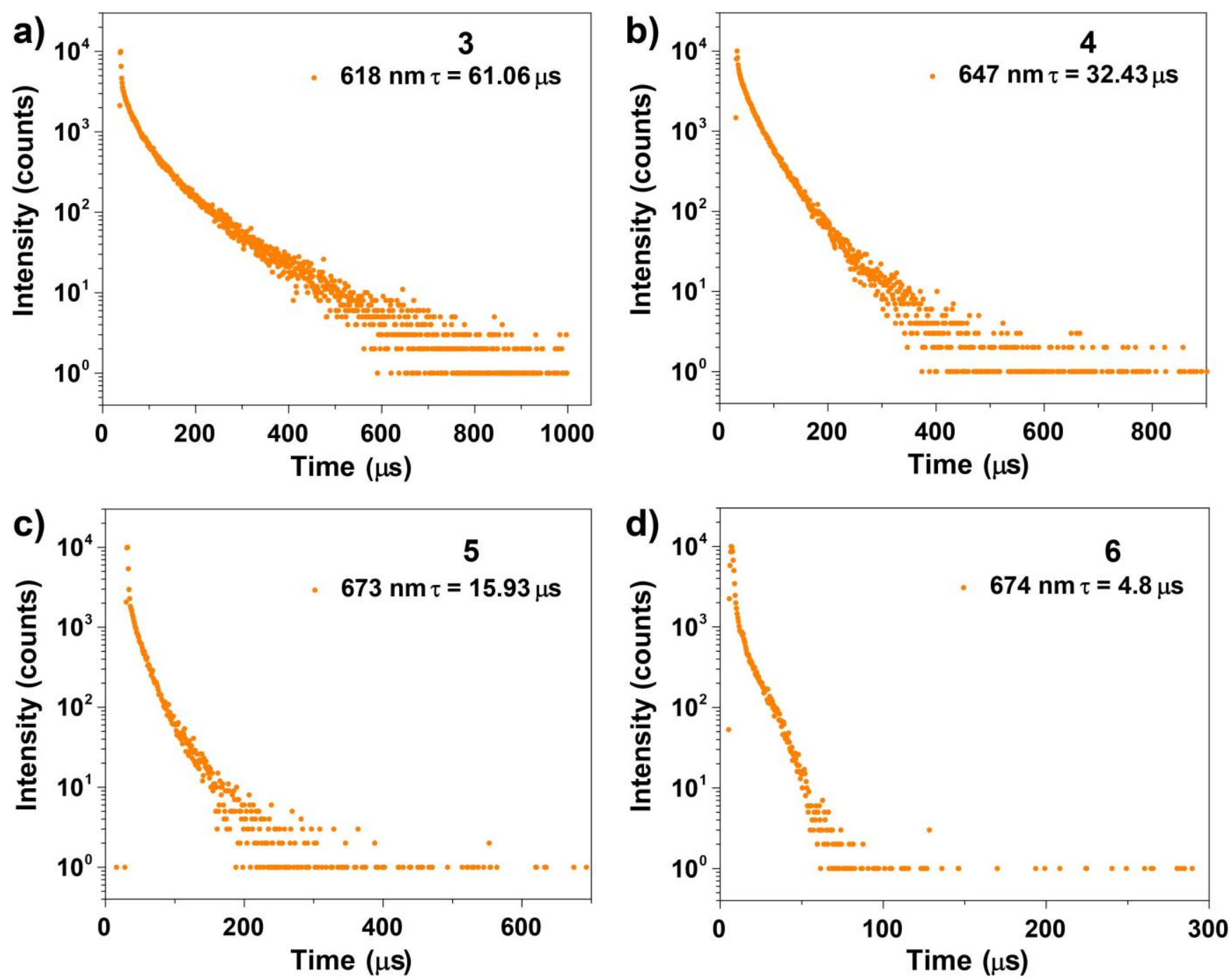

Figure S11. Lifetime decay profiles of phosphorescence bands of 3, 4, 5 and $\mathbf{6}$ solid powders under ambient conditions.

Table S5. Phosphorescence Properties of Bismoviologens in solution and solid states.

\begin{tabular}{|c|c|c|c|c|c|c|}
\hline & \multicolumn{2}{|c|}{ Solution in air } & \multicolumn{2}{c|}{ Solution in Ar } & \multicolumn{2}{c|}{ Solid states } \\
\hline Compound & $\lambda_{\max }(\mathrm{nm})$ & $\tau(\mu \mathrm{s})$ & $\lambda_{\max }(\mathrm{nm})$ & $\tau(\mu \mathrm{s})$ & $\lambda_{\max }(\mathrm{nm})$ & $\tau(\mu \mathrm{s})$ \\
\hline $\mathbf{3}$ & 550 & 0.12 & 545 & 0.13 & 618 & 61.06 \\
\hline $\mathbf{4}$ & 575 & 0.12 & 550 & 4.60 & 647 & 32.43 \\
\hline $\mathbf{5}$ & 580 & 0.16 & 574 & 2.50 & 673 & 15.93 \\
\hline $\mathbf{6}$ & 590 & 0.27 & 587 & 1.02 & 674 & 4.80 \\
\hline
\end{tabular}


6. PL spectra of 5 in different solvents at $298 \mathrm{~K}$

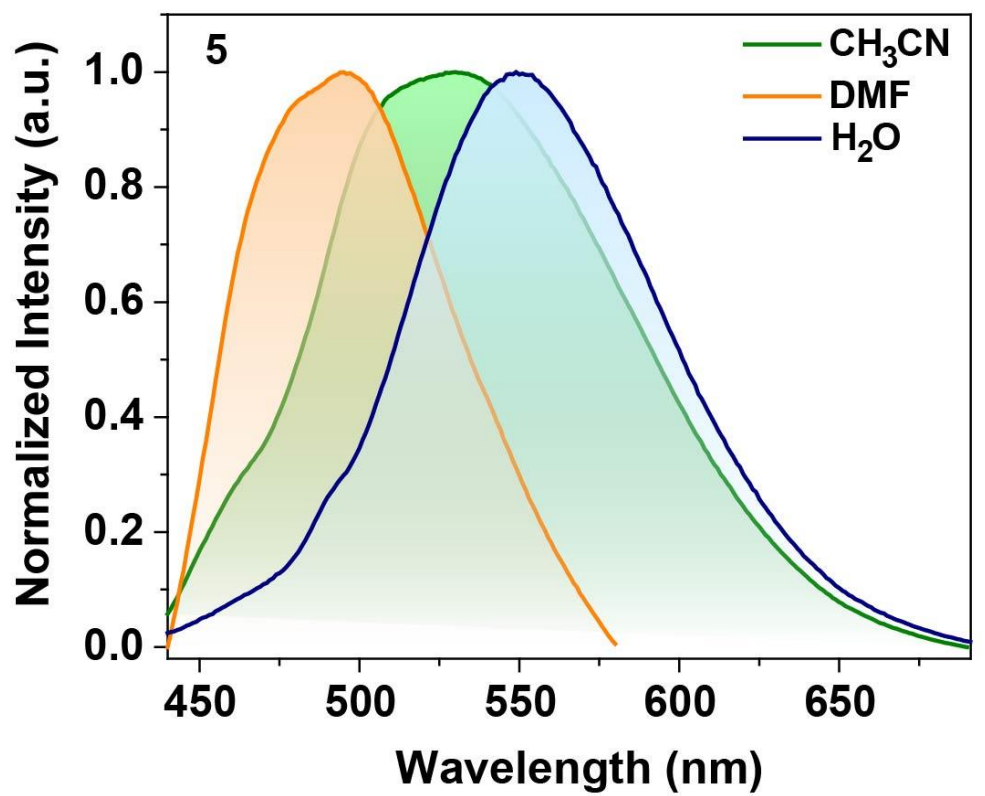

Figure S12. PL spectra of 5 in different solvents at $298 \mathrm{~K}$.

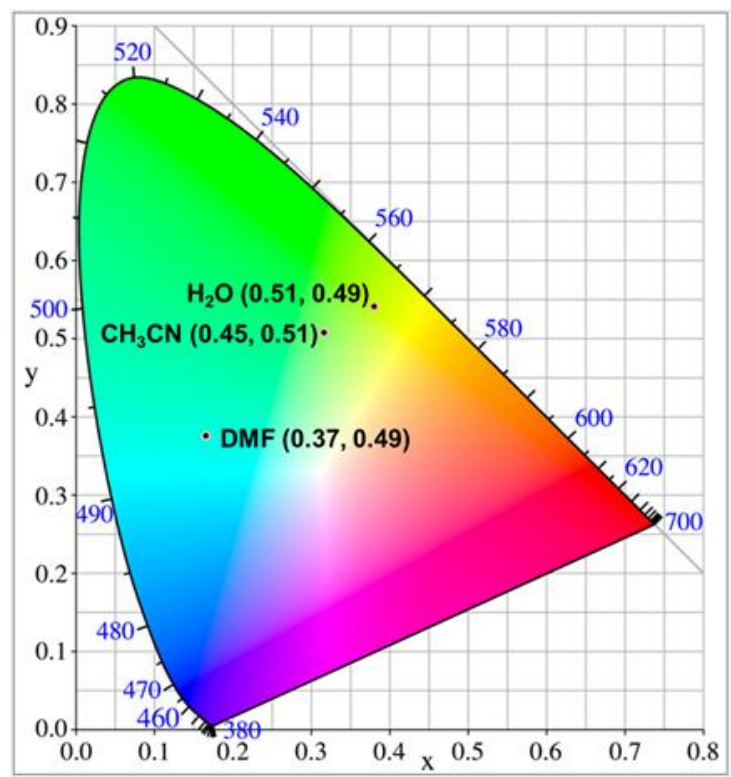

Figure S13. PL spectra of 5 in different solvents plotted in the CIE 1931 chromaticity diagram at $298 \mathrm{~K}$. 


\section{The cyclic voltammogram}
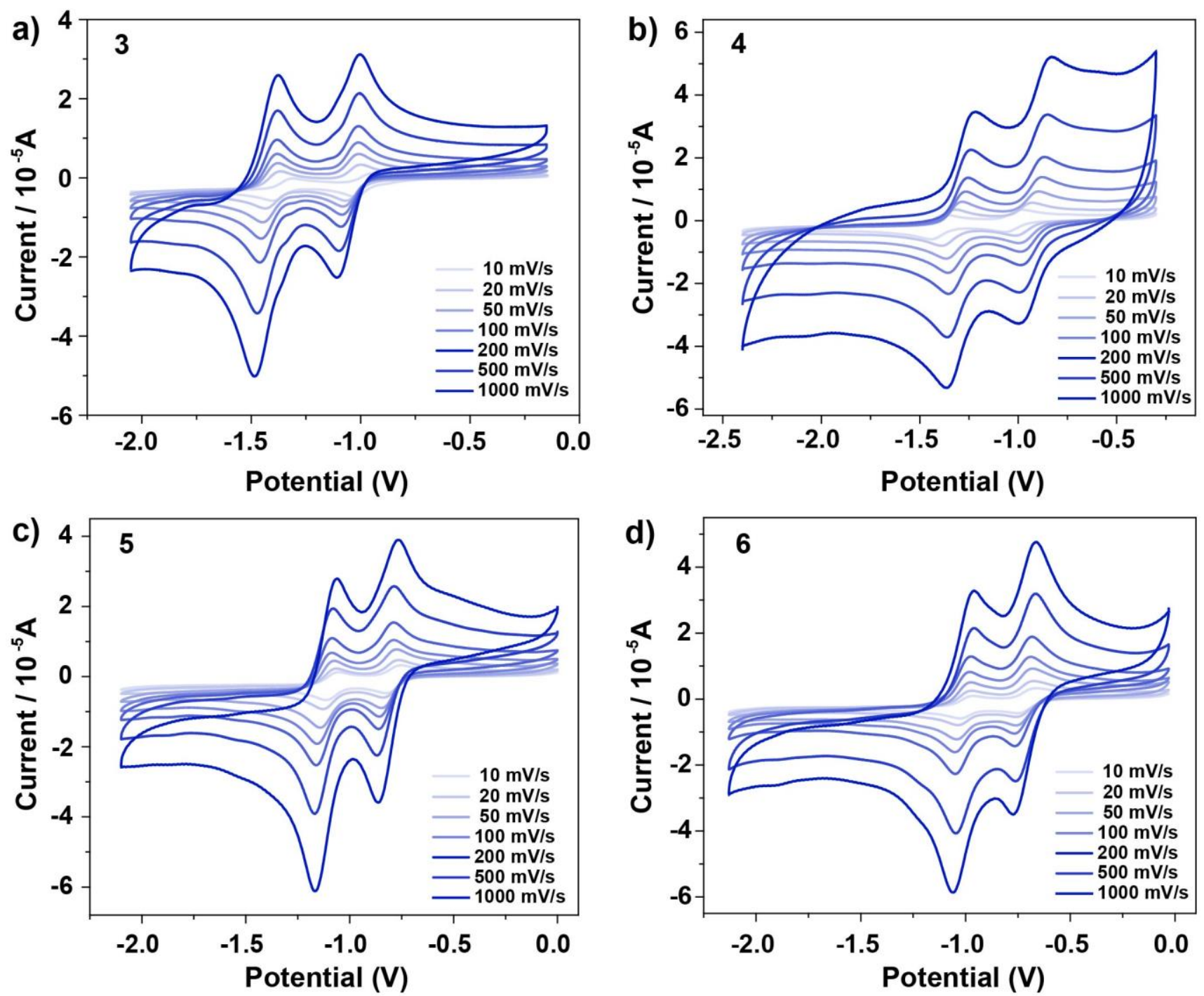

Figure S14. The cyclic voltammogram at different scan rates in DMF solution with tetrabutylammonium hexafluorophosphate (0.1 M) as supporting electrolyte, potential $\mathrm{E}$ referenced to $\mathrm{Fc} / \mathrm{Fc}^{+}, \mathrm{c}=10^{-3} \mathrm{M}$.<smiles></smiles>

$3-6$

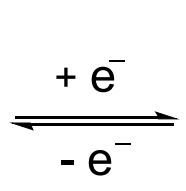<smiles></smiles>

3' - 6'<smiles>[R]N1C=CC2=C3C=CN([R])C=C3[BH-](c3ccccc3)C2=C1</smiles>

3" - 6"

Scheme S1. Redox Reaction of bismuth-Bridged Viologens 
Table S6. Electronic Properties of Bismoviologens.

\begin{tabular}{|c|c|c|c|c|}
\hline Compound & Ered [V] & $\begin{array}{l}E_{\mathrm{g}}[\mathrm{eV}]^{[\mathrm{a}]} \\
(\mathrm{calcd})^{[\mathrm{b}]}\end{array}$ & $\begin{array}{c}\text { ELumo [eV] } \\
\text { calcd }\end{array}$ & $\begin{array}{c}\text { Eномо }[\mathrm{eV}] \\
\text { calcd }\end{array}$ \\
\hline 3 & $-0.91,-1.35$ & $3.85(3.45)$ & -3.70 & -7.15 \\
\hline 4 & $-0.85,-1.23$ & $3.70(3.45)$ & -3.70 & -7.15 \\
\hline 5 & $-0.74,-1.05$ & $3.28(3.32)$ & -3.84 & -7.16 \\
\hline 6 & $-0.64,-0.95$ & $2.71(3.10)$ & -3.97 & -7.07 \\
\hline
\end{tabular}

[a] Energy gap values were calculated from the absorption spectra in DMF. [b] Theoretical calculations have been carried out by using the GAUSSIAN09 suite of programs. 
8. Electrostatic potential surfaces of bismoviologens dications and radical species.
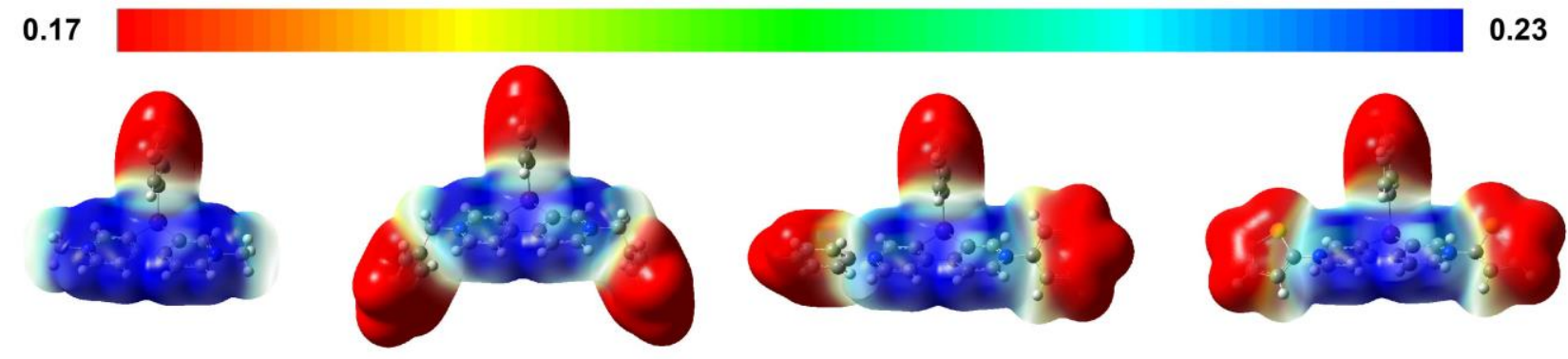

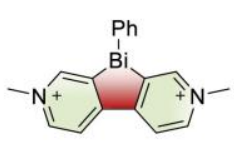

3
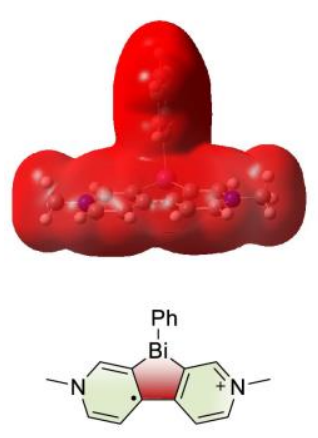

3'

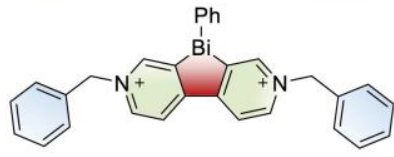

4
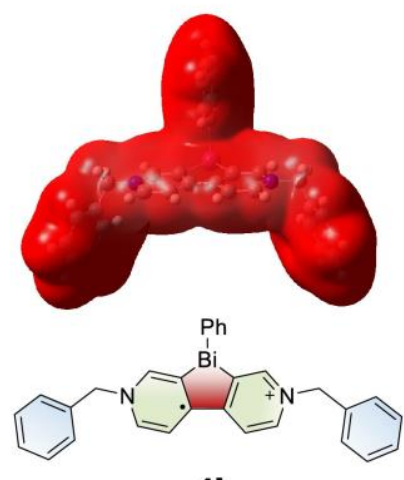

$4^{\prime}$

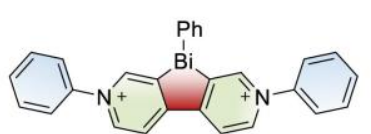

5
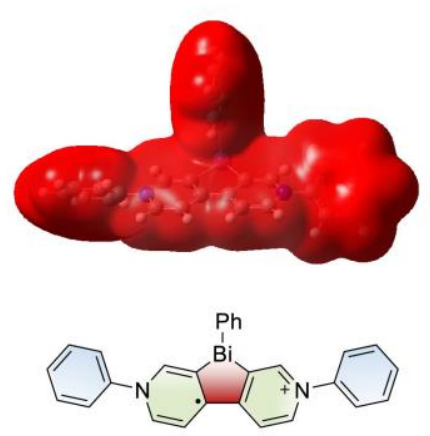

$\mathbf{5}^{\prime}$

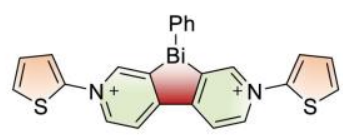

6
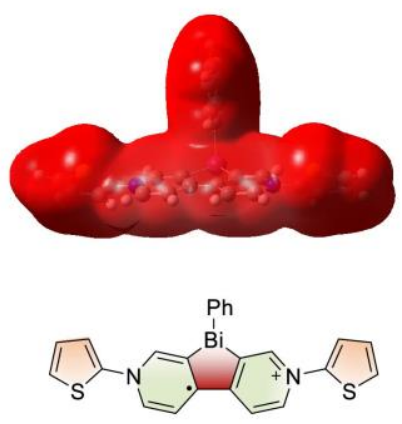

6'

Figure S15. Electrostatic potential surfaces of bismoviologens dications and radical species. 
9. Electrochromism and spectroelectrochemistry of 3, 4 and 6

a)

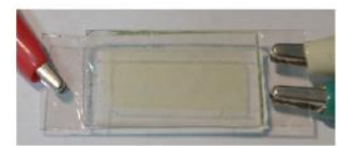

$\stackrel{-0.7}{\stackrel{\text { air }}{\rightleftharpoons}}$

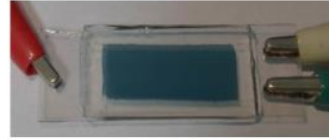

$\stackrel{-1.0}{\stackrel{\text { air }}{\rightleftharpoons}}$

b)

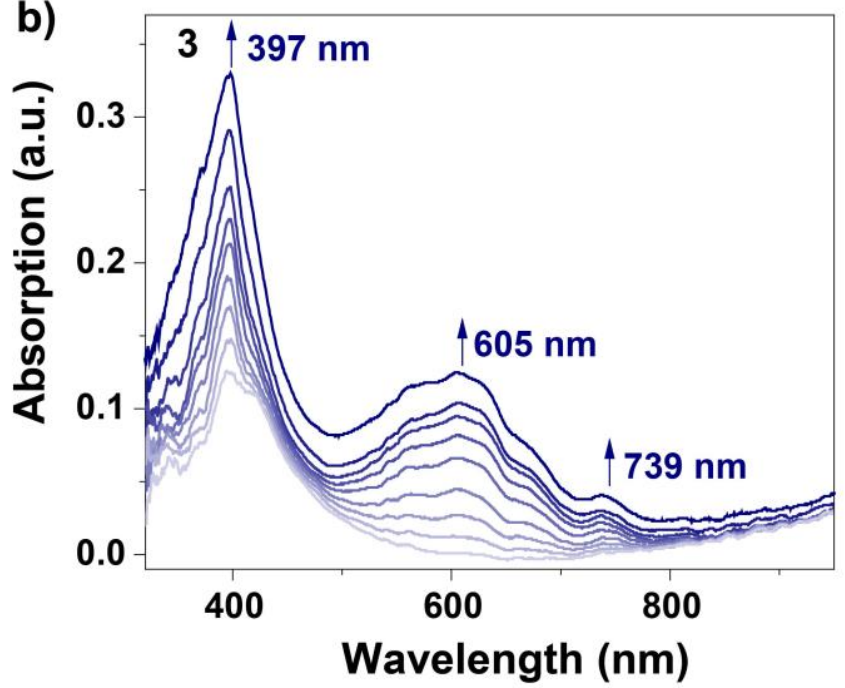

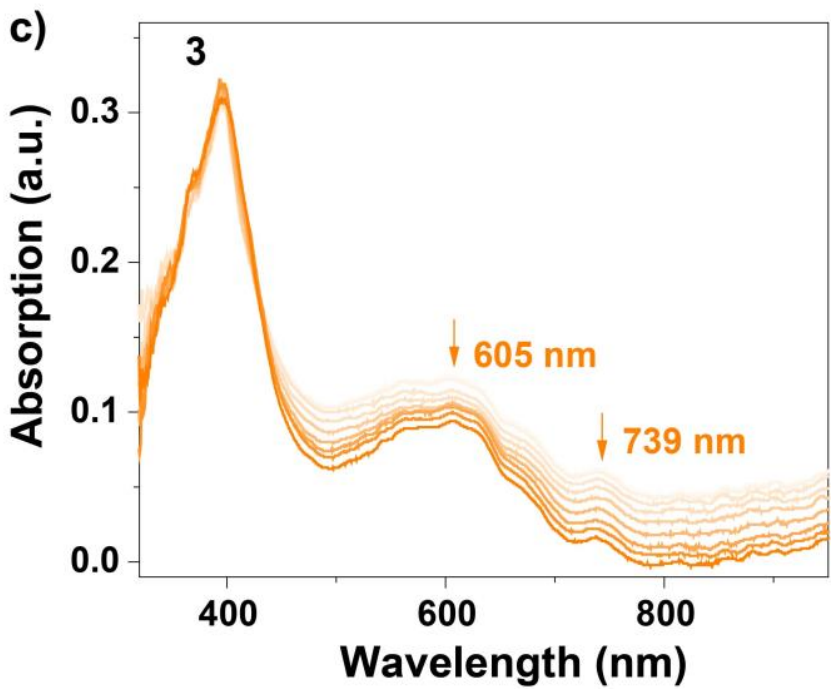

Figure S16. (a) Solution-based electrochromic device with $\mathbf{3}$ (no electrolyte). (b) Spectroelectrochemistry of $\mathbf{3}$ for first reduction. (c) Spectroelectrochemistry of $\mathbf{3}$ for second reduction. $\mathrm{N}, \mathrm{N}$-Dimethylformamide (DMF) was used as the solvent.

a)
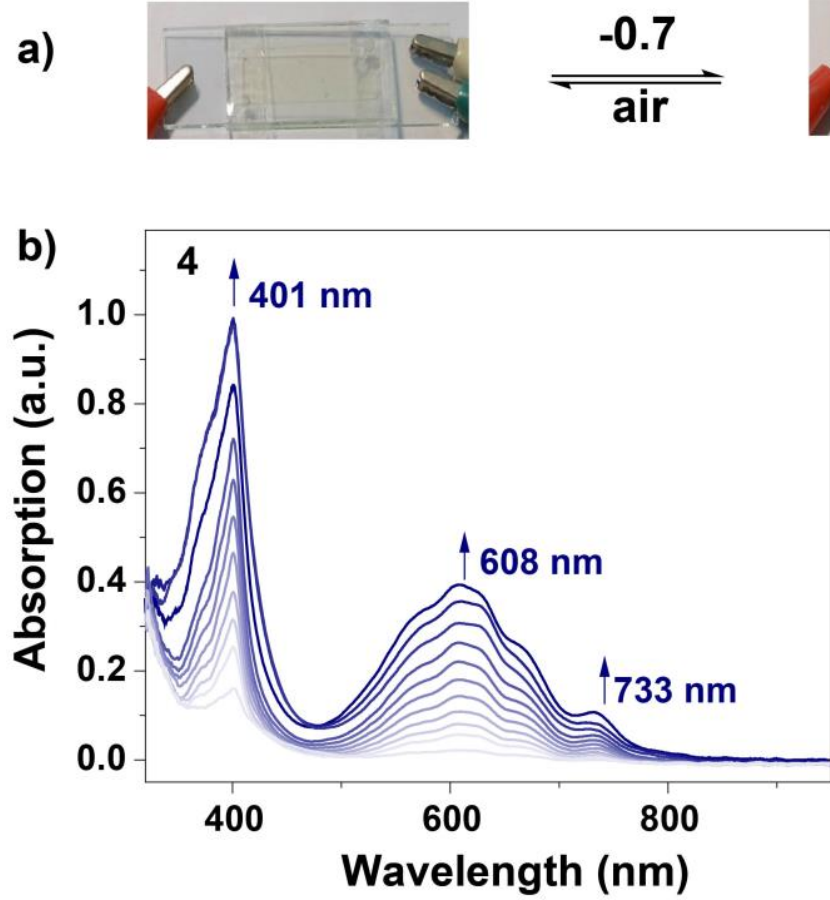
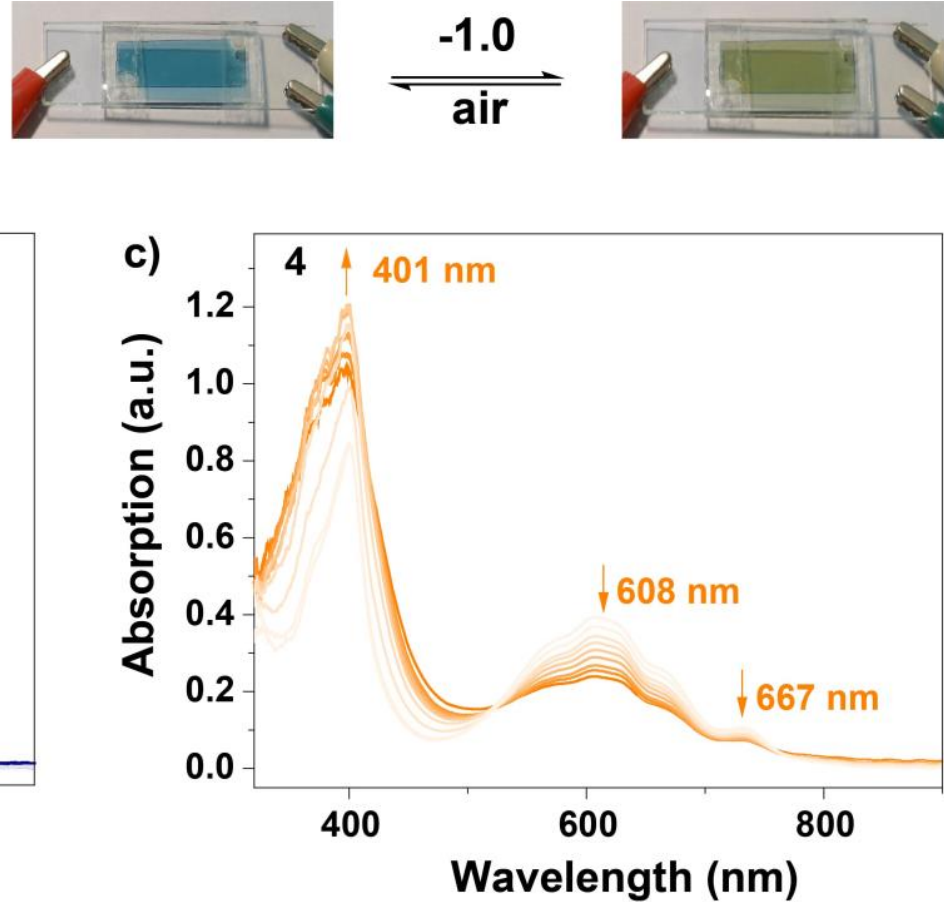

Figure S17. (a) Solution-based electrochromic device with $\mathbf{4}$ (no electrolyte). (b) Spectroelectrochemistry of $\mathbf{4}$ for first reduction. (c) Spectroelectrochemistry of $\mathbf{4}$ for second reduction. $\mathrm{N}, \mathrm{N}$-Dimethylformamide (DMF) was used as the solvent. 
a)

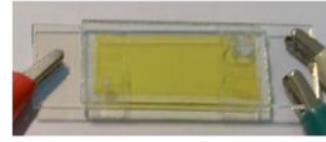

$\stackrel{-0.6}{\stackrel{\text { air }}{\rightleftharpoons}}$

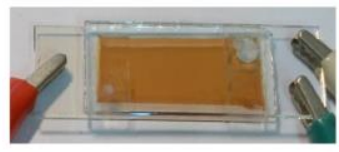

$\stackrel{-1.0}{\stackrel{\text { air }}{\rightleftharpoons}}$
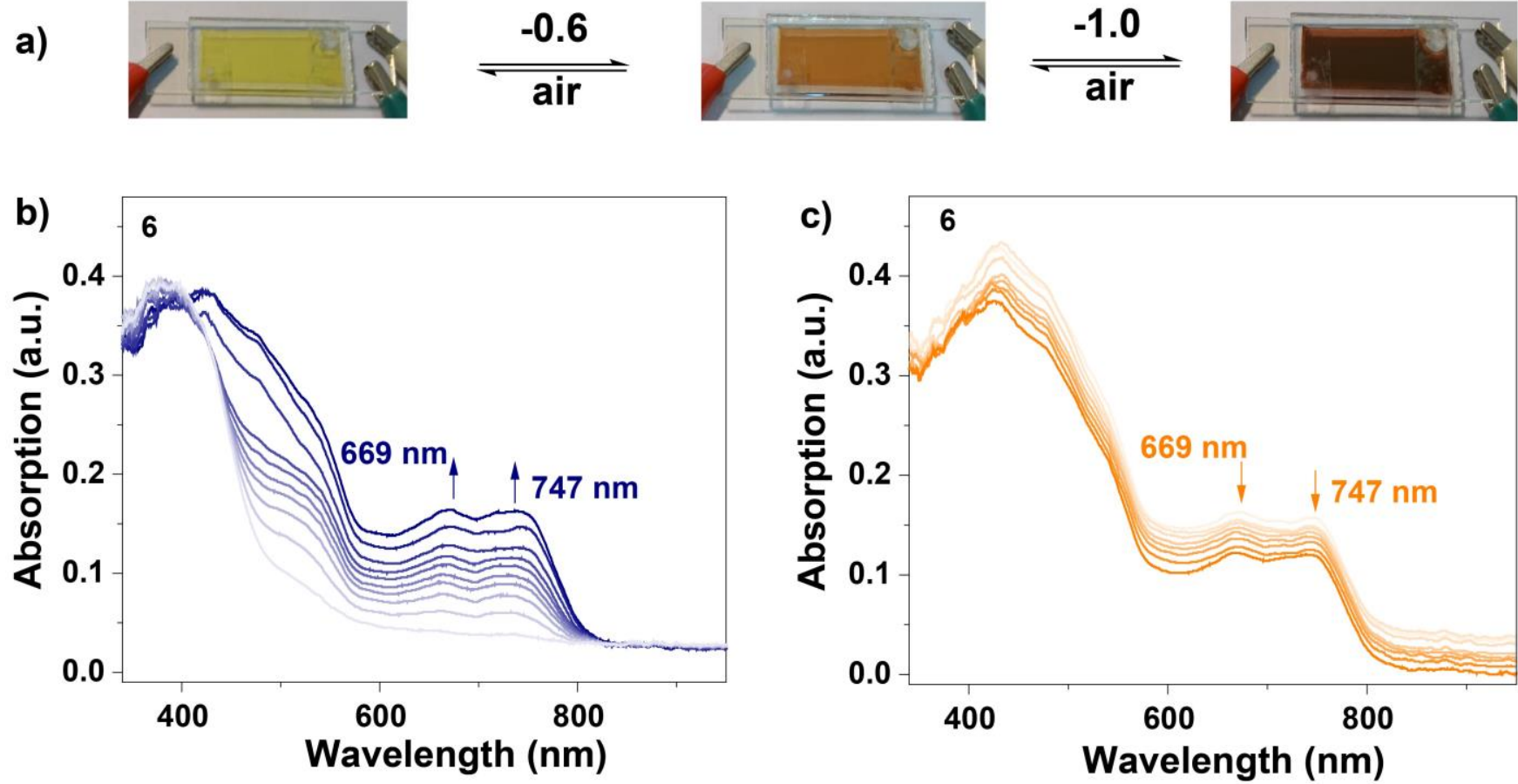

Figure S18. (a) Solution-based electrochromic device with 6 (no electrolyte). (b) Spectroelectrochemistry of 6 for first reduction. (c) Spectroelectrochemistry of 6 for second reduction. $N, N$-Dimethylformamide (DMF) was used as the solvent. 


\section{Optical stability test for electrochromic switching of 5 and $5+\mathrm{FeCp}_{2}$ complex}

The optical stability for electrochromic switching of compound $\mathbf{5}$ and $\mathbf{5}+\mathrm{FeCp}_{\mathbf{2}}$ were tested between 0 and $-2.0 \mathrm{~V}$. For compound $\mathbf{5}$,

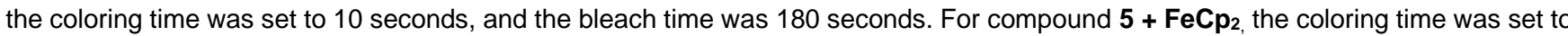
5 seconds, and the bleach time was 90 seconds. The absorbance changes are all at $654 \mathrm{~nm}$.
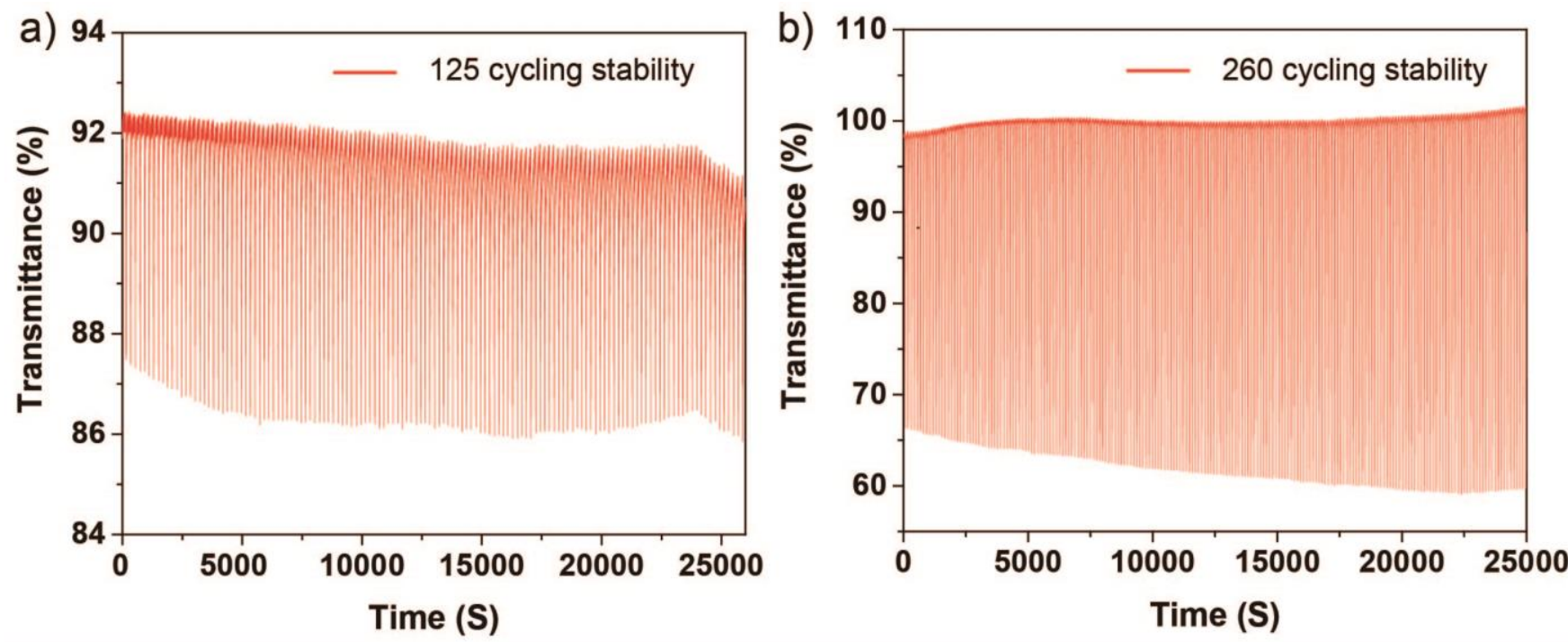

Figure S19. Optical stability test for electrochromic switching of (a) 5 -based ECD and (b) $\mathbf{5}+\mathrm{FeCp}_{2}$-based ECD.

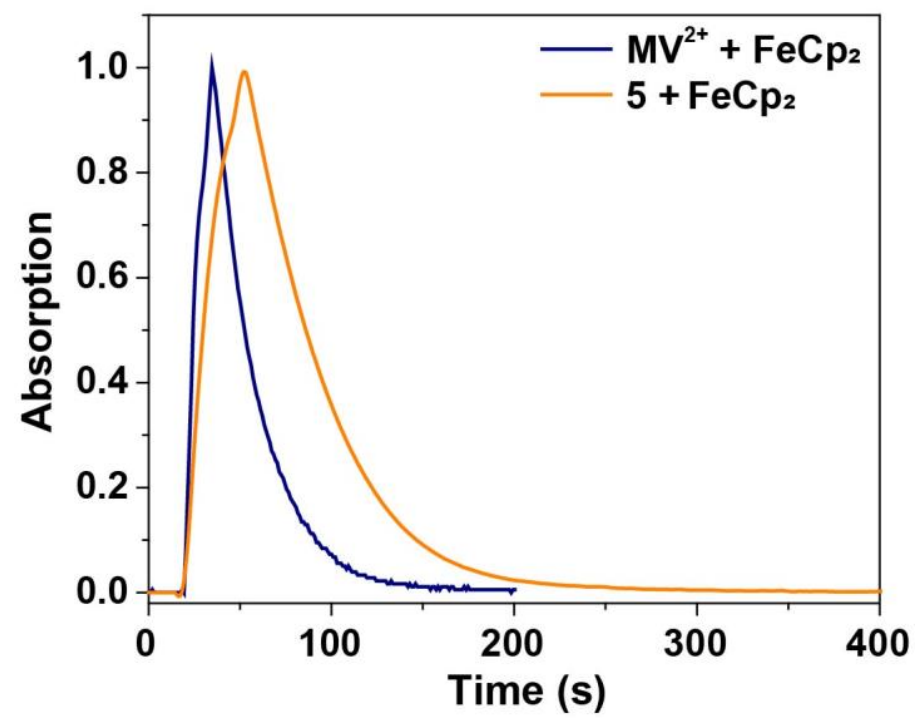

Figure S20. The optical memory of $\mathbf{M V}^{2+}+\mathrm{FeCp}_{2}$ and $\mathbf{5}+\mathrm{FeCp}_{2}$-based ECD at $654 \mathrm{~nm}$ after the applied voltage was cut off. 
11. UV-Vis spectra of radical species and neutral species in DMF.
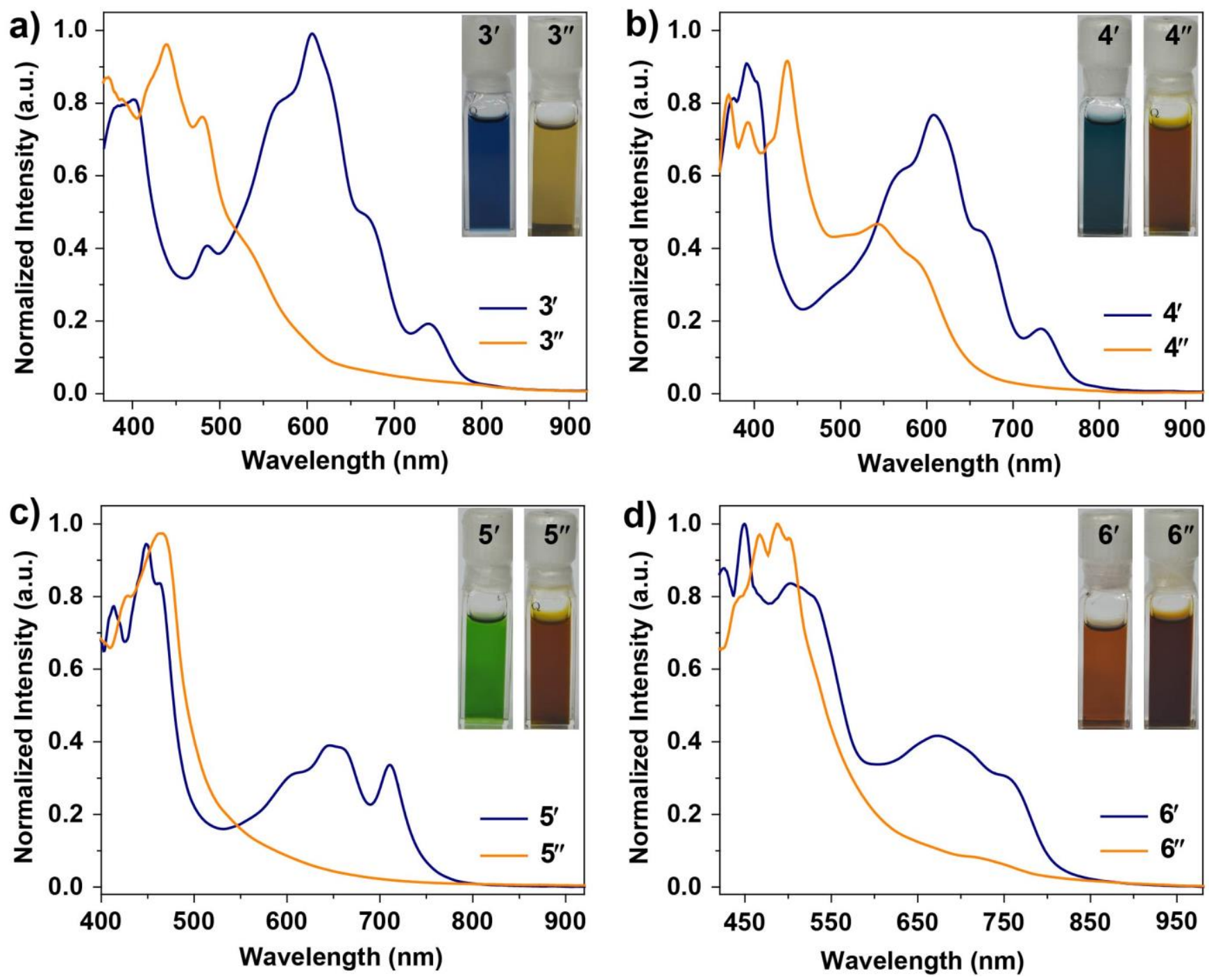

Figure S21. (a) UV-Vis spectra of 3 by chemical reduction with $\mathrm{Zn}\left(\mathbf{3}^{\prime}\right)$ and $\mathrm{Na}\left(\mathbf{3}^{\prime \prime}\right)$, photographs are shown as the inset. (b) UV-Vis spectra of 4 by chemical reduction with $\mathrm{Zn}\left(\mathbf{4}^{\prime}\right)$ and $\mathrm{Na}\left(\mathbf{4}^{\prime \prime}\right)$, photographs are shown as the inset. (c) UV-Vis spectra of 5 by chemical reduction with $\mathrm{Zn}\left(\mathbf{5}^{\prime}\right)$ and $\mathrm{Na}\left(\mathbf{5}^{\prime \prime}\right)$, photographs are shown as the inset. (d) UV-Vis spectra of $\mathbf{6}$ by chemical reduction with $\mathrm{Zn}\left(\mathbf{6}^{\prime}\right)$ and $\mathrm{Na}\left(6^{\prime \prime}\right)$, photographs are shown as the inset. 
12. Photoluminescence spectrum of radical species and neutral species.
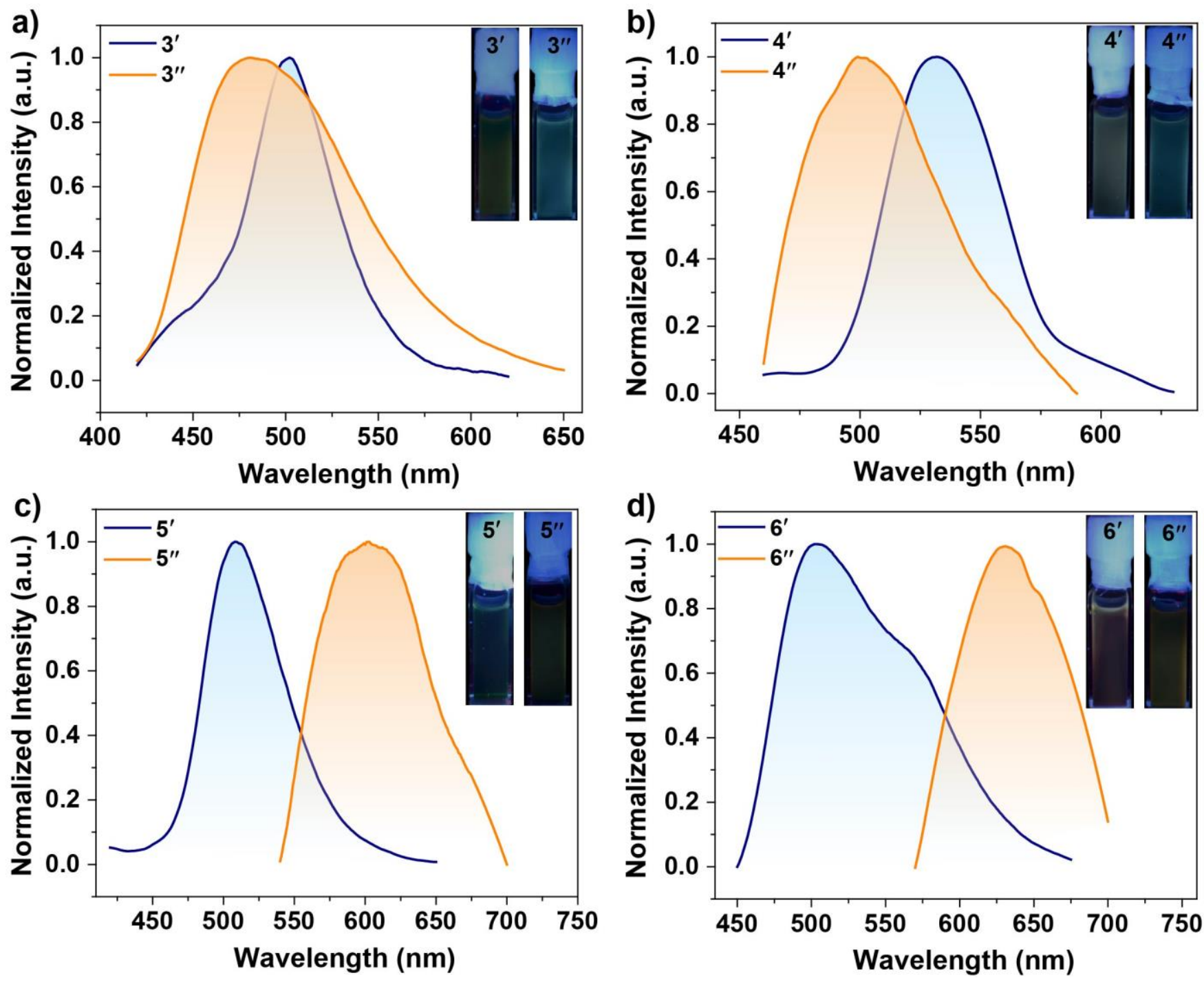

Figure S22. (a) Photoluminescence spectrum of 3 by chemical reduction with $\mathrm{Zn}\left(\mathbf{3}^{\prime}\right)$ and $\mathrm{Na}\left(\mathbf{3}^{\prime \prime}\right)$ in DMF, photographs are shown as the inset. (b) Photoluminescence spectrum of $\mathbf{4}$ by chemical reduction with $\mathrm{Zn}\left(\mathbf{4}^{\prime}\right)$ and $\mathrm{Na}\left(\mathbf{4}^{\prime \prime}\right)$ in DMF, photographs are shown as the inset. (c) Photoluminescence spectrum of 5 by chemical reduction with $\mathrm{Zn}\left(\mathbf{5}^{\prime}\right)$ and $\mathrm{Na}\left(\mathbf{5}^{\prime \prime}\right)$ in DMF, photographs are shown as the inset. (d) Photoluminescence spectrum of 6 by chemical reduction with $\mathrm{Zn}\left(\mathbf{6}^{\prime}\right)$ and $\mathrm{Na}\left(\mathbf{6}^{\prime \prime}\right)$ in DMF, photographs are shown as the inset. 
13. Phosphorescence spectral changes during bulk electrolysis.

a)

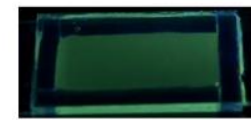

$\stackrel{-0.7}{\text { air }}$

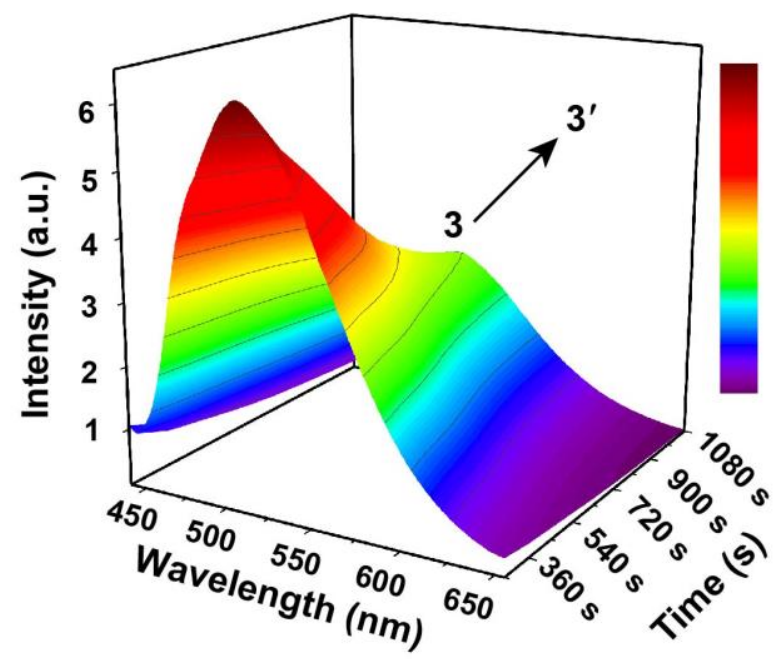

c)
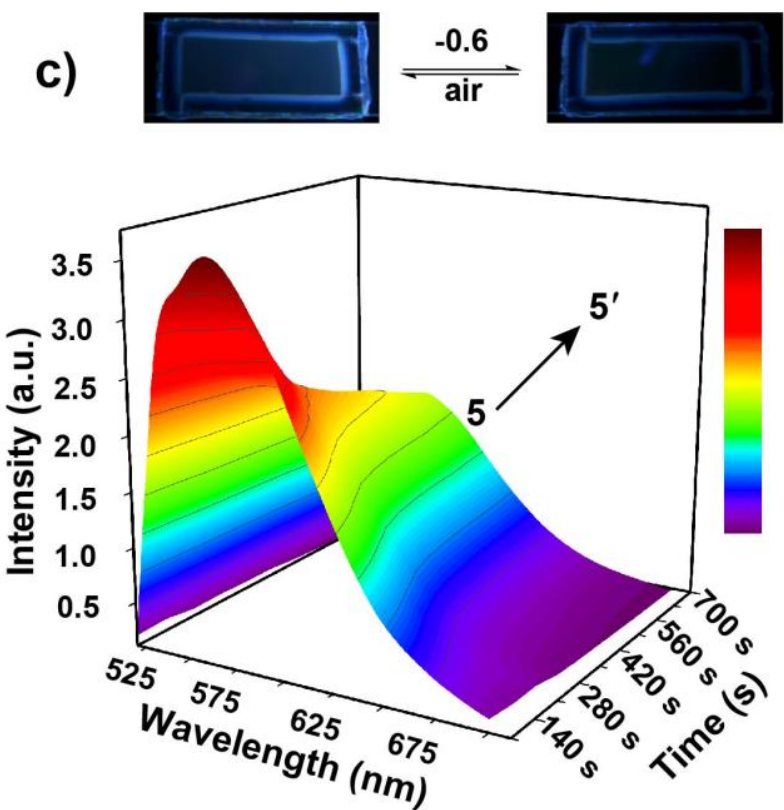

b)
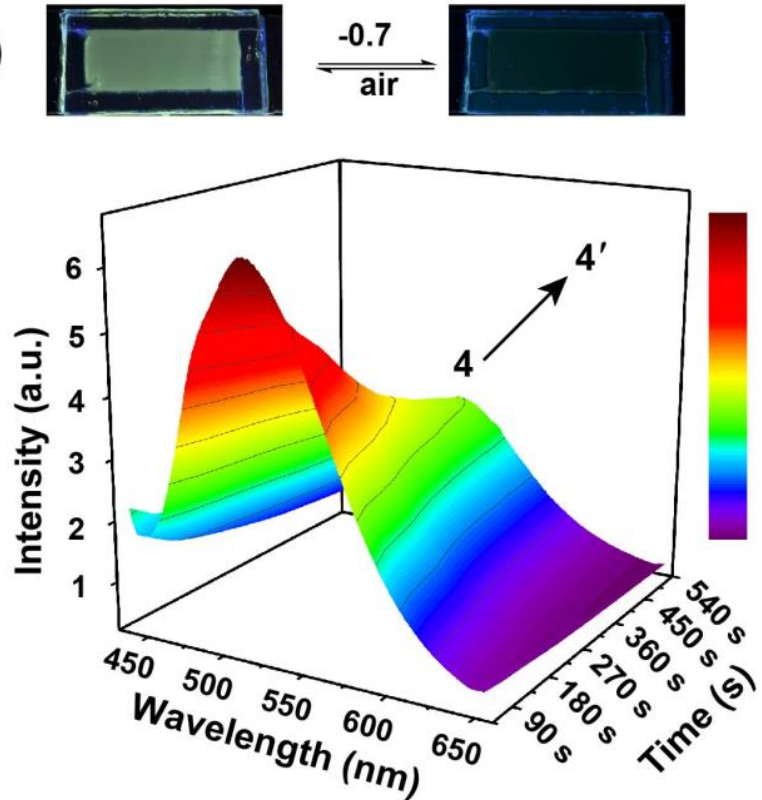

d)
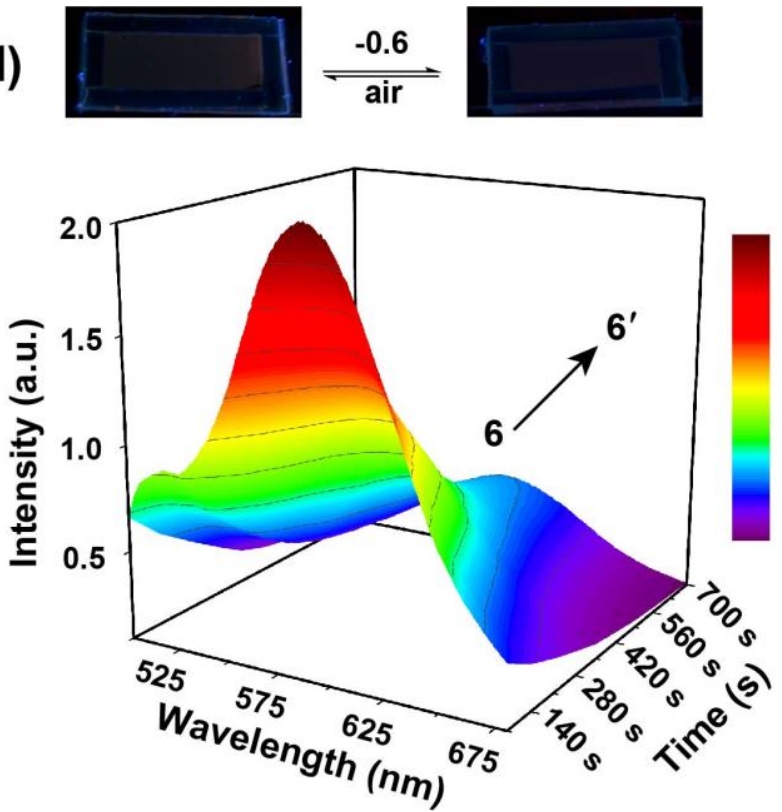

Figure S23. (a) Image of $\mathbf{3}$ and $\mathbf{3}$ ' in DMF solutions encased in a glass ITO electrode window under UV illumination, phosphorescence spectral changes of $\mathbf{3}$ during bulk electrolysis. $\lambda_{\mathrm{ex}}=\mathbf{4 3 0} \mathrm{nm}$. (b) Image of $\mathbf{4}$ and $\mathbf{4}$ ' in DMF solutions encased in a glass ITO electrode window under UV illumination, phosphorescence spectral changes of $\mathbf{4}$ during bulk electrolysis. $\lambda_{\mathrm{ex}}=\mathbf{4 3 0} \mathrm{nm}$. (c) Image of $\mathbf{5}$ and $\mathbf{5}$ ' in DMF solutions encased in a glass ITO electrode window under UV illumination, phosphorescence spectral changes of $\mathbf{5}$ during bulk electrolysis. $\lambda_{\mathrm{ex}}=480 \mathrm{~nm}$. (d) Image of 6 and 6 ' in DMF solutions encased in a glass ITO electrode window under UV illumination, phosphorescence spectral changes of 6 during bulk electrolysis. $\lambda_{\mathrm{ex}}=480 \mathrm{~nm}$. 


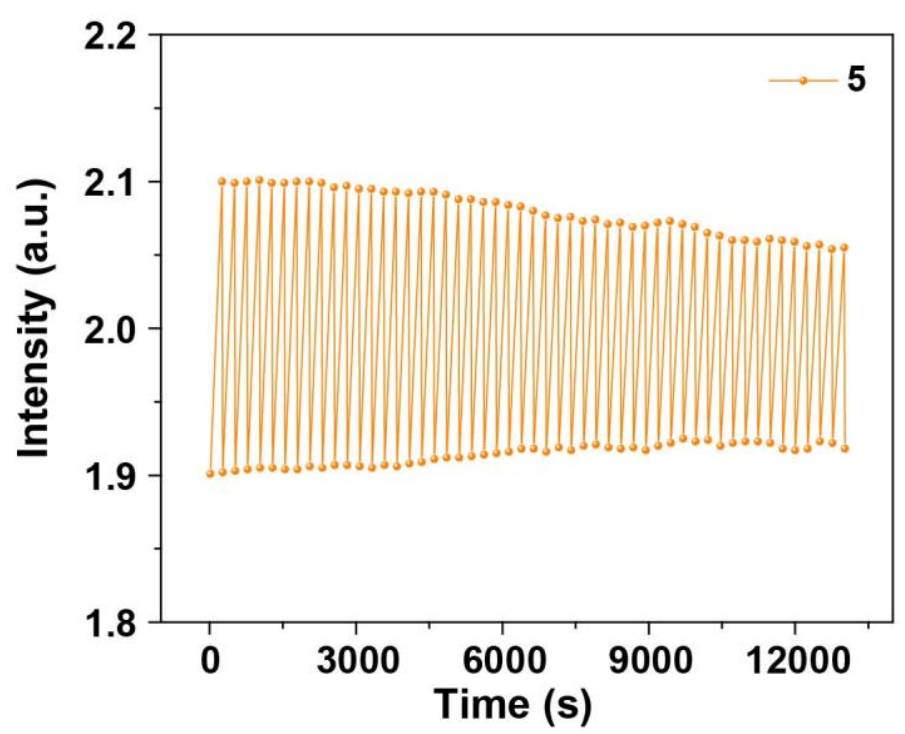

Figure S24. Electrophosphorochromic switching achieved with repetitive square-wave potentials at $565 \mathrm{~nm}$ between $-2.5 \mathrm{~V}$ for $15 \mathrm{~s}$ and $0 \mathrm{~V}$ for $240 \mathrm{~s}$. $\lambda_{\mathrm{ex}}=480 \mathrm{~nm}$. 
14. EPR spectrum and spin densitiesofradical species (3', 4', 5' and 6')
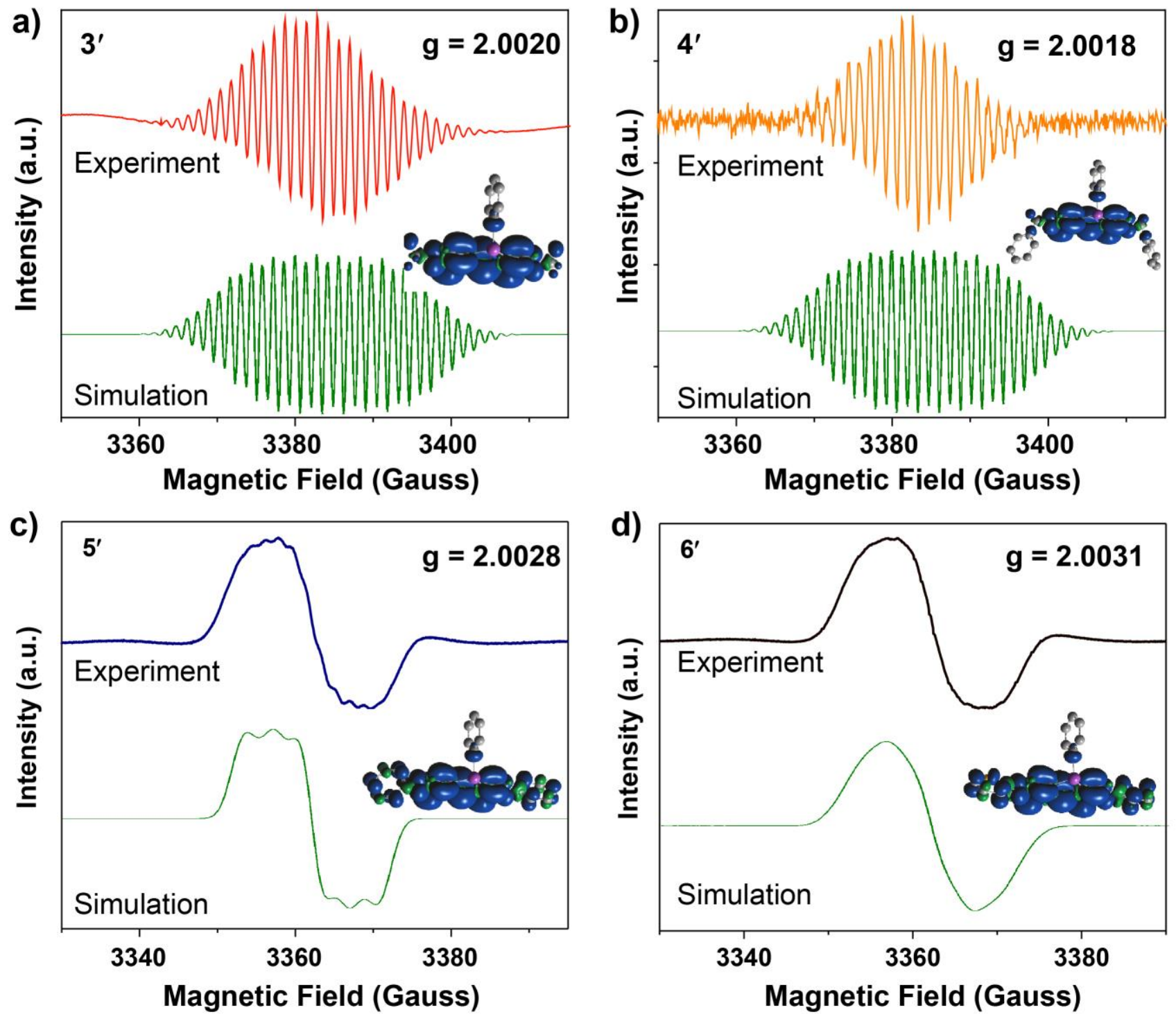

Figure S25. EPR spectrum of bismoviologens-based radicals. 


\section{Visible light-induced cross-dehydrogenative coupling reactions}

\section{General Procedure Cross-Dehydrogenative Coupling Reaction.}

$\mathrm{N}$-phenyl-tetrahydroisoquinoline $(20.9 \mathrm{mg}, 0.1 \mathrm{mmol})$, nucleophile $(1 \mathrm{mmol}, 10 \mathrm{eq})$ and $5(2 \mathrm{mmol} \%)$ were $\mathrm{mixed}$ in the $2 \mathrm{~mL} \mathrm{MeOH}$ with magnetic stirring bar. The tube was irradiated by white LEDs for $30 \mathrm{~h}$. After the solvent was removed by rotary evaporation and purified by column chromatography on silica gel using petroleum ether/ethyl acetate (10:1) as eluent.

Nitromethyl-2-phenyl-tetrahydroisoquinoline (8): Purified by column chromatography on silica gel (eluting with hexane/ethyl acetate). The data were consistent with the previous report. ${ }^{11}{ }^{1} \mathrm{H} \mathrm{NMR}(400 \mathrm{MHz}, \mathrm{CDCl} 3) \delta=7.28-7.10(\mathrm{~m}, 6 \mathrm{H}), 6.97(\mathrm{~d}, J=8.0 \mathrm{~Hz}, 2 \mathrm{H}), 6.85$ $(\mathrm{t}, J=7.3 \mathrm{~Hz}, 1 \mathrm{H}), 5.53(\mathrm{t}, J=7.2 \mathrm{~Hz}, 1 \mathrm{H}), 4.85(\mathrm{dd}, J=11.8,7.8 \mathrm{~Hz}, 1 \mathrm{H}), 4.54(\mathrm{dd}, J=11.8,6.6 \mathrm{~Hz}, 1 \mathrm{H}), 3.68-3.56(\mathrm{~m}, 2 \mathrm{H}), 3.10-$ $3.03(\mathrm{~m}, 1 \mathrm{H}), 2.77(\mathrm{dt}, J=16.4,4.9 \mathrm{~Hz}, 1 \mathrm{H})$.

Dimethy 2-(2-phenyl-tetrahydroisoquinolin-1-yl)malonate (9): Purified by column chromatography on silica gel (eluting with hexane/ethyl acetate). The data were consistent with the previous report. ${ }^{11}{ }^{1} \mathrm{H} \mathrm{NMR}\left(400 \mathrm{MHz}, \mathrm{CDCl}_{3}\right) \delta=7.24-7.08(\mathrm{~m}, 6 \mathrm{H}), 6.99$ $(\mathrm{d}, J=8.2,2 \mathrm{H}), 6.77(\mathrm{t}, J=7.3,1 \mathrm{H}), 5.71(\mathrm{~d}, J=9.4,1 \mathrm{H}), 3.96(\mathrm{~d}, J=9.4,1 \mathrm{H}), 3.74-3.59(\mathrm{~m}, 5 \mathrm{H}), 3.54(\mathrm{~s}, 3 \mathrm{H}), 3.10-3.02(\mathrm{~m}, 1 \mathrm{H})$, $2.87(\mathrm{dt}, J=16.5,5.1,1 \mathrm{H})$.

Table S7. The cross-dehydrogenative coupling reaction of $\mathbf{N}$-aryltetrahydroisoquinolines.

\begin{tabular}{|c|c|c|c|c|}
\hline Entry ${ }^{[a]}$ & Nucleophile & Catalyst & Solvent & Yield $^{[b]}$ \\
\hline 1 & Nitromethane & $5(1 \mathrm{~mol} \%)$ & $\mathrm{CH}_{3} \mathrm{CN}(2 \mathrm{~mL})$ & $8(33 \%)$ \\
\hline 2 & Nitromethane & $5(1 \mathrm{~mol} \%)$ & DMF (2 mL) & $8(47 \%)$ \\
\hline 3 & Nitromethane & $5(1 \mathrm{~mol} \%)$ & $\mathrm{EtOH}(2 \mathrm{~mL})$ & $8(34 \%)$ \\
\hline 4 & Nitromethane & $5(1 \mathrm{~mol} \%)$ & $\mathrm{MeOH}(2 \mathrm{~mL})$ & $8(79 \%)$ \\
\hline 5 & Nitromethane & 5 (2 mol\%) & $\mathrm{MeOH}(2 \mathrm{~mL})$ & $8(81 \%)$ \\
\hline $6^{[c]}$ & Nitromethane & $5(2 \mathrm{~mol} \%)$ & $\mathrm{MeOH}(2 \mathrm{~mL})$ & n.r. \\
\hline 7 & Nitromethane & 3 (2 mol\%) & $\mathrm{MeOH}(2 \mathrm{~mL})$ & $8(78 \%)$ \\
\hline 8 & Nitromethane & $4(2 \mathrm{~mol} \%)$ & $\mathrm{MeOH}(2 \mathrm{~mL})$ & $8(73 \%)$ \\
\hline 9 & Nitromethane & $6(2 \mathrm{~mol} \%)$ & $\mathrm{MeOH}(2 \mathrm{~mL})$ & $8(31 \%)$ \\
\hline 10 & Nitromethane & $\mathrm{MV}^{2+}(2 \mathrm{~mol} \%)$ & $\mathrm{MeOH}(2 \mathrm{~mL})$ & $8(6 \%)$ \\
\hline 11 & Nitromethane & $\mathrm{PhV}^{2+}(2 \mathrm{~mol} \%)$ & $\mathrm{MeOH}(2 \mathrm{~mL})$ & $8(7 \%)$ \\
\hline 12 & Nitromethane & Bismole (2 mol\%) & $\mathrm{MeOH}(2 \mathrm{~mL})$ & $8(5 \%)$ \\
\hline 13 & Nitromethane & $\mathrm{S}-\mathrm{PhV}^{2+}(2 \mathrm{~mol} \%)$ & $\mathrm{MeOH}(2 \mathrm{~mL})$ & $8(12 \%)$ \\
\hline 14 & Nitromethane & $\mathrm{Se}-\mathrm{PhV}^{2+}(2 \mathrm{~mol} \%)$ & $\mathrm{MeOH}(2 \mathrm{~mL})$ & $8(42 \%)$ \\
\hline 15 & Nitromethane & $\mathrm{Te}-\mathrm{PhV}^{2+}(2 \mathrm{~mol} \%)$ & $\mathrm{MeOH}(2 \mathrm{~mL})$ & $8(70 \%)$ \\
\hline 16 & Dimethyl malonates & 5 (2 mol\%) & $\mathrm{MeOH}(2 \mathrm{~mL})$ & $9(79 \%)$ \\
\hline
\end{tabular}

[a]. Reaction conditions: 7 (0.1 mmol), Cat., $\mathrm{MeNO}_{2}$ (1 mmol, 10 equiv), $\mathrm{MeOH}(2 \mathrm{~mL})$, White LED irradiation, and under air condition for $30 \mathrm{~h}$. [b]. The yields detected by ${ }^{1} \mathrm{H}$ NMR spectroscopy using mesitylene as an internal standard. [c] no light. 

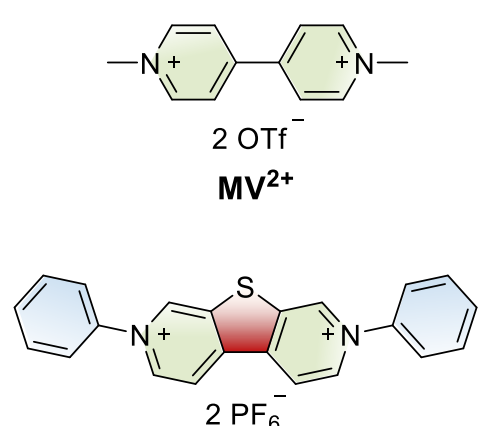

$\mathrm{S}-\mathrm{PhV}^{2+}$<smiles></smiles>

3

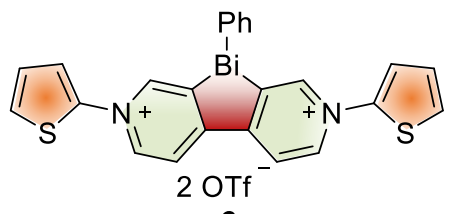

6

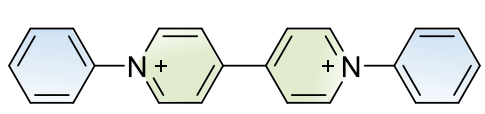

$2 \mathrm{OTf}^{-}$

$\mathrm{PhV}^{2+}$

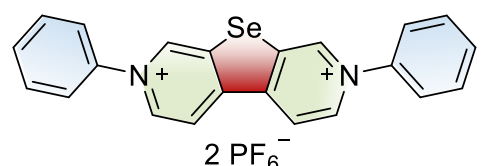

Se-PhV ${ }^{2+}$

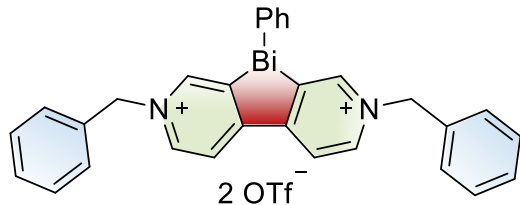

4

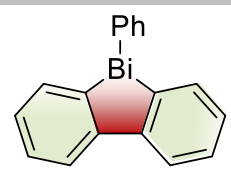

bismole

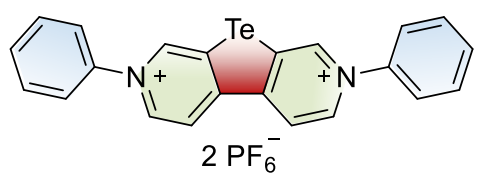

Te-PhV ${ }^{2+}$<smiles>[R]c1cc[n+](-c2ccccc2)cc1[B-](c1ccccc1)c1cc[n+](-c2ccccc2)cc1-c1ccccc1</smiles>

5

Scheme S2. Screen of viologens and bismole analogs for the cross-dehydrogenative coupling reaction. 


\section{Quantum yield measurements}

According to the procedure of Yoon ${ }^{12}$, the photon flux of the spectrophotometer was determined by standard ferrioxalate actinometry. A $0.15 \mathrm{M}$ solution of ferrioxalate was prepared by dissolving potassium ferrioxalate hydrate $(1.47 \mathrm{~g})$ in $\mathrm{H}_{2} \mathrm{SO}_{4}(20 \mathrm{~mL}$ of a $0.05 \mathrm{M}$ solution). A buffered solution of 1,10-phenanthroline was prepared by dissolving phenanthroline (25 $\mathrm{mg}$ ) and sodium acetate (5.63 $\mathrm{g}$ ) in $\mathrm{H}_{2} \mathrm{SO}_{4}$ (25 mL of a $0.5 \mathrm{M}$ solution). Both solutions were stored in the dark. To determine the photon flux of the spectrophotometer, the ferrioxalate solution $(2.0 \mathrm{~mL})$ was placed in a cuvette and irradiated for 90 seconds at $\lambda=402 \mathrm{~nm}$. After irradiation, the phenanthroline solution $(0.35 \mathrm{~mL})$ was added to the cuvette and the mixture was allowed to rest in the dark for 1 hour to allow the ferrous ions to completely coordinate to the phenanthroline. The absorbance of the solution was measured at $510 \mathrm{~nm}$. A non-irradiated sample was also prepared and the absorbance at $510 \mathrm{~nm}$ was measured. Conversion was calculated using equation (1).

For 3 , in the equation (1), the total volume $(\mathrm{V})$ is $0.00235 \mathrm{~L}$, the difference in absorbance at $510 \mathrm{~nm}(\Delta \mathrm{A})$ is 1.936 , the path length (I) is $1.000 \mathrm{~cm}$, the molar absorptivity at $510 \mathrm{~nm}(\varepsilon)$ is $11,100 \mathrm{~L} \mathrm{~mol}^{-1} \mathrm{~cm}^{-1}$; the amount of conversion mol $\left(\mathrm{Fe}^{2+}\right)$ is calculated to be $4.10 \times$ $10^{-7} \mathrm{~mol}$ by equation (1). In the equation (2), the absorbance of the above ferrioxalate solution at $402 \mathrm{~nm}(\mathrm{~A})$ is 1.996 , the fraction of light absorbed at $402 \mathrm{~nm}$ (f) is calculated to be 0.98991 by equation (2). In the equation (3), the quantum yield for the ferrioxalate actinometer $\left(\Phi_{1}\right)$ is $1.07^{13}(0.15 \mathrm{M}$ solution at $\lambda=402 \mathrm{~nm})$, the irradiated reaction time $\left(\mathrm{t}_{1}\right)$ is $90.0 \mathrm{~s}$, the photon flux is calculated to be $4.30 \times 10^{-9}$ einstein $\mathrm{s}^{-1}$ by equation (3). In the equation (4), the amount of product mol (prod) is $10^{-5} \mathrm{~mol}$, the reaction time ( $\mathrm{t}_{2}$ ) is 21,600 $\mathrm{s}$, The absorbance of 3 at $402 \mathrm{~nm}$ is 0.716 at the reaction concentration indicating the fraction of light absorbed (f) is 0.80769 . the quantum yield $\Phi_{2}$ for the reaction is calculated to be 0.13 .

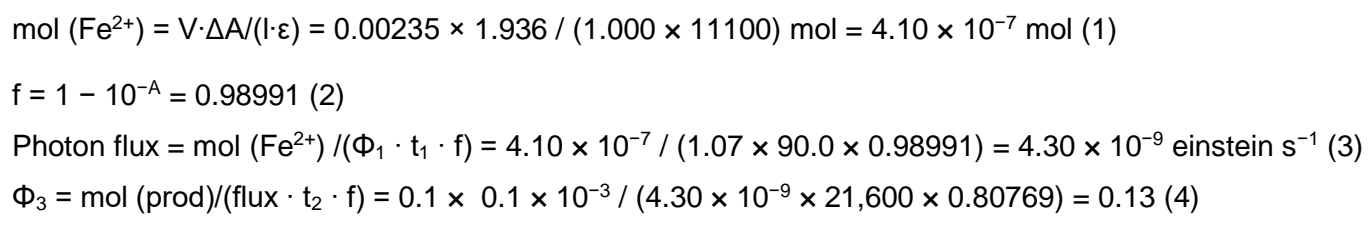

For 5 , in the equation (1), the total volume $(\mathrm{V})$ is $0.00235 \mathrm{~L}$, the difference in absorbance at $510 \mathrm{~nm}(\Delta \mathrm{A})$ is 1.936 , the path length $(\mathrm{l})$ is $1.000 \mathrm{~cm}$, the molar absorptivity at $510 \mathrm{~nm}(\varepsilon)$ is $11,100 \mathrm{~L} \mathrm{~mol}^{-1} \mathrm{~cm}^{-1}$; the amount of conversion mol $\left(\mathrm{Fe}^{2+}\right)$ is calculated to be $4.10 \times$ $10^{-7} \mathrm{~mol}$ by equation (1). In the equation (2), the absorbance of the above ferrioxalate solution at $402 \mathrm{~nm}(\mathrm{~A})$ is 1.996 , the fraction of light absorbed at $402 \mathrm{~nm}$ (f) is calculated to be 0.98991 by equation (2). In the equation (3), the quantum yield for the ferrioxalate actinometer $\left(\Phi_{1}\right)$ is $1.07^{13}(0.15 \mathrm{M}$ solution at $\lambda=402 \mathrm{~nm})$, the irradiated reaction time $\left(\mathrm{t}_{1}\right)$ is $90.0 \mathrm{~s}$, the photon flux is calculated to be $4.30 \times 10^{-9}$ einstein $\mathrm{s}^{-1}$ by equation (3). In the equation (4), the amount of product mol (prod) is $3 \times 10^{-5}$ mol, the reaction time ( $t_{2}$ ) is $21,600 \mathrm{~s}$, The absorbance of 5 at $402 \mathrm{~nm}$ is 1.506 at the reaction concentration indicating the fraction of light absorbed (f) is 0.96881 . the quantum yield $\Phi_{2}$ for the reaction is calculated to be 0.33 .

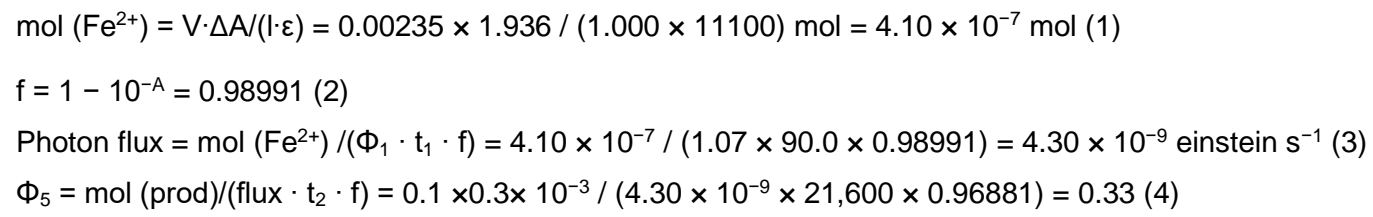




\section{Computed UV-vis spectra.}

The simulated UV-Vis spectra for optimized molecules were performed at the time dependent density functional theory (TD-DFT) at the ground-state equilibrium geometries in DMF solution, both low-lying singlet and triplet states were determined using the B3LYP, in association with the LANL08(d) basis set applied for the Bi atom and 6-311G(d,p) basis set for all other atoms.

Table S8. Calculated $\left(\lambda_{\text {TD-DFT }}\right)$ wavelengths $(n m)$ of 3. Molecular orbitals (MOs) involved in the main electronic transition, $f$ corresponds to the oscillator strength.

\begin{tabular}{|c|c|c|c|}
\hline$\lambda_{\text {TD-DFT }}$ & $\begin{array}{c}\text { Oscillator } \\
\text { Strength, } \mathrm{f}\end{array}$ & MOs & \\
\hline 390.79 & 0.0973 & HOMO-2 -> LUMO & $98.3 \%$ \\
\hline 294.10 & 0.4325 & HOMO-3 -> LUMO & $93.4 \%$ \\
\hline \multirow{2}{*}{280.72} & 0.2210 & HOMO-4 -> LUMO & $86.1 \%$ \\
\cline { 2 - 4 } & 0.2255 & HOMO -> LUMO+1 & $6.0 \%$ \\
\hline 270.21 & HOMO-2 -> LUMO+1 & $94.5 \%$ \\
\hline
\end{tabular}

Table S9. Calculated $\left(\lambda_{\mathrm{TD}-\mathrm{DFT}}\right)$ wavelengths $(\mathrm{nm})$ of 4 . Molecular orbitals $(\mathrm{MOs})$ involved in the main electronic transition, $\mathrm{f}$ corresponds to the oscillator strength.

\begin{tabular}{|c|c|c|c|}
\hline \multirow{2}{*}{$\lambda_{\text {TD-DFT }}$} & $\begin{array}{c}\text { Oscillator } \\
\text { Strength, } \mathrm{f}\end{array}$ & MOs & \\
\hline \multirow{2}{*}{384.49} & \multirow{2}{*}{0.0622} & HOMO-6 -> LUMO & $74.6 \%$ \\
\cline { 3 - 4 } & & HOMO-4 -> LUMO & $22.5 \%$ \\
\hline 293.02 & 0.5130 & HOMO-7 -> LUMO & $94.7 \%$ \\
\hline \multirow{2}{*}{281.57} & \multirow{2}{*}{0.2120} & HOMO-8 -> LUMO & $78.3 \%$ \\
\cline { 3 - 4 } & & HOMO -> LUMO+1 & $9.9 \%$ \\
\hline \multirow{2}{*}{252.67} & \multirow{2}{*}{0.2164} & HOMO-1 -> LUMO+3 & $94.5 \%$ \\
\cline { 3 - 4 } & & HOMO -> LUMO+2 & $16.8 \%$ \\
\cline { 3 - 4 } & & HOMO -> LUMO+3 & $53.2 \%$ \\
\hline
\end{tabular}


Table S10. Calculated $\left(\lambda_{\text {TD-DFT }}\right)$ wavelengths $(\mathrm{nm})$ of 5 . Molecular orbitals (MOs) involved in the main electronic transition, $f$ corresponds to the oscillator strength.

\begin{tabular}{|c|c|c|c|}
\hline$\lambda_{\text {TD-DFT }}$ & $\begin{array}{l}\text { Oscillator } \\
\text { Strength, } f\end{array}$ & MOs & \\
\hline \multirow{2}{*}{407.19} & \multirow{2}{*}{0.1215} & HOMO-3 -> LUMO & $7.3 \%$ \\
\hline & & HOMO-2 -> LUMO & $83.2 \%$ \\
\hline \multirow{2}{*}{391.44} & \multirow{2}{*}{0.7149} & HOMO-3 -> LUMO & $83.9 \%$ \\
\hline & & HOMO-2 -> LUMO & $15.0 \%$ \\
\hline 276.82 & 0.3104 & HOMO-9 -> LUMO & $84.9 \%$ \\
\hline \multirow{4}{*}{253.98} & \multirow{4}{*}{0.1358} & HOMO-6 -> LUMO+1 & $6.9 \%$ \\
\hline & & HOMO-3 -> LUMO+2 & $8.4 \%$ \\
\hline & & HOMO-2 -> LUMO+2 & $60.4 \%$ \\
\hline & & HOMO-2 -> LUMO+3 & $6.3 \%$ \\
\hline
\end{tabular}

Table S11. Calculated $\left(\lambda_{\mathrm{TD}-\mathrm{DFT}}\right)$ wavelengths $(\mathrm{nm})$ of 6 . Molecular orbitals (MOs) involved in the main electronic transition, $\mathrm{f}$ corresponds to the oscillator strength.

\begin{tabular}{|c|c|c|c|}
\hline$\lambda_{\text {TD-DFT }}$ & $\begin{array}{l}\text { Oscillator } \\
\text { Strength, } f\end{array}$ & MOs & \\
\hline 483.62 & 0.7514 & HOMO -> LUMO & $98.2 \%$ \\
\hline \multirow{2}{*}{455.48} & \multirow{2}{*}{0.1198} & HOMO-2 -> LUMO & $17.5 \%$ \\
\hline & & HOMO-1 -> LUMO & $81.5 \%$ \\
\hline \multirow{2}{*}{276.63} & \multirow{2}{*}{0.3218} & HOMO-11 -> LUMO & $19.6 \%$ \\
\hline & & HOMO-9 -> LUMO & $67.7 \%$ \\
\hline \multirow{3}{*}{271.49} & \multirow{3}{*}{0.2784} & HOMO-10 -> LUMO & $16.2 \%$ \\
\hline & & HOMO-4 -> LUMO+1 & $70.0 \%$ \\
\hline & & HOMO-3 -> LUMO+1 & $8.6 \%$ \\
\hline
\end{tabular}




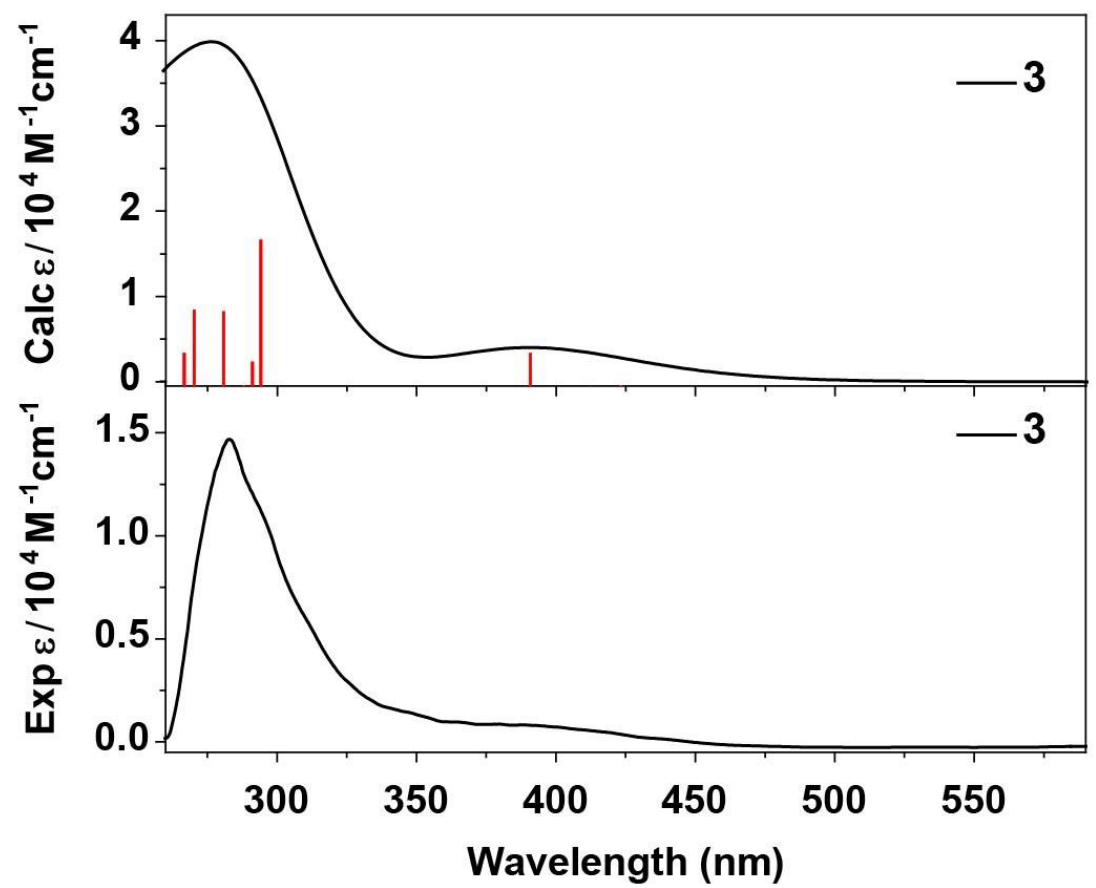

Figure S26. Computed UV/Vis absorbance spectrum at the TD-B3LYP/6-311G(d,p) [LANL08(d) for Bi] level of theory in DMF, and experimental UV-vis spectra in DMF of 3.

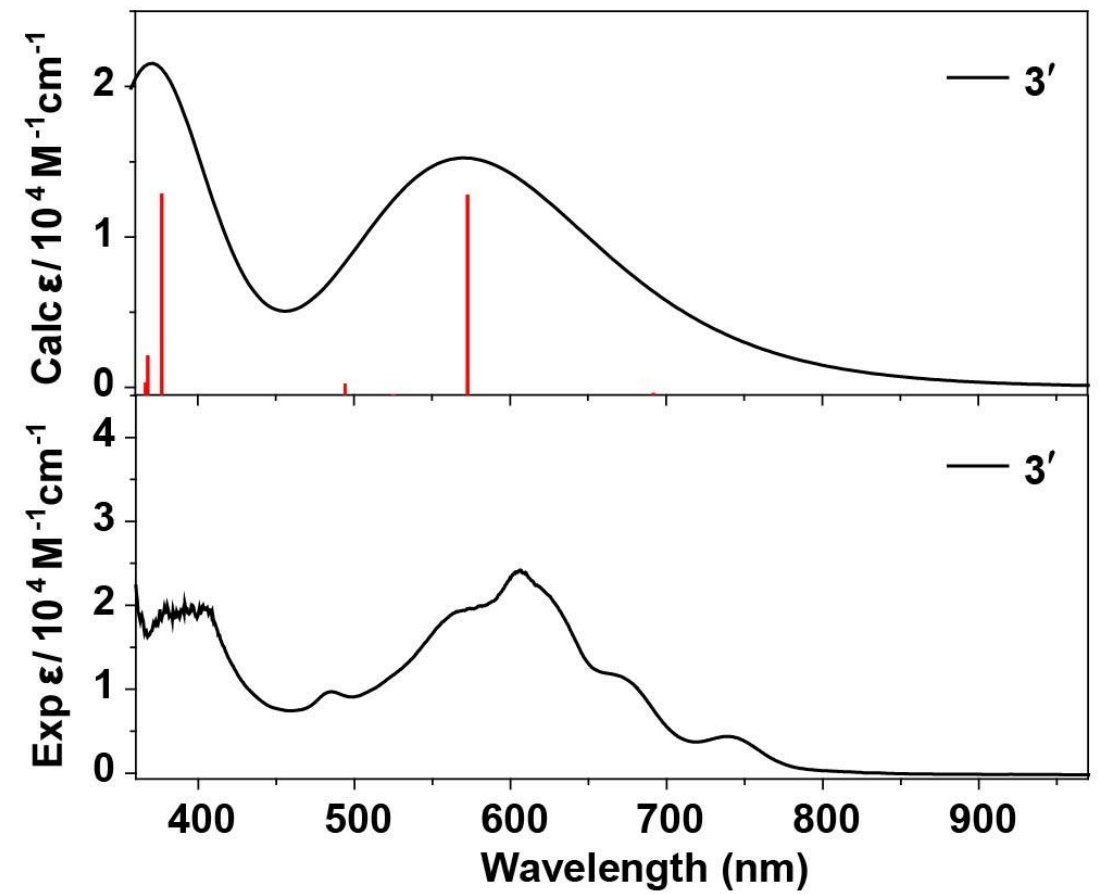

Figure S27. Computed UV/Vis absorbance spectrum at the TD-B3LYP/6-311G(d,p) [LANL08(d) for Bi] level of theory in DMF, and experimental UV-vis spectra in DMF of $\mathbf{3}^{\prime}$. 


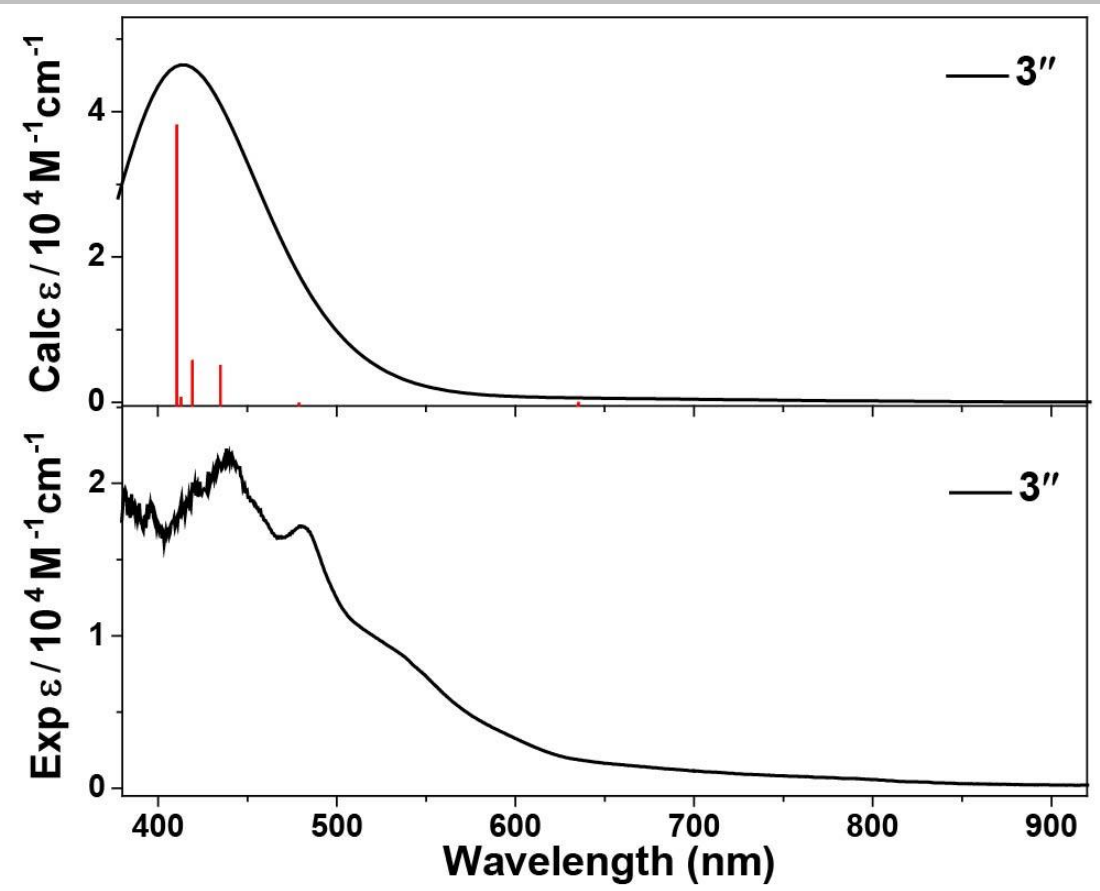

Figure S28. Computed UV/Vis absorbance spectrum at the TD-B3LYP/6-311G(d,p) [LANL08(d) for Bi] level of theory in DMF, and experimental UV-vis spectra in DMF of 3".

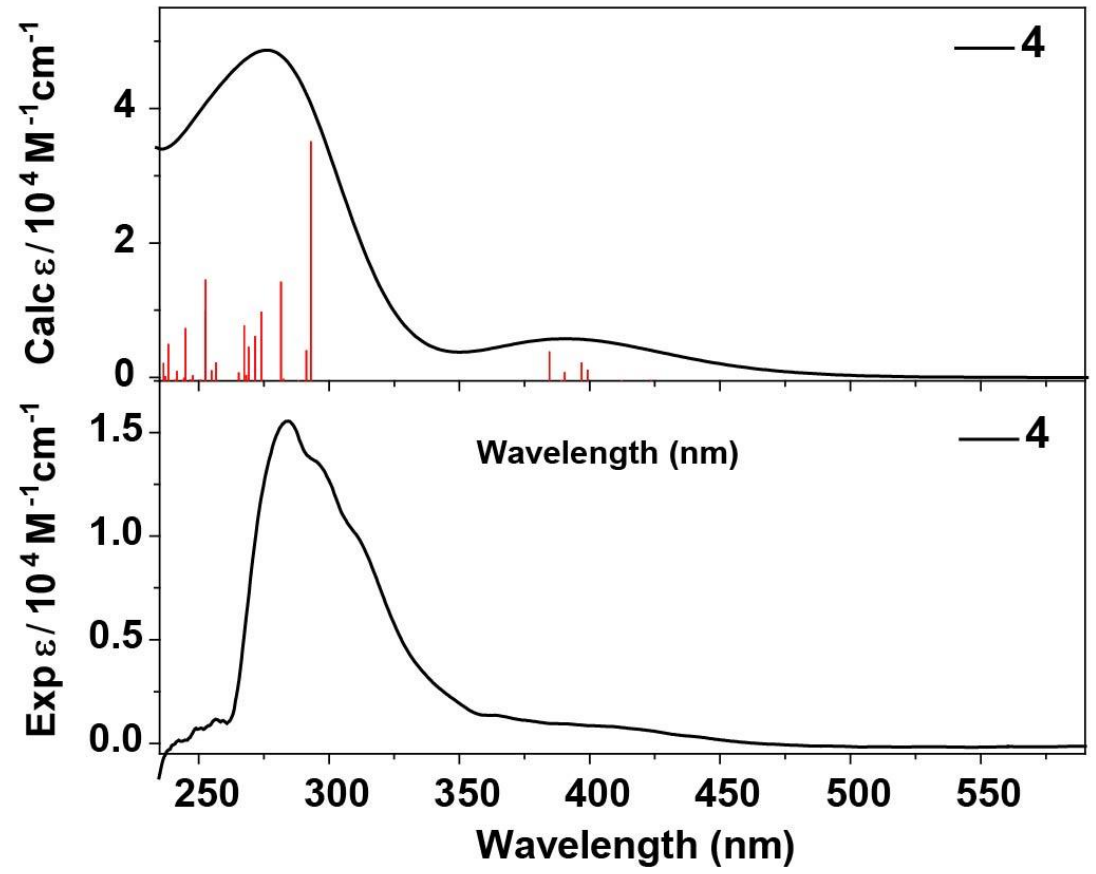

Figure S29. Computed UV/Vis absorbance spectrum at the TD-B3LYP/6-311G(d,p) [LANL08(d) for Bi] level of theory in DMF, and experimental UV-vis spectra in DMF of 4. 


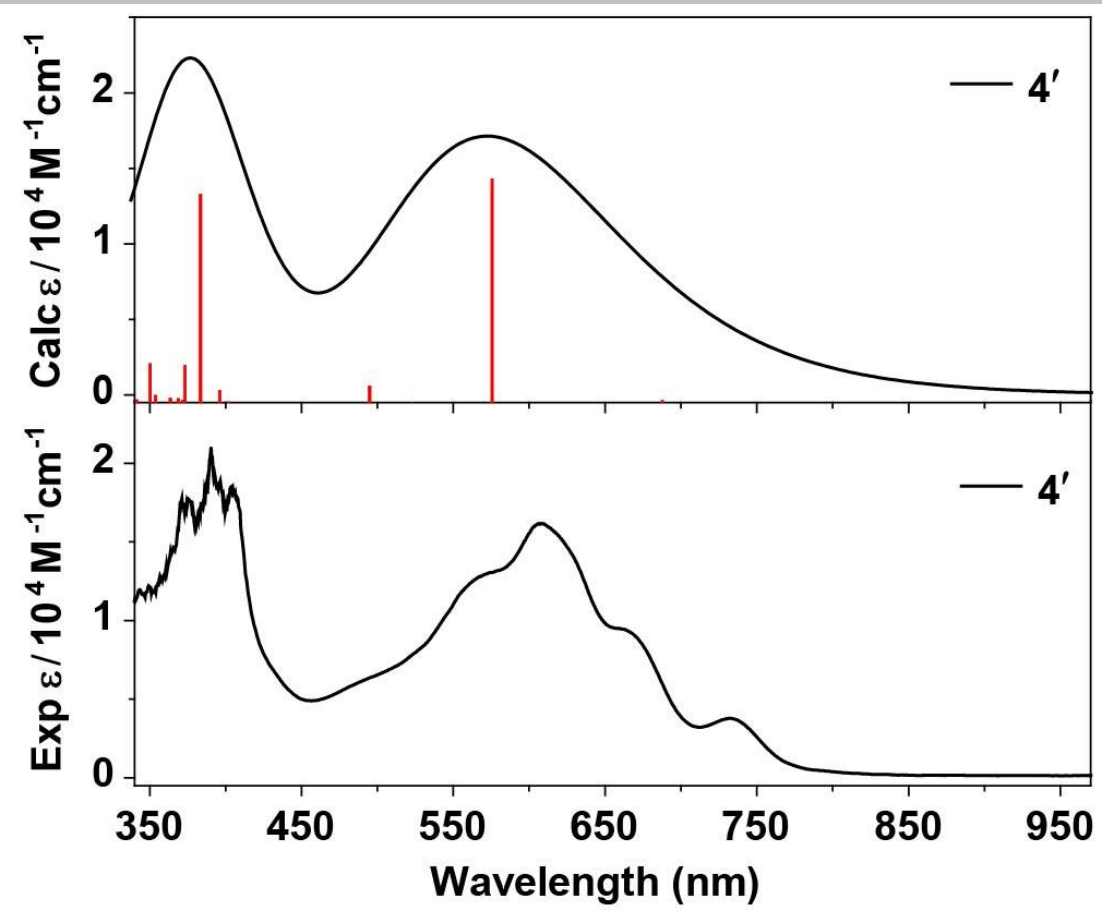

Figure S30. Computed UV/Vis absorbance spectrum at the TD-B3LYP/6-311G(d,p) [LANL08(d) for Bi] level of theory in DMF, and experimental UV-vis spectra in DMF of 4 '.

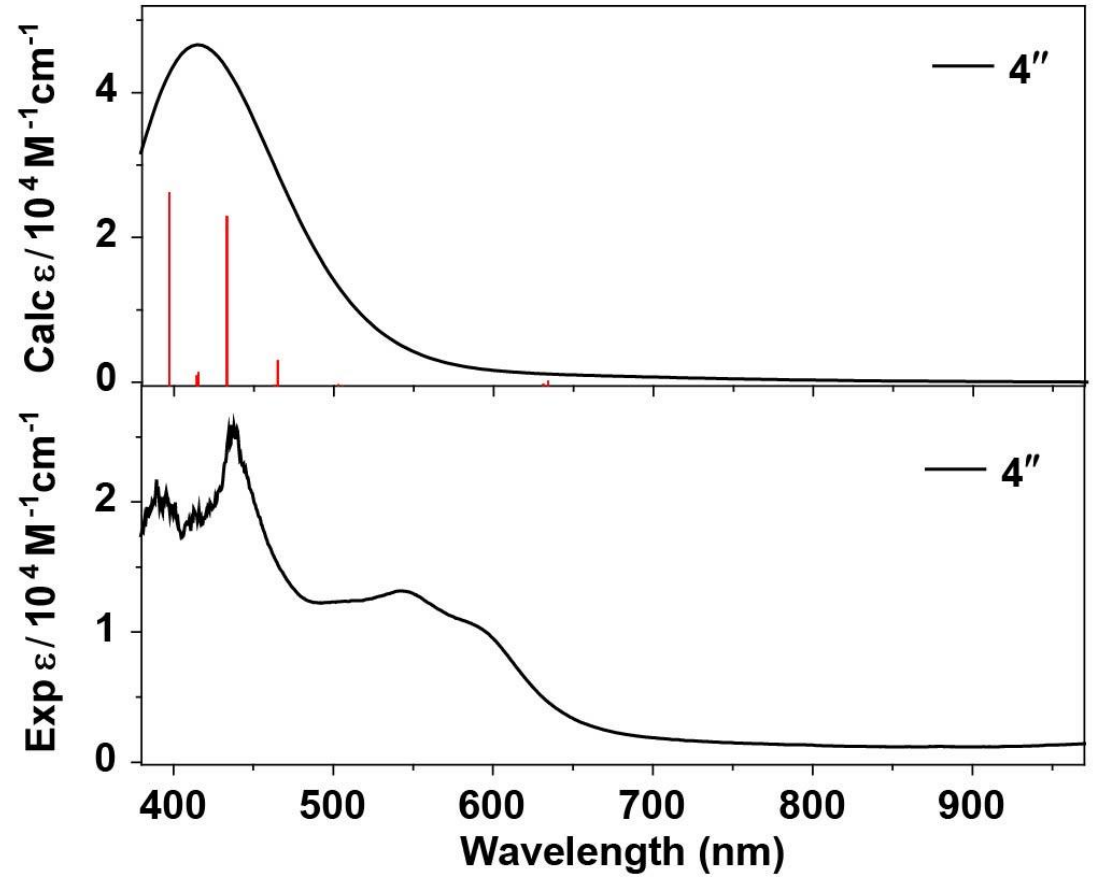

Figure S31. Computed UV/Vis absorbance spectrum at the TD-B3LYP/6-311G(d,p) [LANL08(d) for Bi] level of theory in DMF, and experimental UV-vis spectra in DMF of 4". 


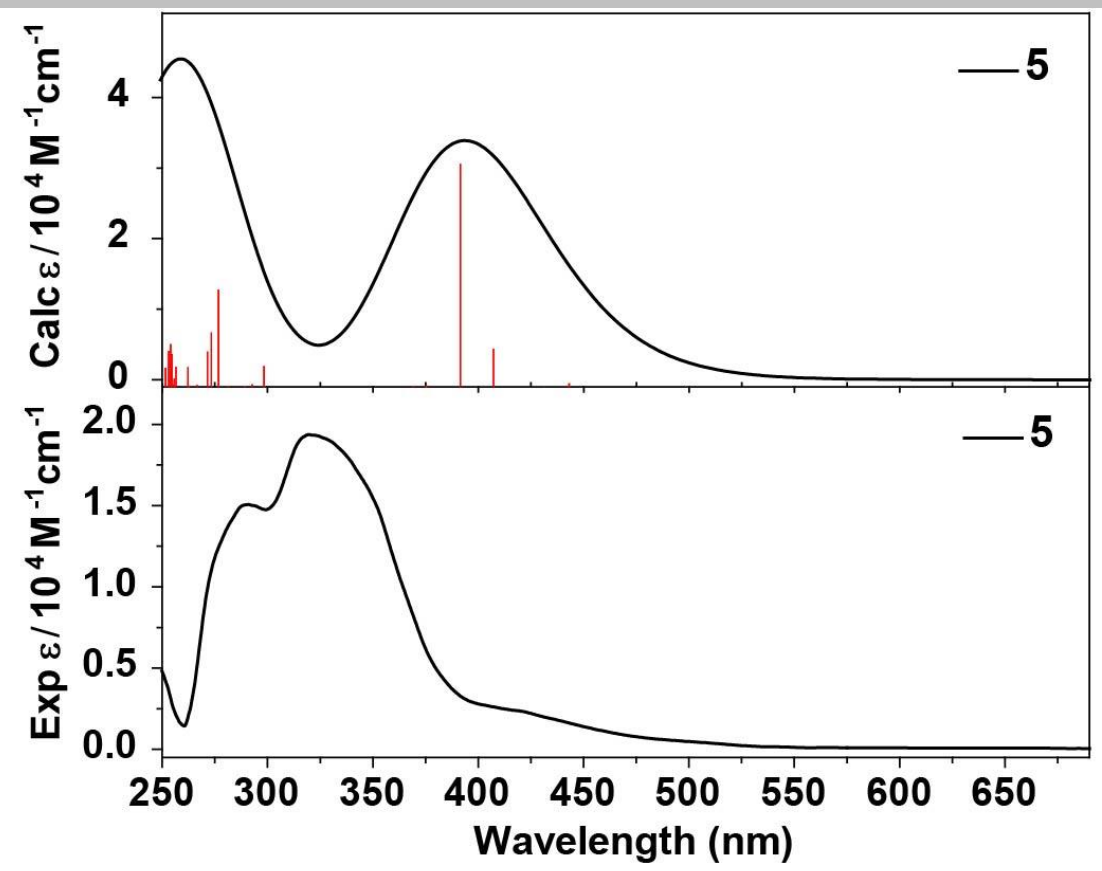

Figure S32. Computed UV/Vis absorbance spectrum at the TD-B3LYP/6-311G(d,p) [LANL08(d) for Bi] level of theory in DMF, and experimental UV-vis spectra in DMF of 5.

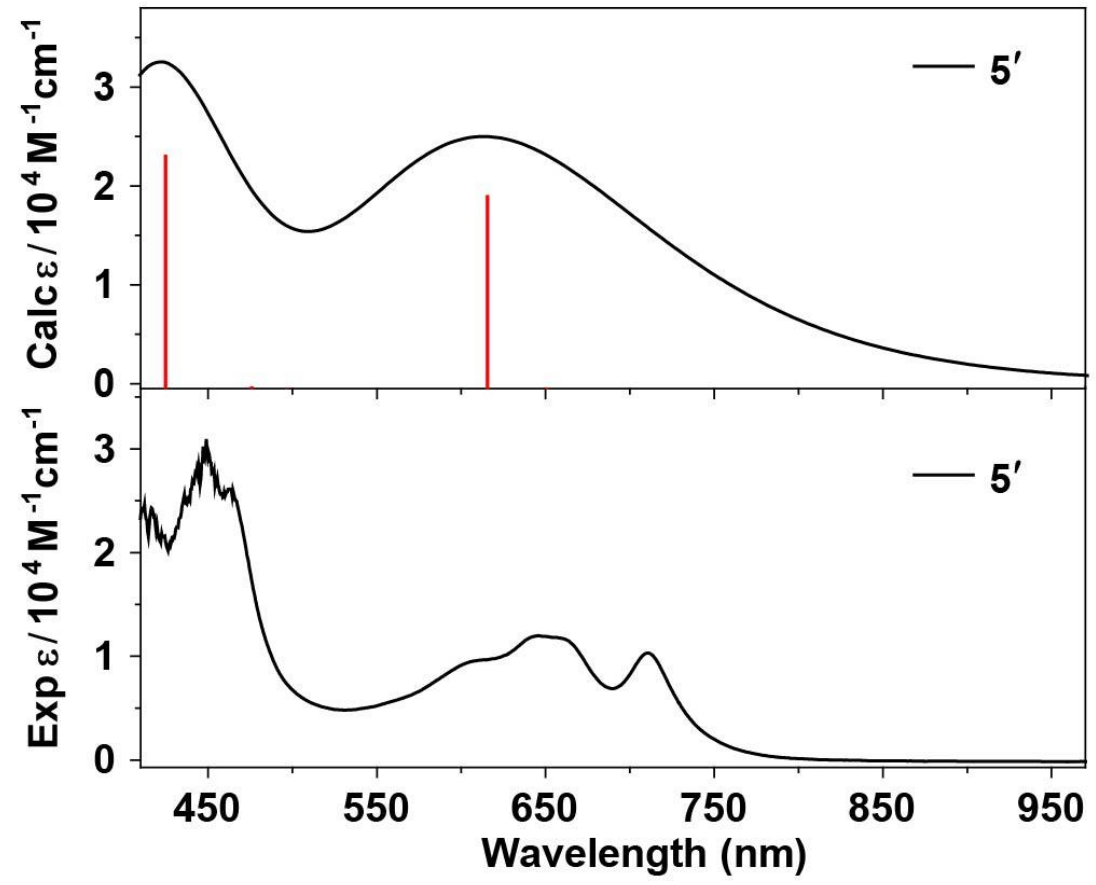

Figure S33. Computed UV/Vis absorbance spectrum at the TD-B3LYP/6-311G(d,p) [LANL08(d) for Bi] level of theory in DMF, and experimental UV-vis spectra in DMF of $5^{\prime}$. 


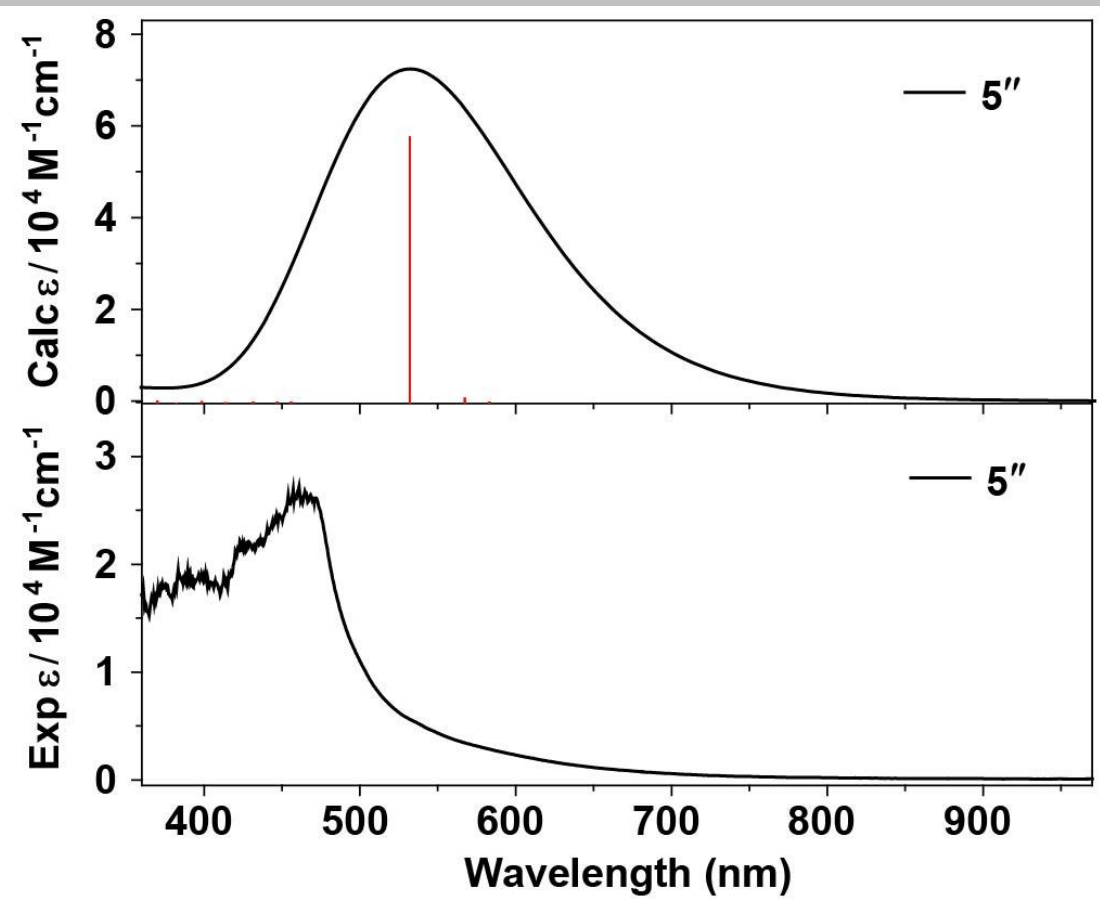

Figure S34. Computed UV/Vis absorbance spectrum at the TD-B3LYP/6-311G(d,p) [LANL08(d) for Bi] level of theory in DMF, and experimental UV-vis spectra in DMF of 5".

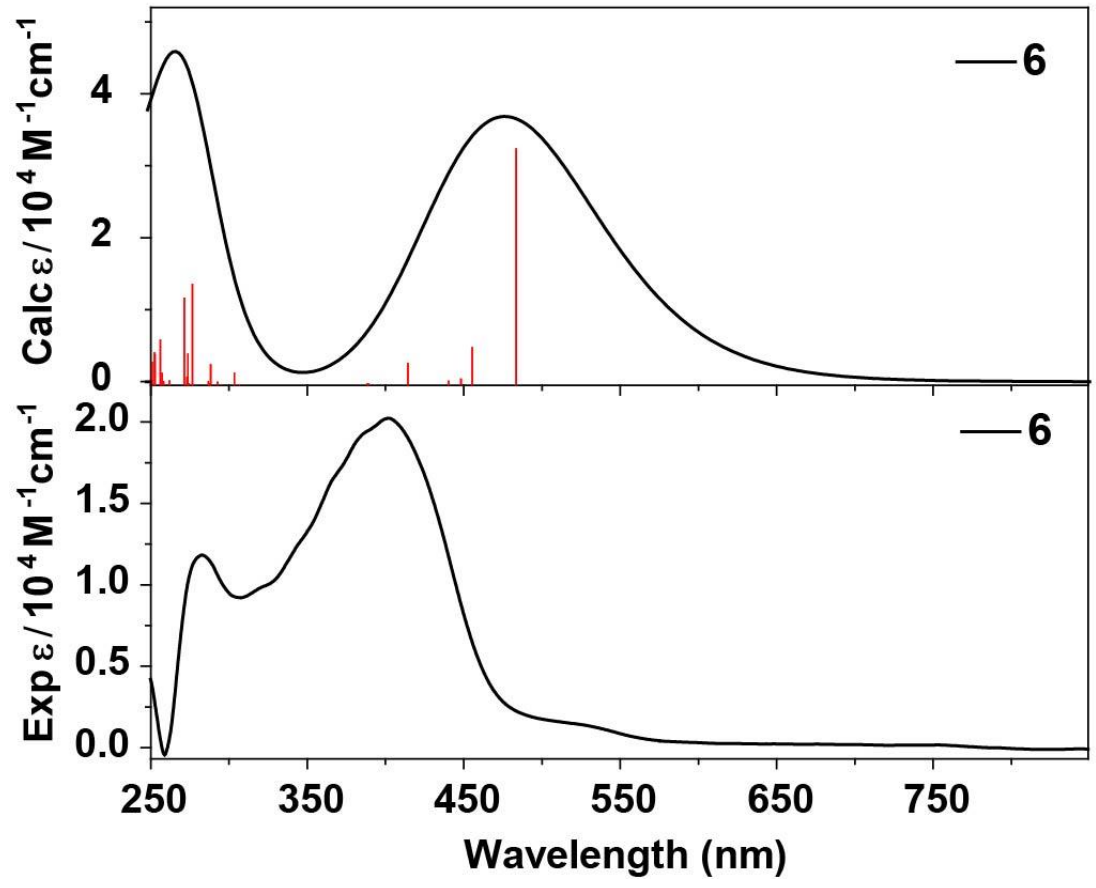

Figure S35. Computed UV/Vis absorbance spectrum at the TD-B3LYP/6-311G(d,p) [LANL08(d) for Bi] level of theory in DMF, and experimental UV-vis spectra in DMF of 6 . 


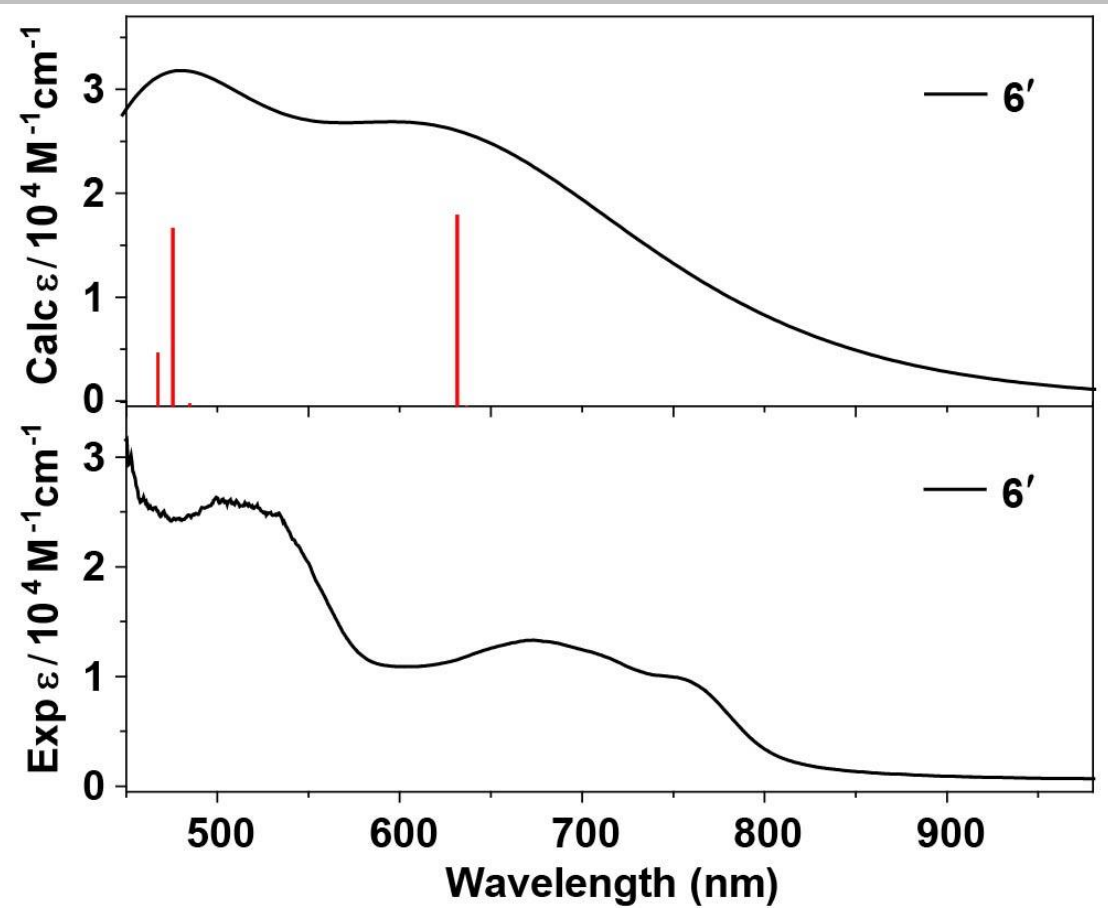

Figure S36. Computed UV/Vis absorbance spectrum at the TD-B3LYP/6-311G(d,p) [LANL08(d) for Bi] level of theory in DMF, and experimental UV-vis spectra in DMF of $6^{\prime}$.

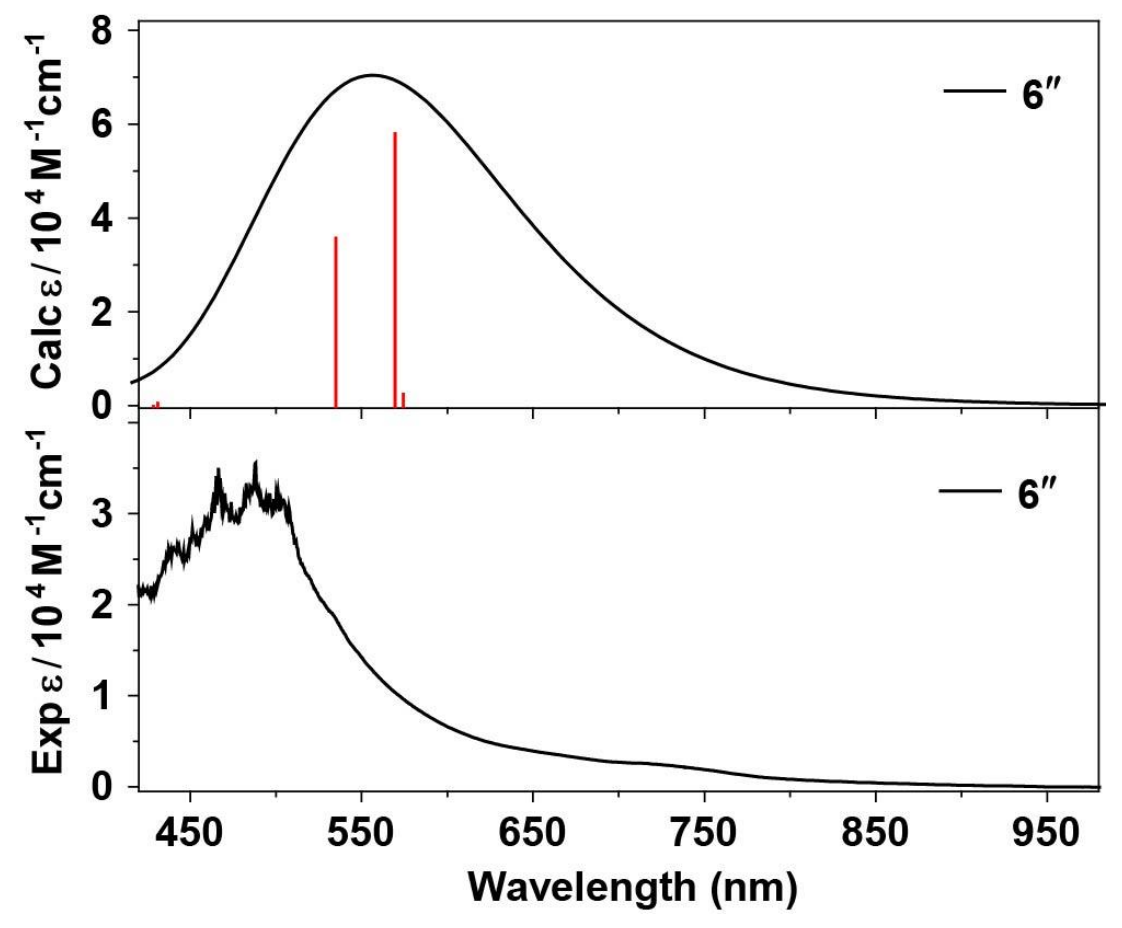

Figure S37. Computed UV/Vis absorbance spectrum at the TD-B3LYP/6-311G(d,p) [LANL08(d) for Bi] level of theory in DMF, and experimental UV-vis spectra in DMF of 6". 
18. DFT Calculations

\section{3} LUMO + 1 - $2.22 \mathrm{eV}$

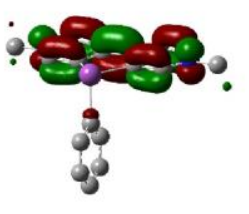

HOMO
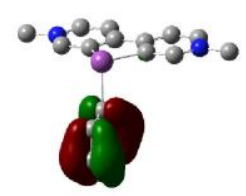

- 88 ร8.

HOMO - 1

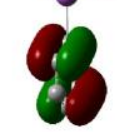

$-7.20 \mathrm{eV}$

HOMO - 2 \%

$-7.58 \mathrm{eV}$

HOMO - 3 8.398

$3^{\prime \prime}$

LUMO + 1

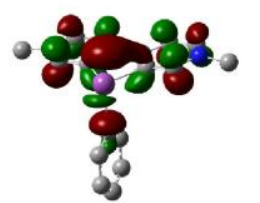

$-0.47 \mathrm{eV}$

LUMO

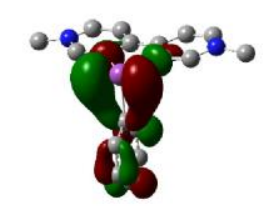

$-0.64 \mathrm{eV}$

HOMO

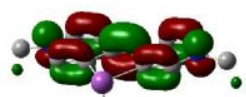

$-3.25 \mathrm{eV}$

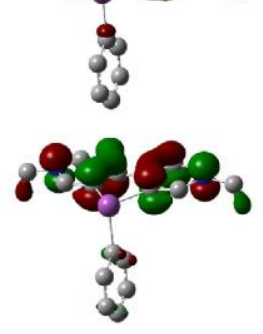

$-6.23 \mathrm{eV}$

HOMO - 1

$-3.70 \mathrm{eV}$

$-7.15 \mathrm{eV}$
LUMO

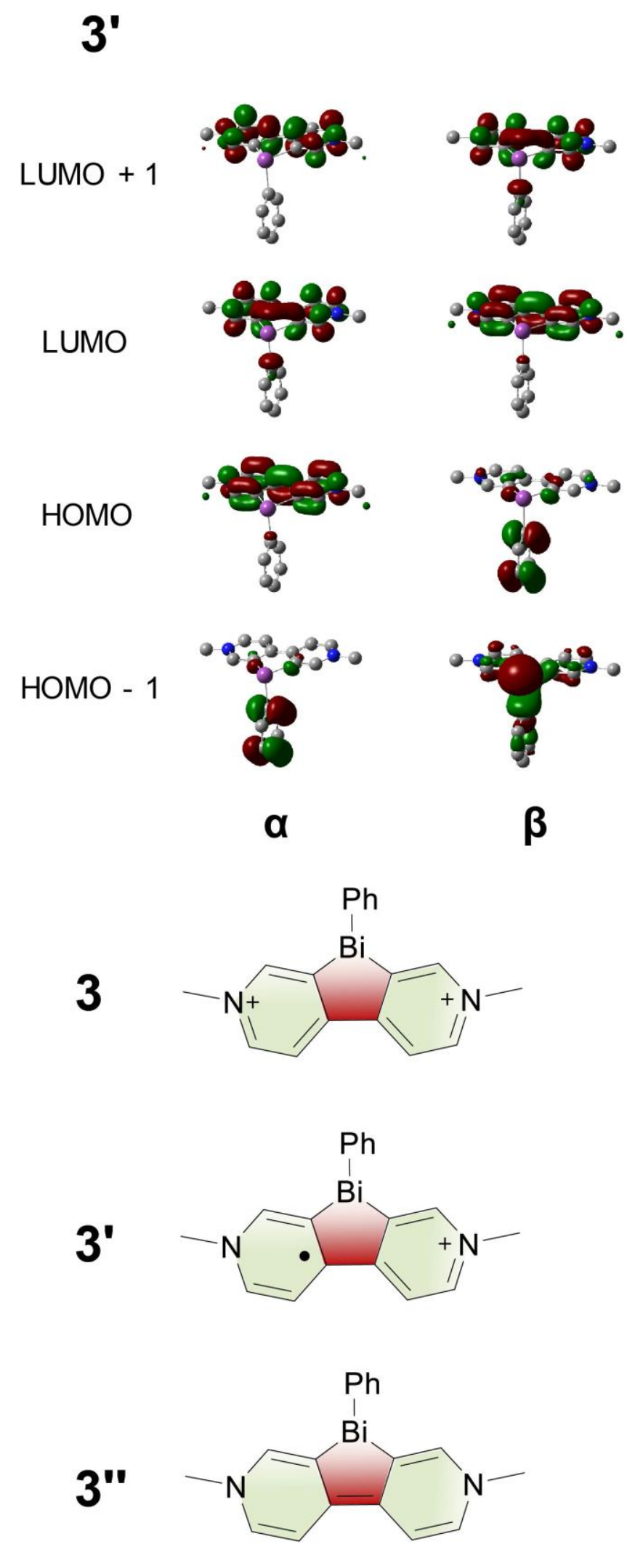

3'

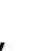




\section{4}

LUMO + 1

LUMO

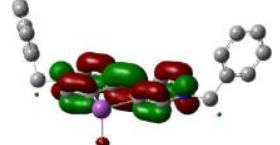

\%

HOMO

g.

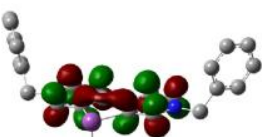

$\%$

$-2.21 \mathrm{eV}$

$-3.70 \mathrm{eV}$

$-7.15 \mathrm{eV}$

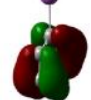

HOMO - 1

g

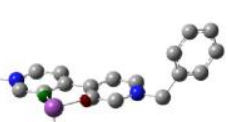

$-7.19 \mathrm{eV}$

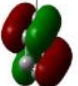

HOMO - 2

HOMO - 3

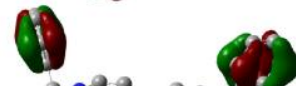

$-7.26 \mathrm{eV}$

$\nexists^{3}$

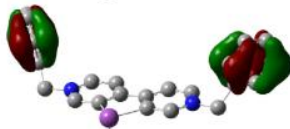

के

$4 "$

LUMO + 1

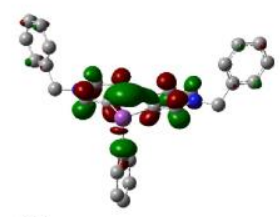

$-0.51 \mathrm{eV}$

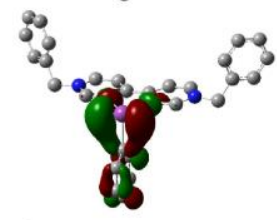

$-0.67 \mathrm{eV}$

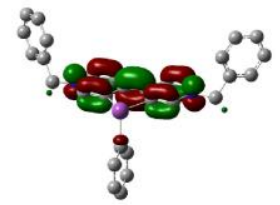

HOMO - 1
How0

$-3.28 \mathrm{eV}$

$-6.21 \mathrm{eV}$

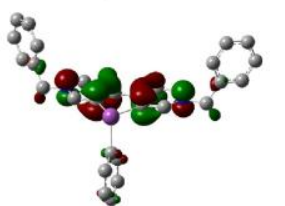

4'

LUMO + 1
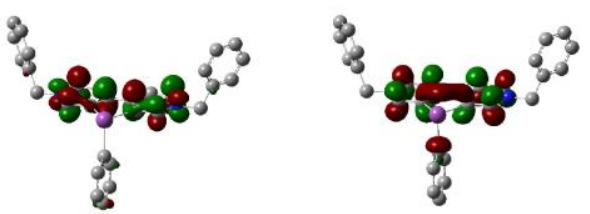

LUMO
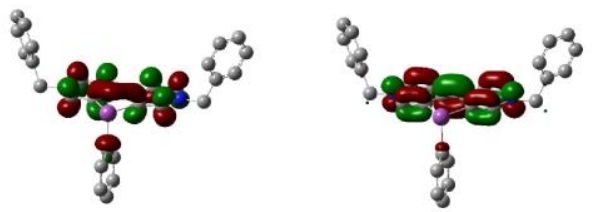

HOMO
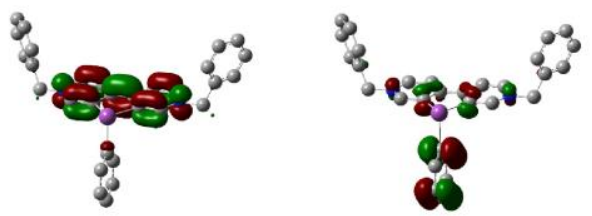

HOMO - 1
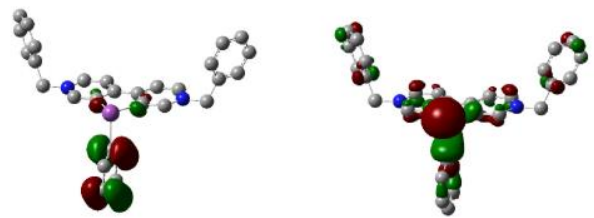

$\alpha$

$\beta$
4
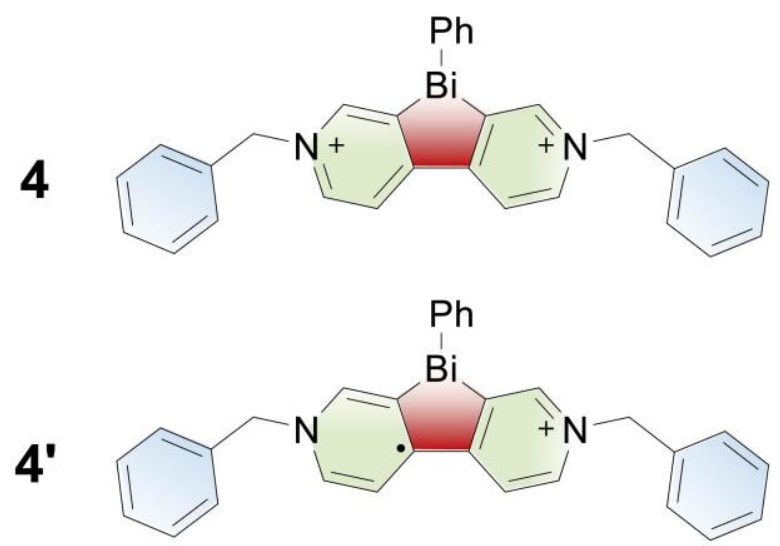

4"

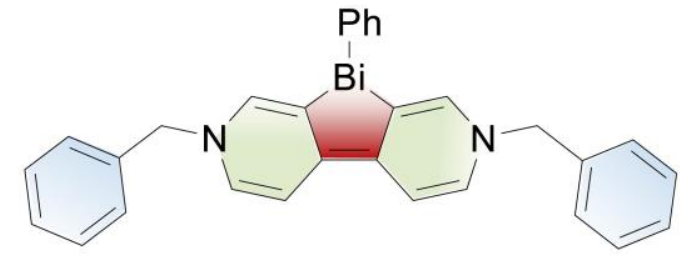


5

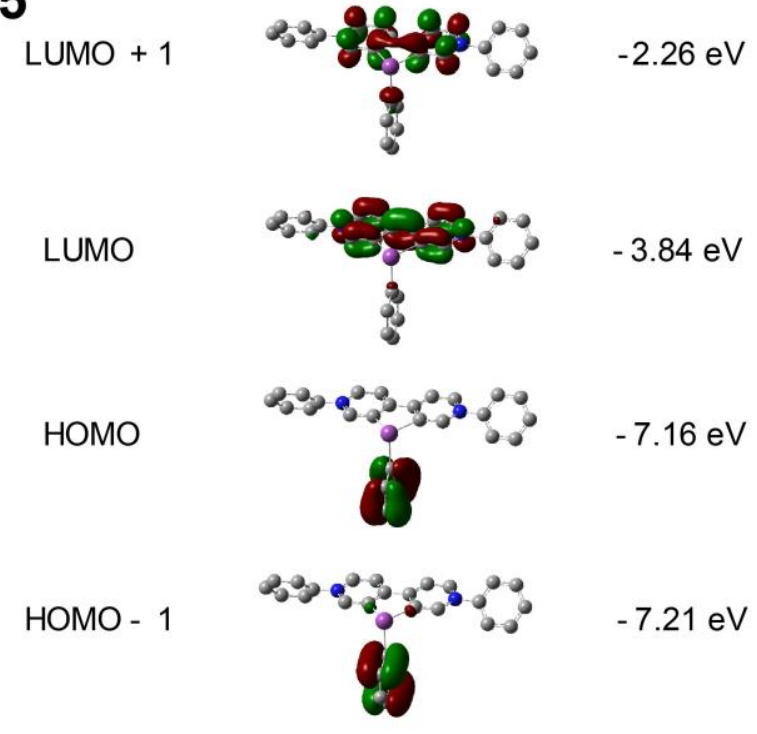

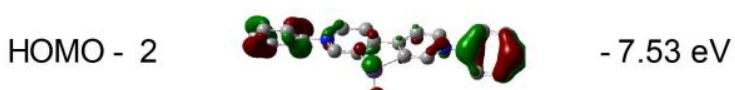
8

HOMO - $3 \quad 288^{\circ} 280-7.60 \mathrm{eV}$

5"

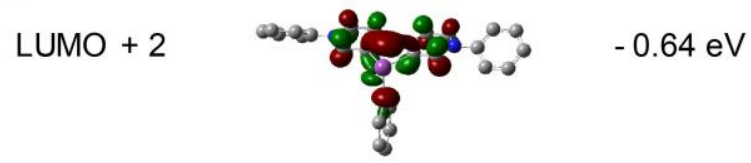

$\mathrm{LUMO}+1 \quad-0.74 \mathrm{eV}$

LUMO

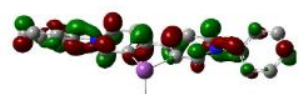

$-0.80 \mathrm{eV}$ :

HOMO

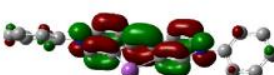

:

HOMO - 1

$-3.55 \mathrm{eV}$
5'

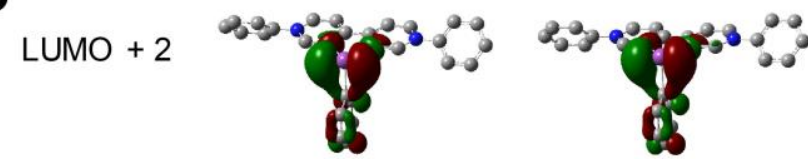

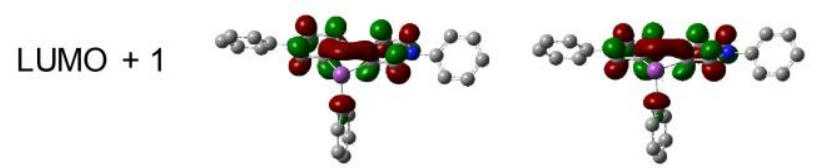

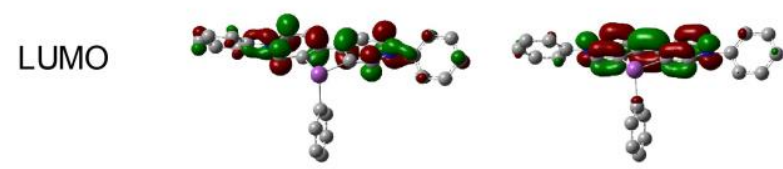

HOMO

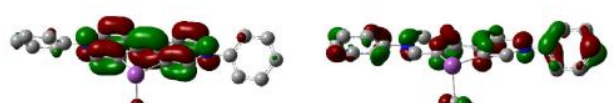

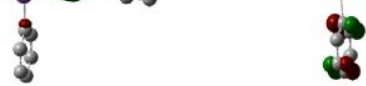

HOMO - 1 ค8.

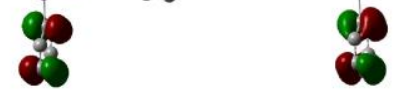

a

$\beta$

5

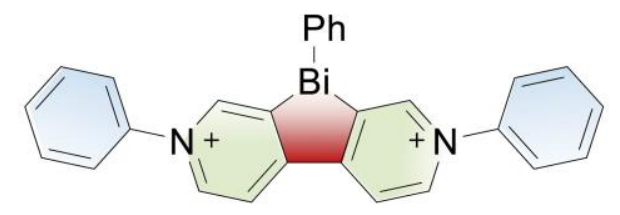

51

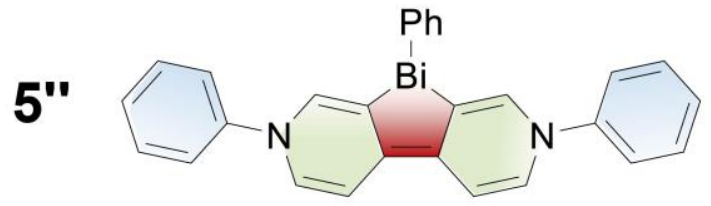




\section{6}

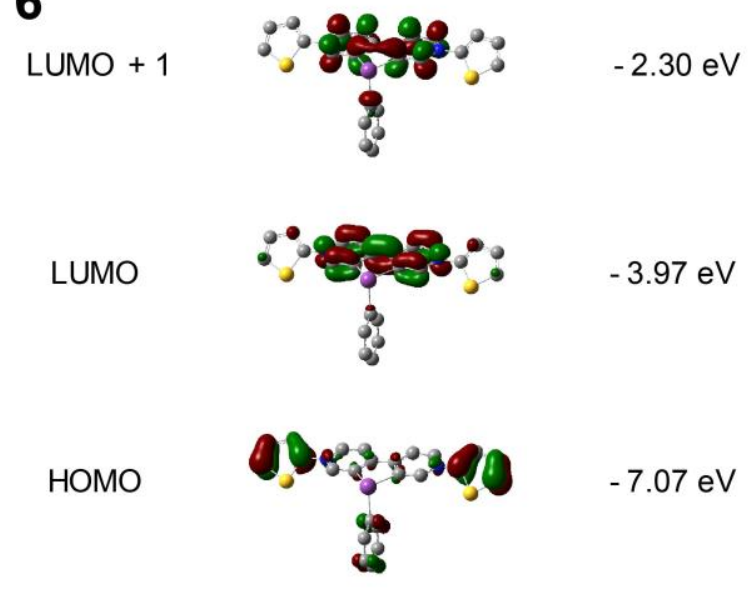

HOMO - 1

HOMO - 2 :

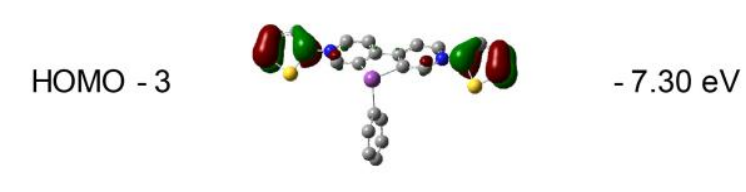

6"

LUMO + 1

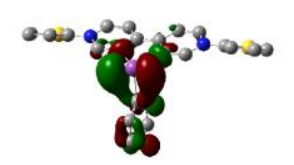

$-0.78 \mathrm{eV}$

LUMO

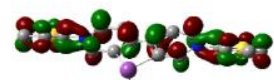

$-1.04 \mathrm{eV}$

$$
\infty
$$

HOMO

HOMO - 1
6'

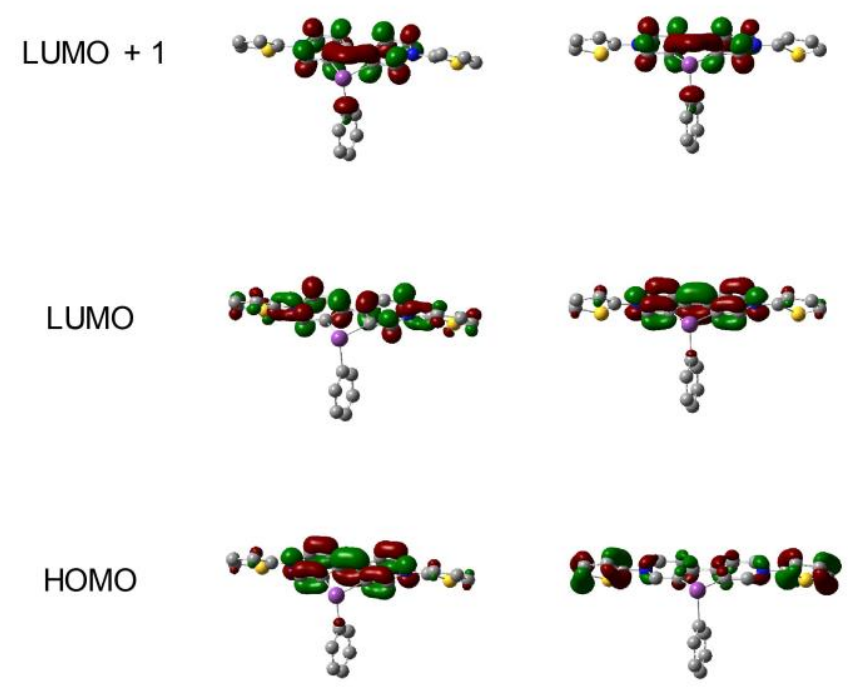

HOMO - 1

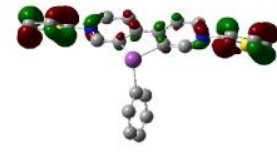

$\alpha$
$88 \%$ ำร 398 $\beta$<smiles>[B]1c2c[n+](-c3cccs3)ccc2-c2cc[n+](-c3cccs3)cc21</smiles><smiles></smiles><smiles>[O+]c1ccc(N2C=Cc3[b-](-c4ccccc4)c4cn(-c5cccs5)ccc-4c3C=C2)s1</smiles>

Figure S38. The calculated orbitals of 3, 3', 3", 4, 4', 4", 5, 5', 5", 6, 6', 6". 
19. Calculated spin density plots for the radical species

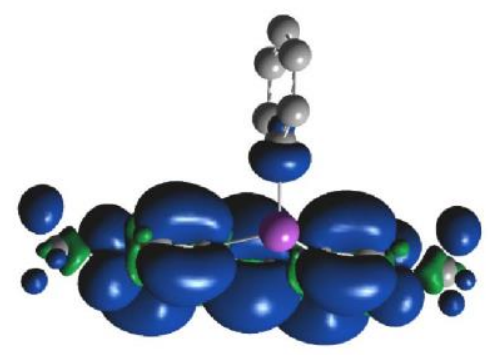

3'
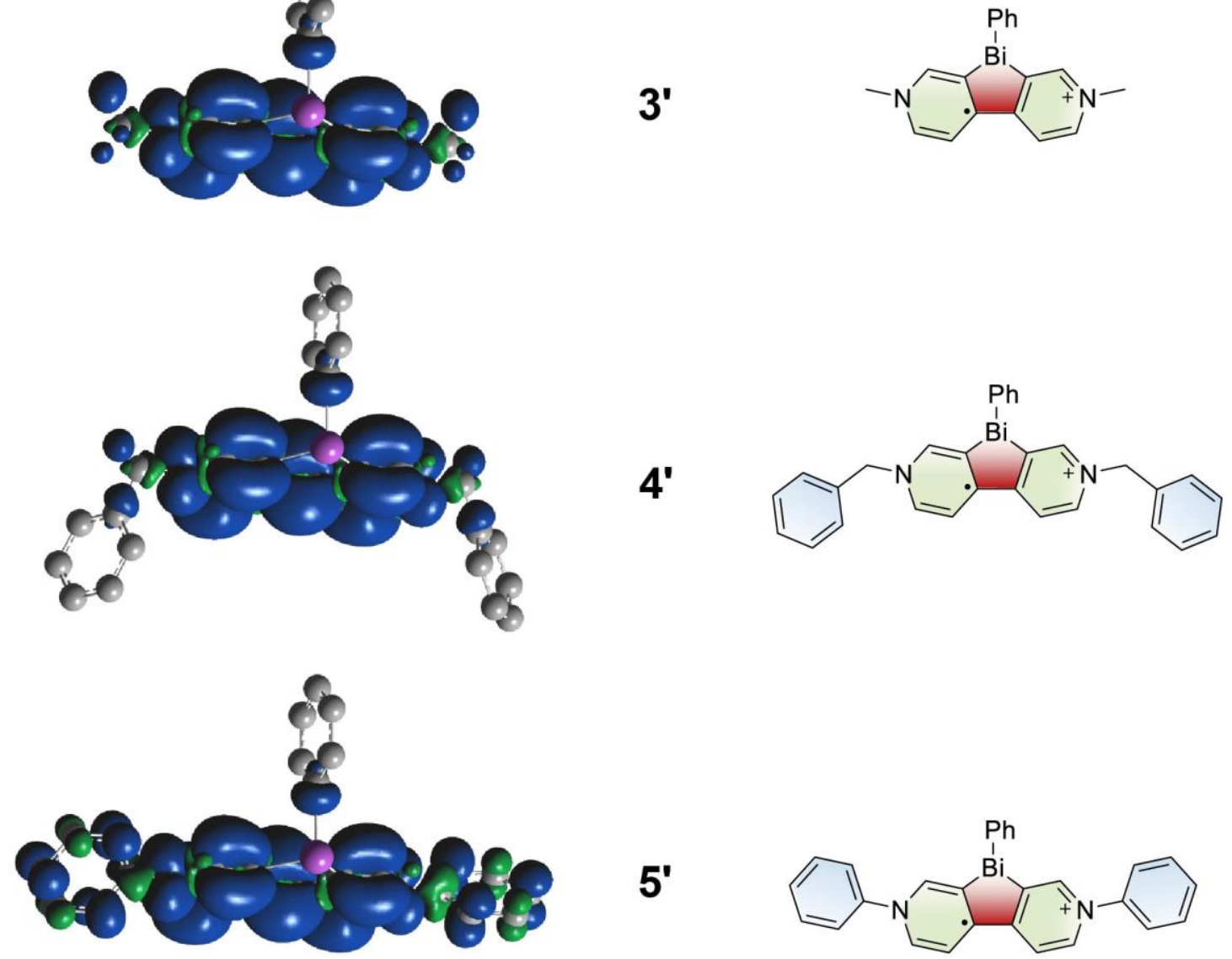

$\mathbf{5}^{\prime}$
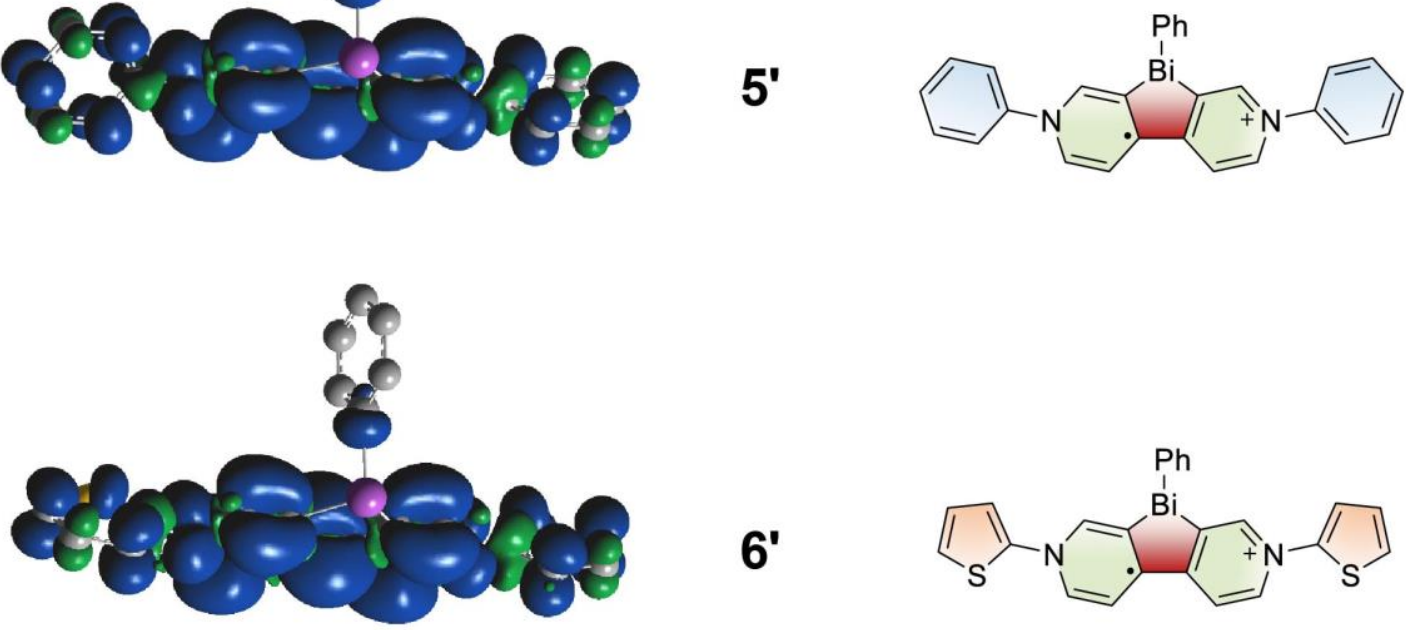

6'

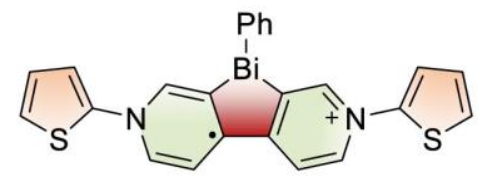

Figure S39. The calculated spin density plots for the radical species. 
20. Mulliken charge distribution.

Color Range: $\quad-0.922$ to 0.922

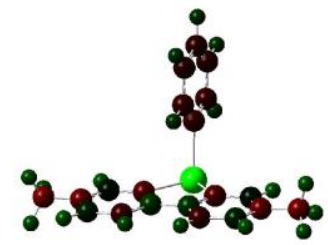

3 (Bi: 0.922, N: -0.317)
Color Range: $\quad-0.785$ to 0.785

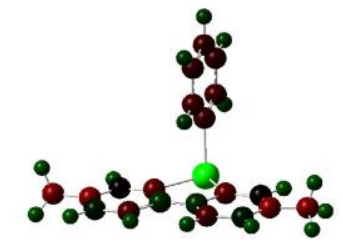

3' (Bi: $0.785, \mathrm{~N}:-0.345)$
-0.785 to 0.785

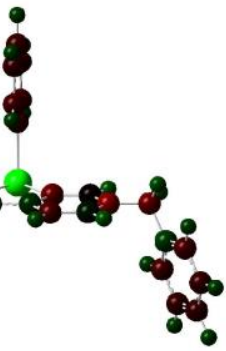

4' (Bi: 0.785, N: -0.342)

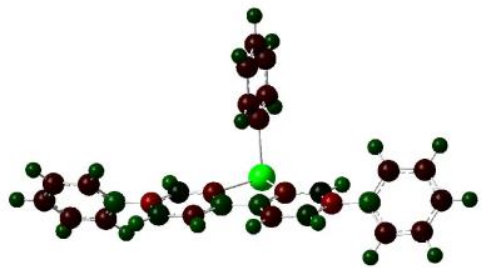

5 (Bi: $0.925, \mathrm{~N}:-0.389$ )

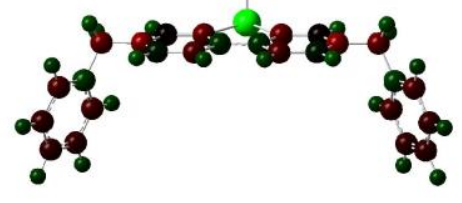

lor Range: $\quad-0.801$ to 0.801

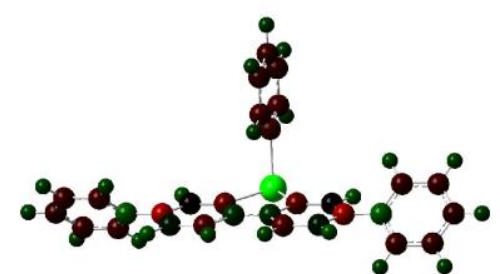

5' (Bi: 0.801, N: -0.428)

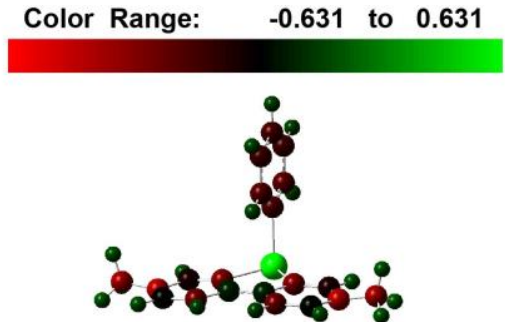

3" (Bi: 0.631, N: -0.378)

-0.632 to 0.632

Color Range:$$
3
$$

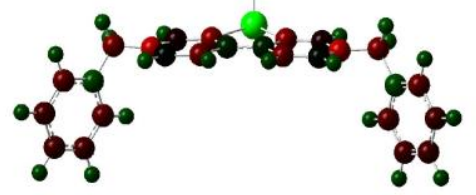

4" (Bi: 0.632, N: -0.381)

Color Range: $\quad-\mathbf{0 . 6 7 5}$ to $\mathbf{0 . 6 7 5}$

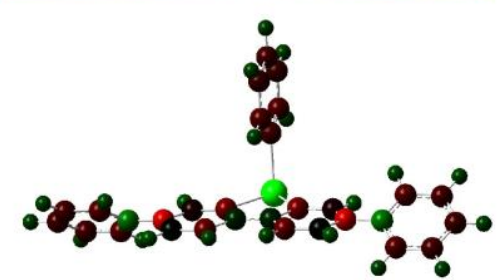

5" (Bi: 0.675, N: -0.472)

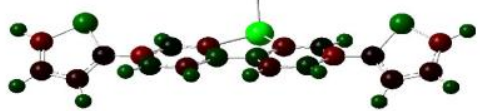

8

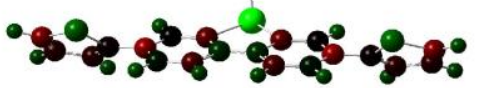

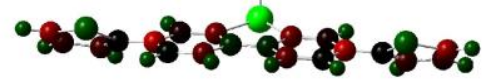

6 (Bi: 0.932, S: 0.335, N:-0.364) 6' (Bi: 0.813, S: 0.282, N: -0.395) 6" (Bi: 0.695, S: 0.219, N: -0.425)

Figure S40. The calculated Mulliken charge distribution for the bismoviologen and their radicals. 
21. Natural bond orbital (NBO) charge distribution.

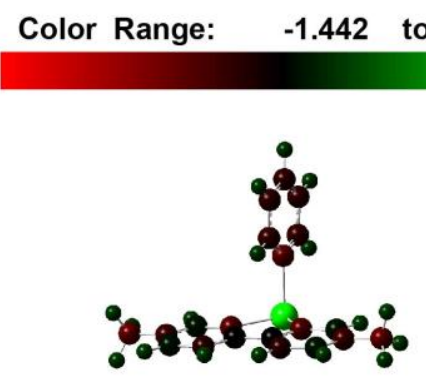

3 (Bi: 1.442, N: -0.286)
Color Range:

-1.336 to 1.336

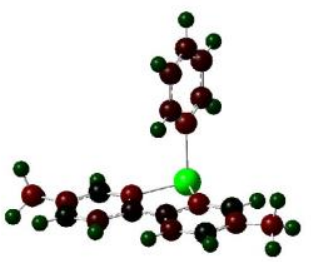

3' (Bi: 1.336, N: -0.345)
Color Range: $\quad-1.222$ to 1.222

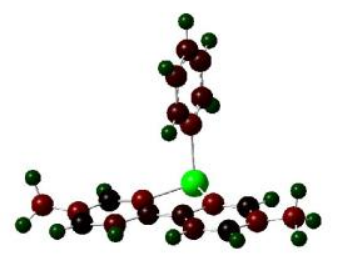

3" (Bi: 1.222, N: -0.424)

Color Range: -1.439 to 1.439
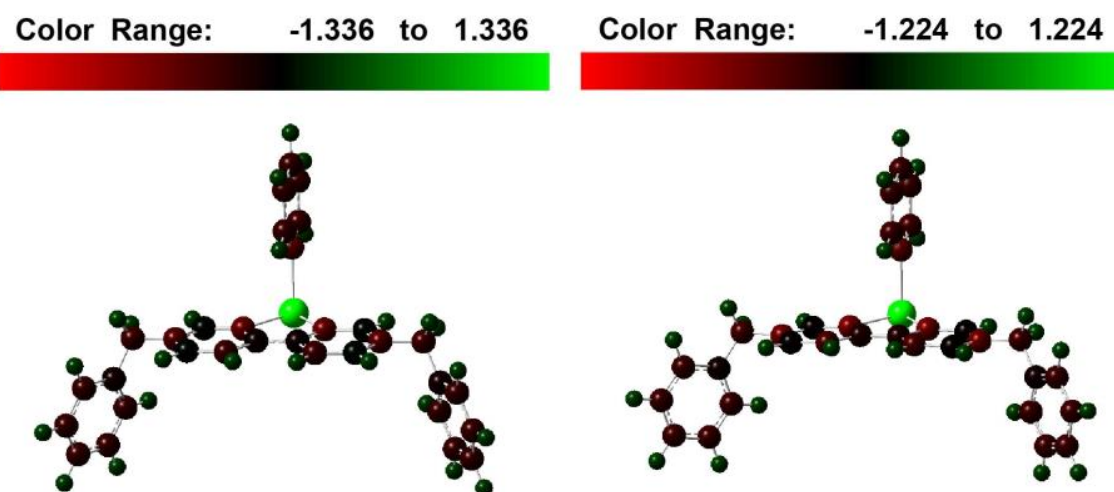

4 (Bi: 1.439, N: -0.287)

Color Range: -1.445 to 1.445

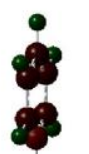

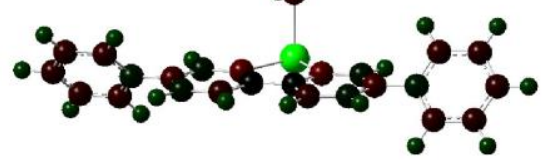

5 (Bi: 1.445, N: -0.288)
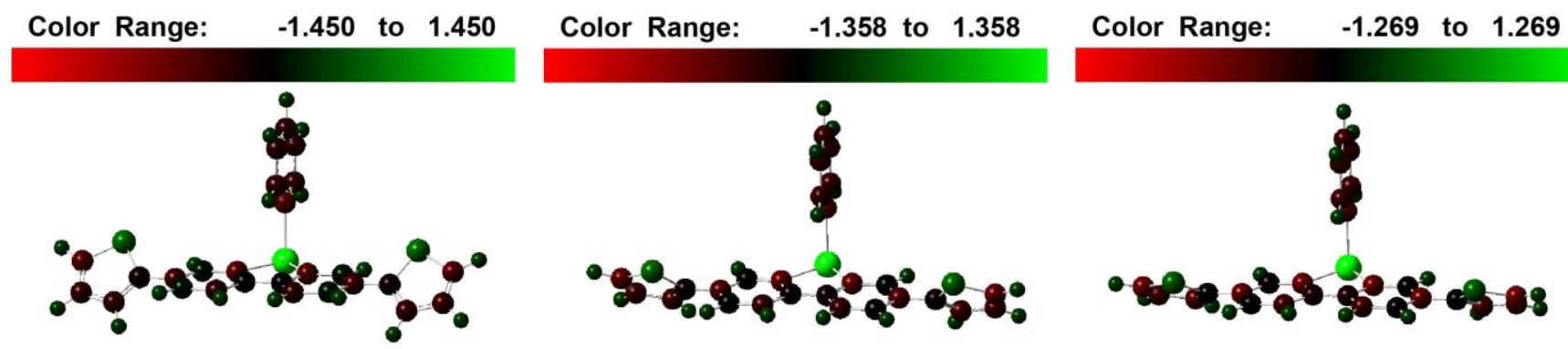

6 (Bi: 1.450, S: 0.506, N: -0.300) 6' (Bi: 1.358, S: 0.463, N: -0.357) 6" (Bi: 1.269, S: 0.402, N: -0.411)

Figure S41. The natural bond orbital (NBO) charge distribution of bismoviologen and their radicals. 
22. ${ }^{1} \mathrm{H},{ }^{13} \mathrm{C},{ }^{19} \mathrm{~F}$ NMR spectra

${ }^{1} \mathrm{H}$ NMR (400 MHz, DMSO-d6) spectrum of 2.

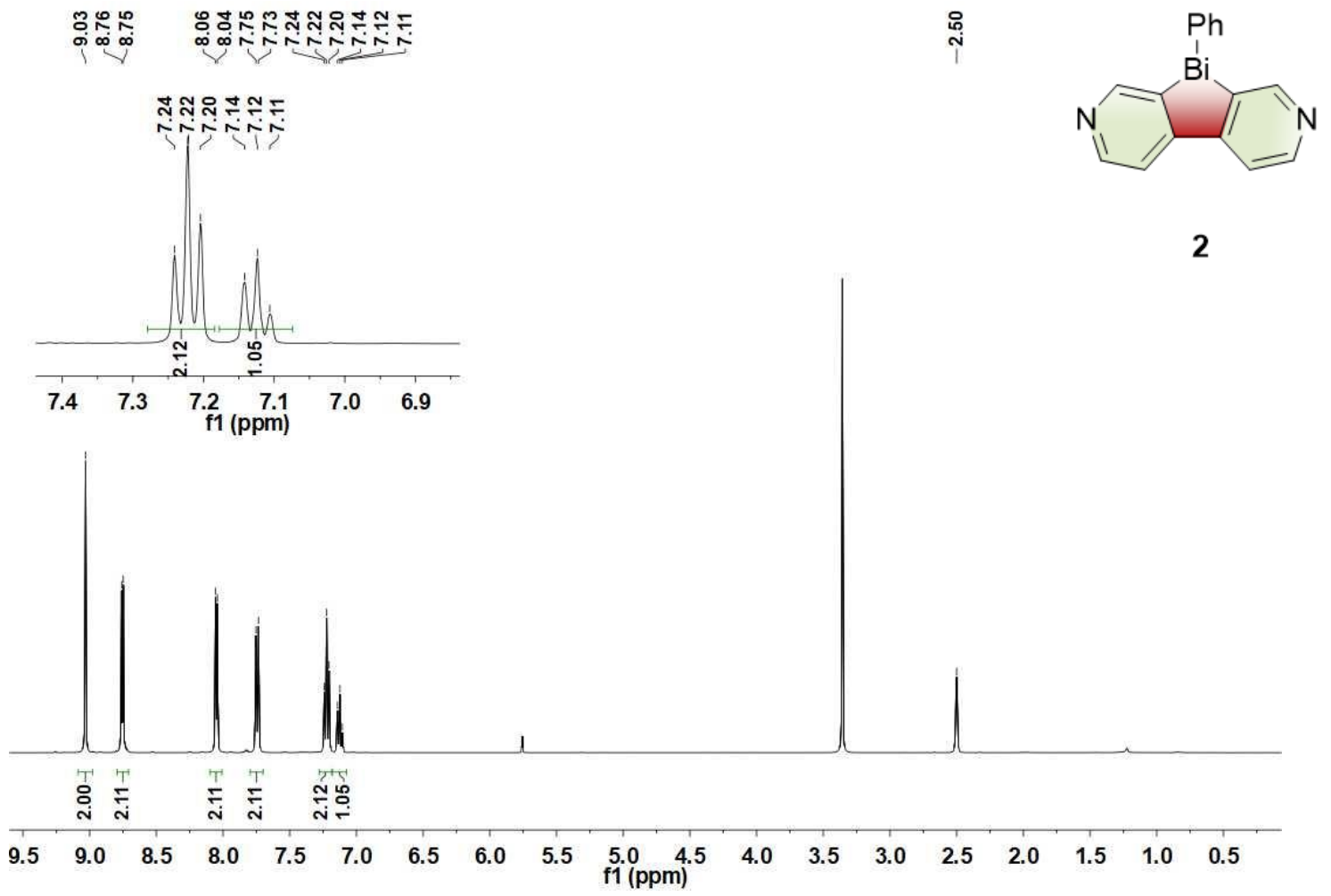

${ }^{13} \mathrm{C}$ NMR (100 MHz, DMSO-d6) spectrum of 2.

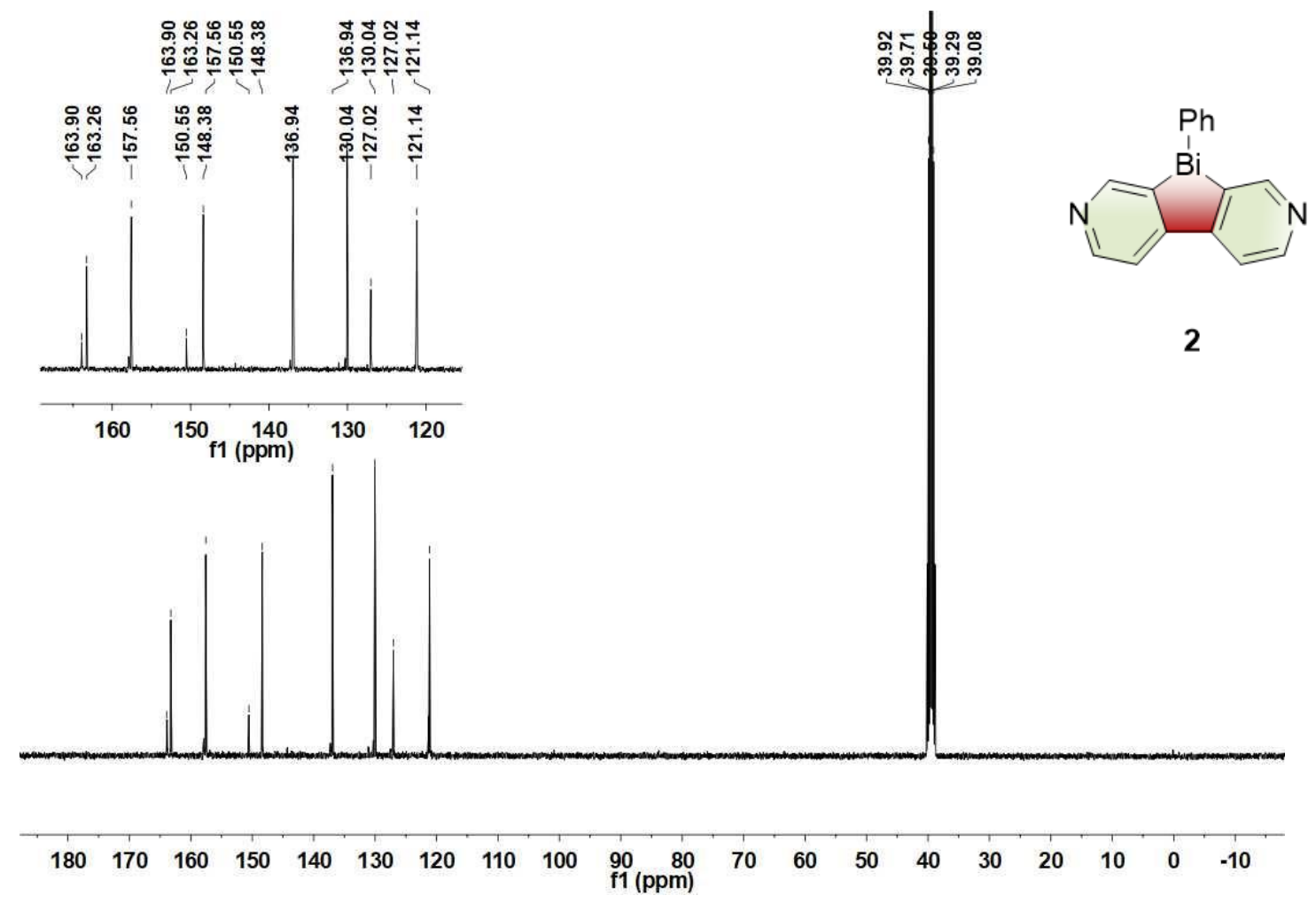


${ }^{1} \mathrm{H}$ NMR $(400 \mathrm{MHz}$, DMSO-d6) spectrum of 3.

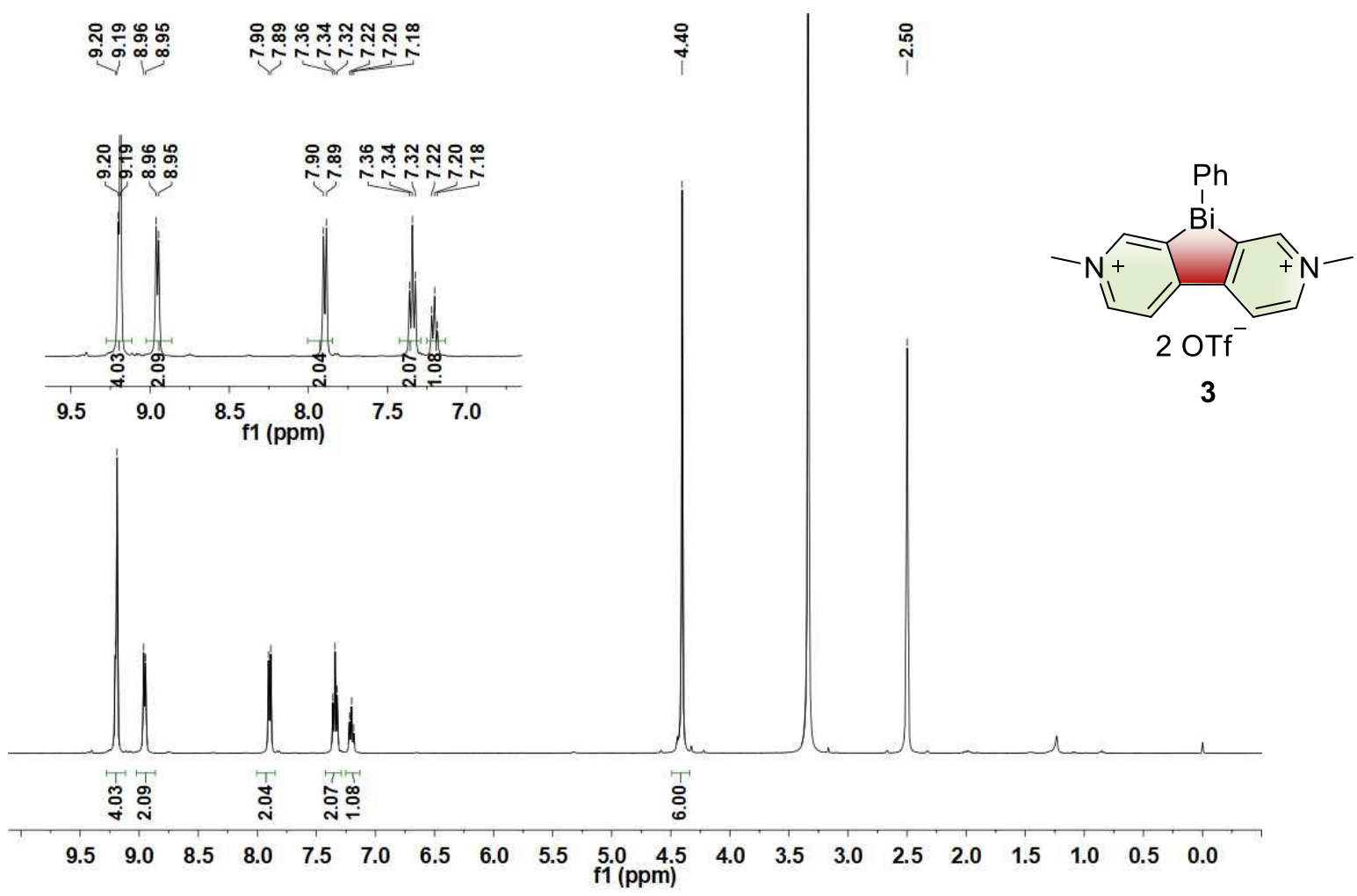

${ }^{13} \mathrm{C}$ NMR (100 MHz, DMSO-d6) spectrum of 3.

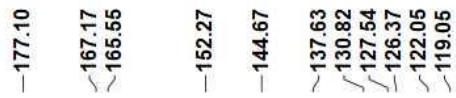

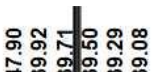

नें क्लां

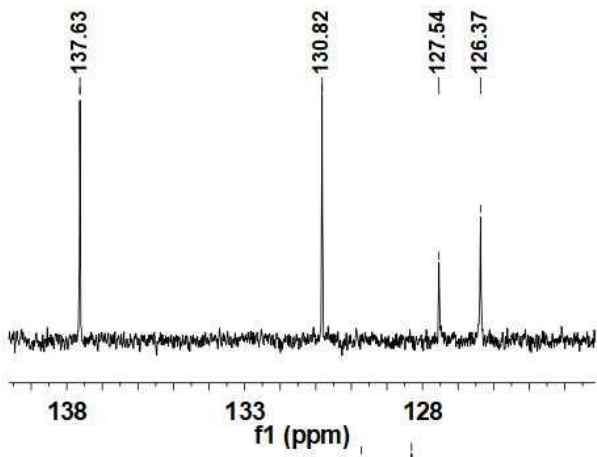

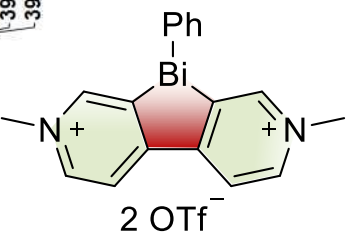

3

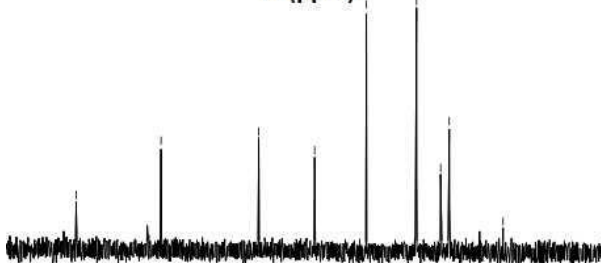

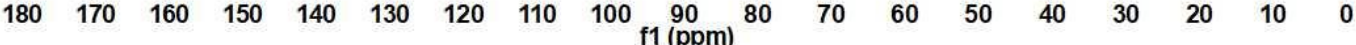


${ }^{19} \mathrm{~F}$ NMR (376 MHz, DMSO-d6) spectrum of 3.

$\stackrel{\mathbb{N}}{i}$

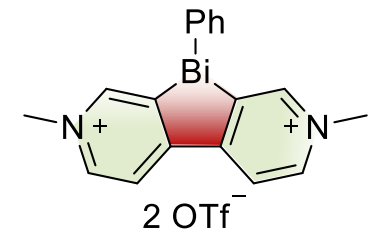

3

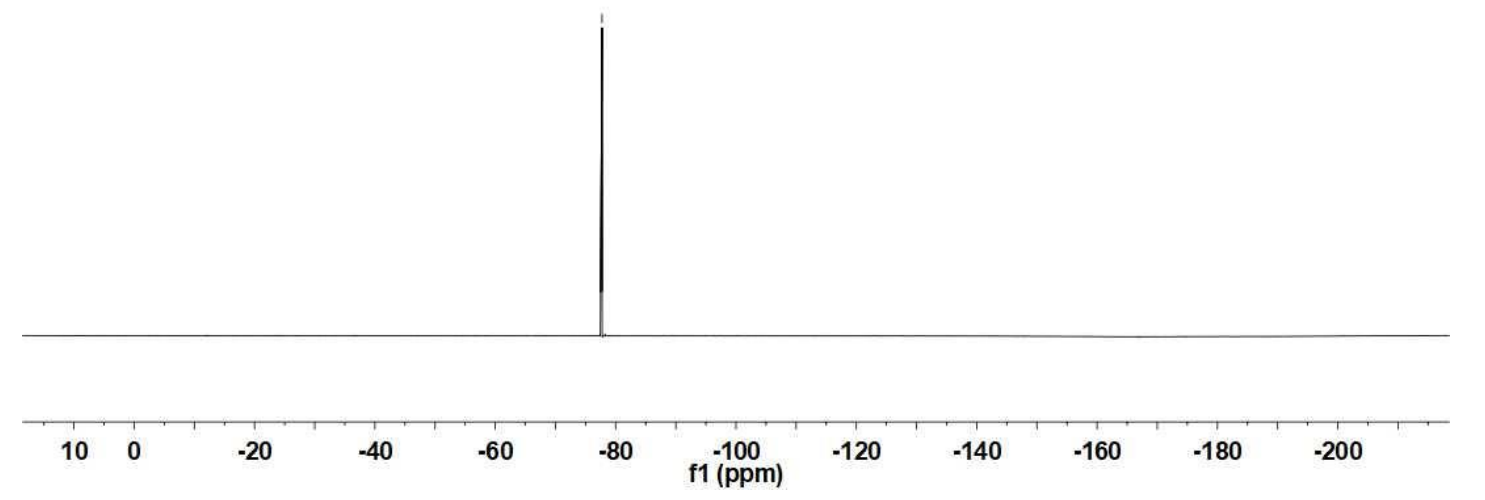


${ }^{1} \mathrm{H}$ NMR (400 MHz, DMSO-d6) spectrum of 4.

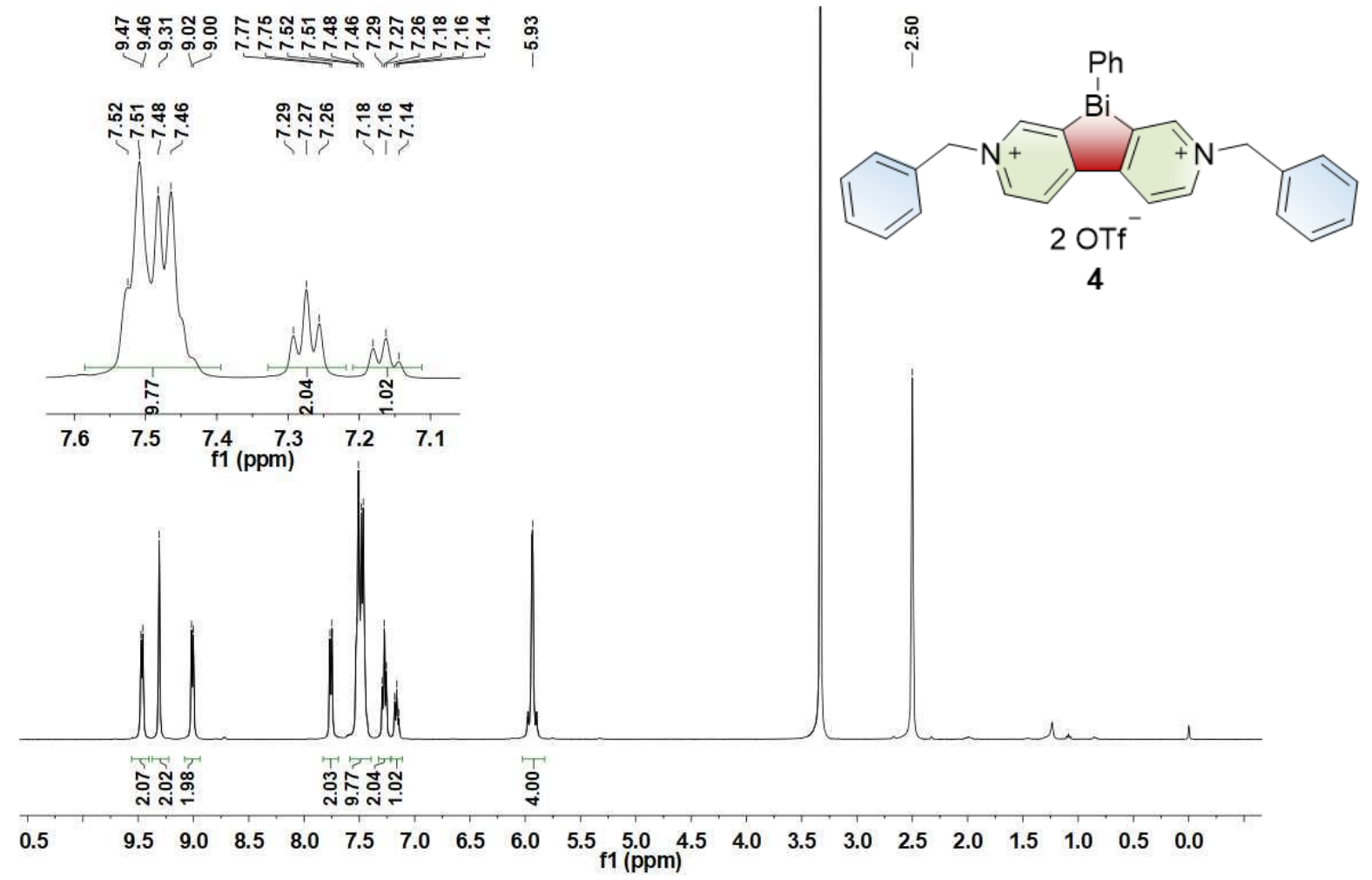

${ }^{13} \mathrm{C}$ NMR (100 MHz, DMSO-d6) spectrum of 4.

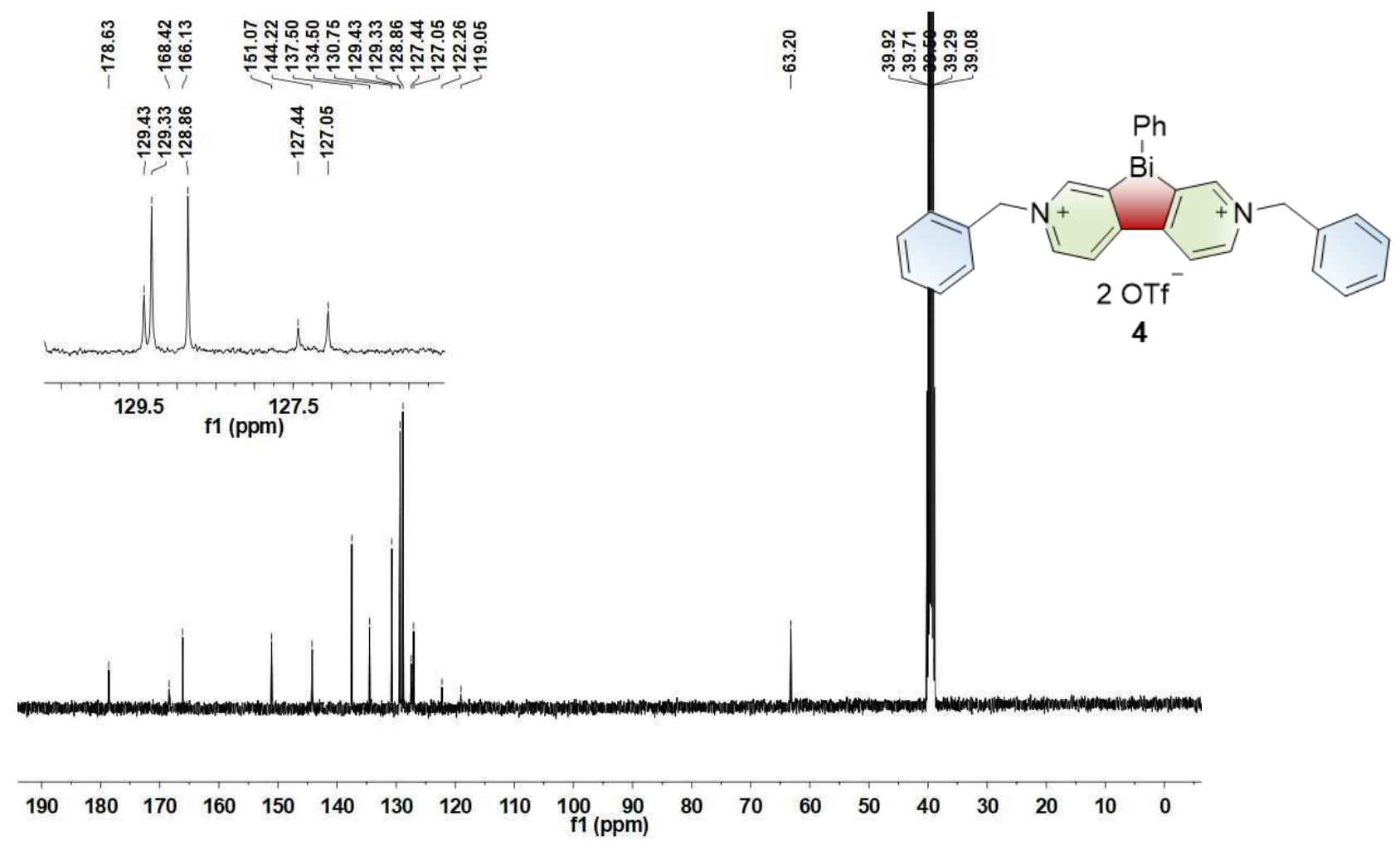


${ }^{19} \mathrm{~F} \mathrm{NMR} \mathrm{(376} \mathrm{MHz,} \mathrm{DMSO-d6)} \mathrm{spectrum} \mathrm{of} 4$.

$$
\stackrel{\text { T }}{\stackrel{i}{T}}
$$
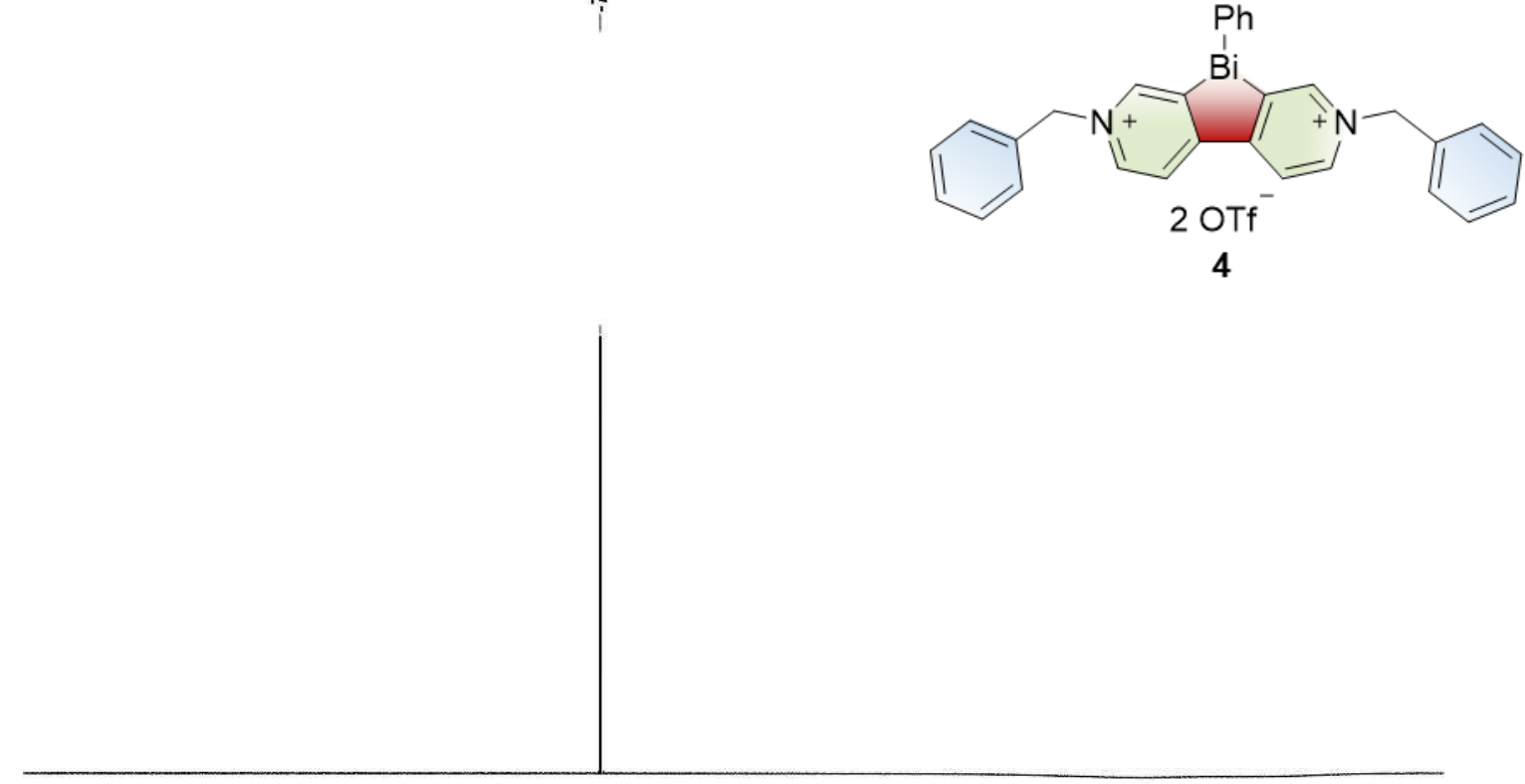

$\begin{array}{llllllllllll}10 & 0 & -20 & -40 & -60 & -80 & -100 & -120 & -140 & -160 & -180 & -200\end{array}$


${ }^{1} \mathrm{H}$ NMR (400 MHz, DMSO-d6) spectrum of $\mathbf{5}$.

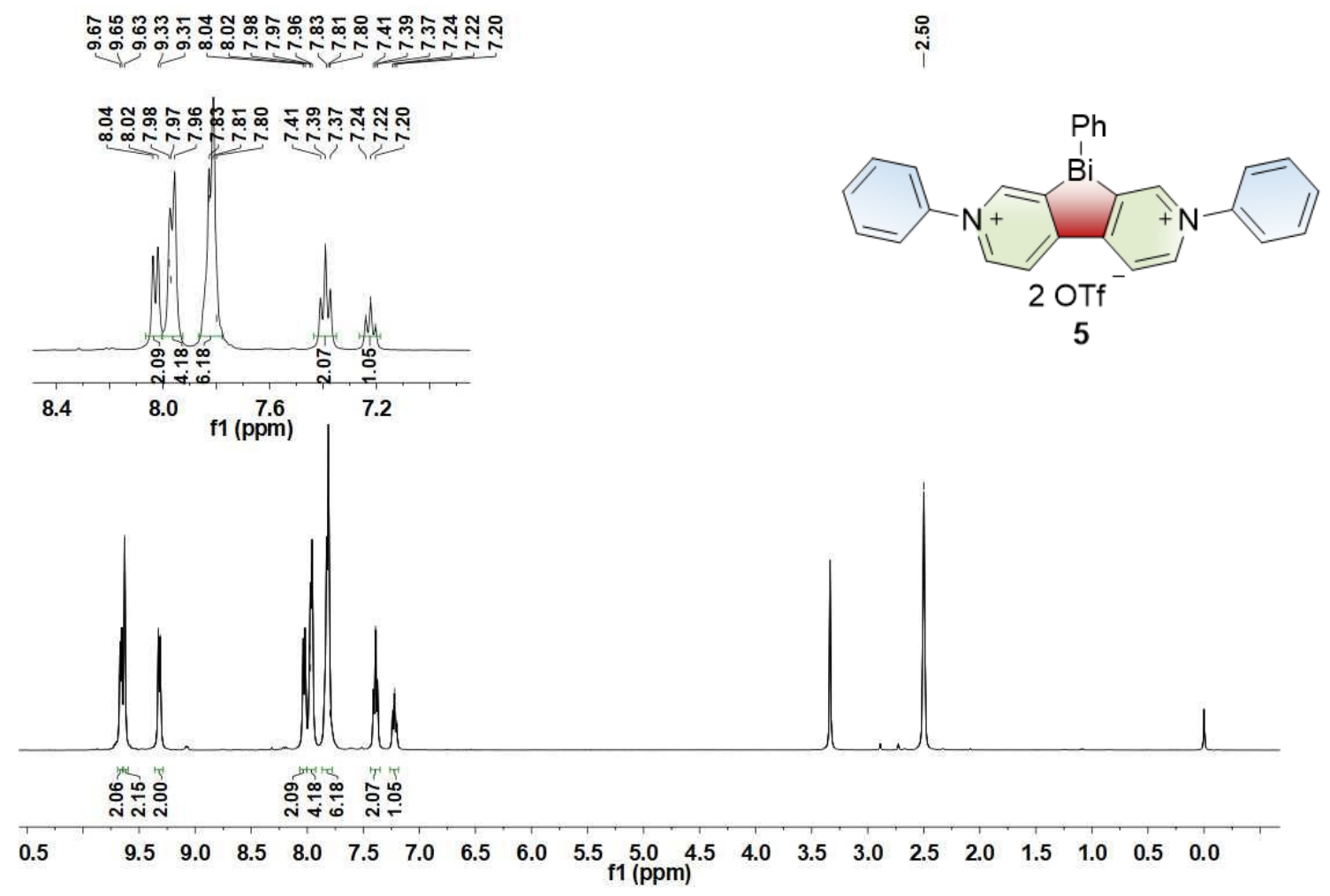

${ }^{13} \mathrm{C}$ NMR (100 MHz, DMSO-d6) spectrum of 5.

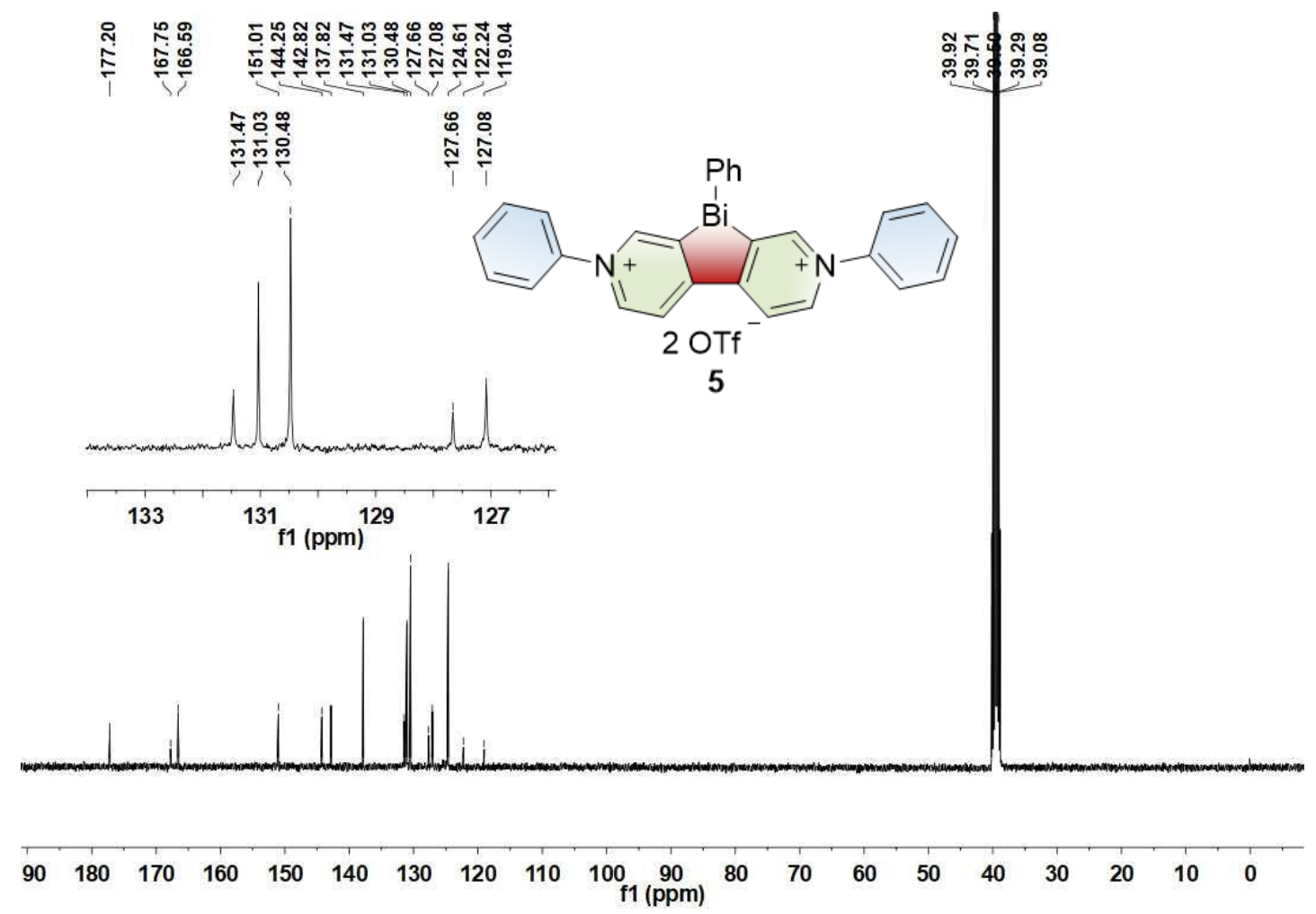


${ }^{19} \mathrm{~F}$ NMR (376 MHz, DMSO-d6) spectrum of $\mathbf{5}$.

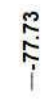
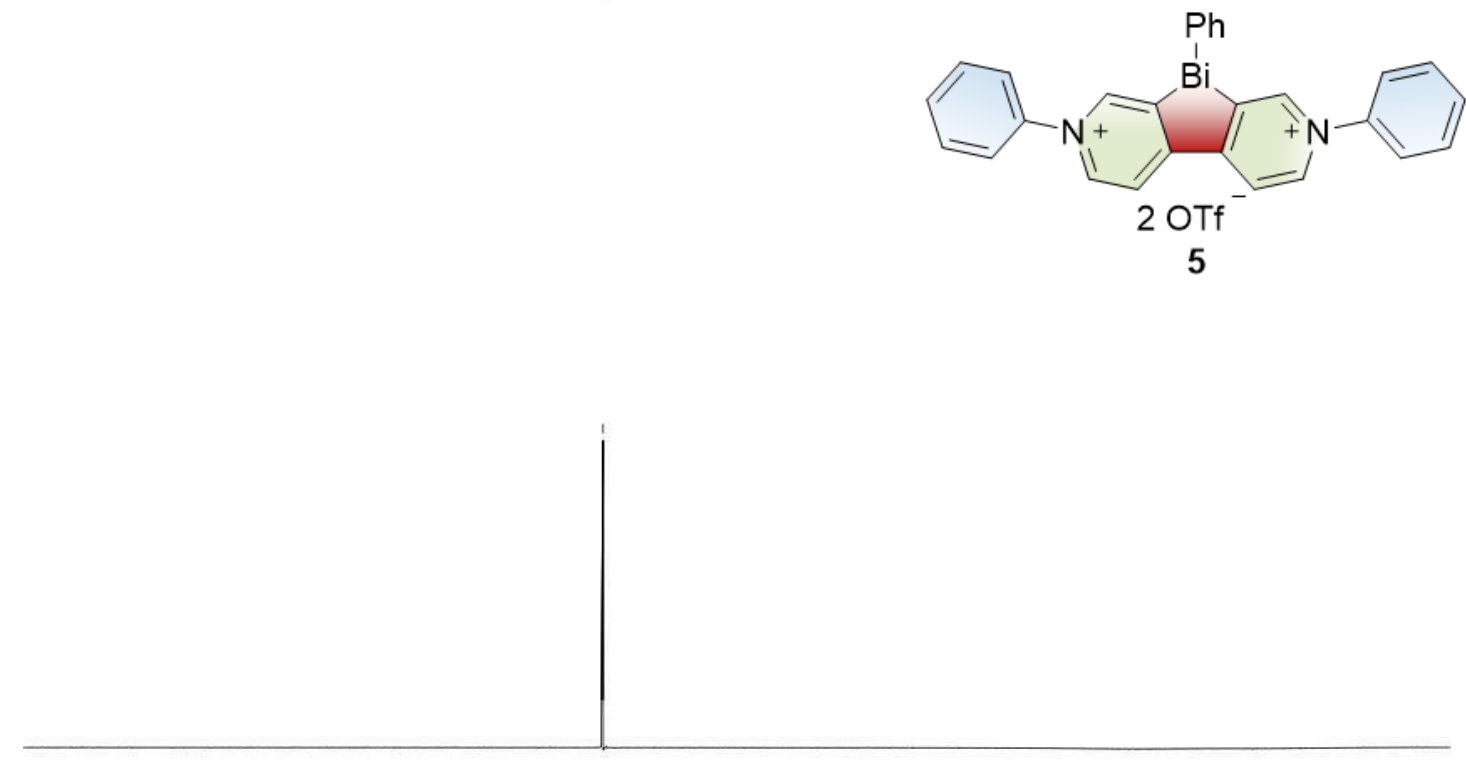

\begin{tabular}{|c|c|c|c|c|c|c|c|c|c|c|}
\hline 100 & -20 & -40 & -60 & -80 & $\begin{array}{c}-100 \\
\mathrm{f} 1(\mathrm{ppm})\end{array}$ & -120 & -140 & -160 & -180 & -200 \\
\hline
\end{tabular}


${ }^{1} \mathrm{H}$ NMR (400 MHz, $\left.\mathrm{CD}_{3} \mathrm{CN}-d 3\right)$ spectrum of 6.

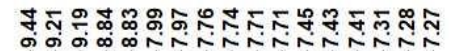
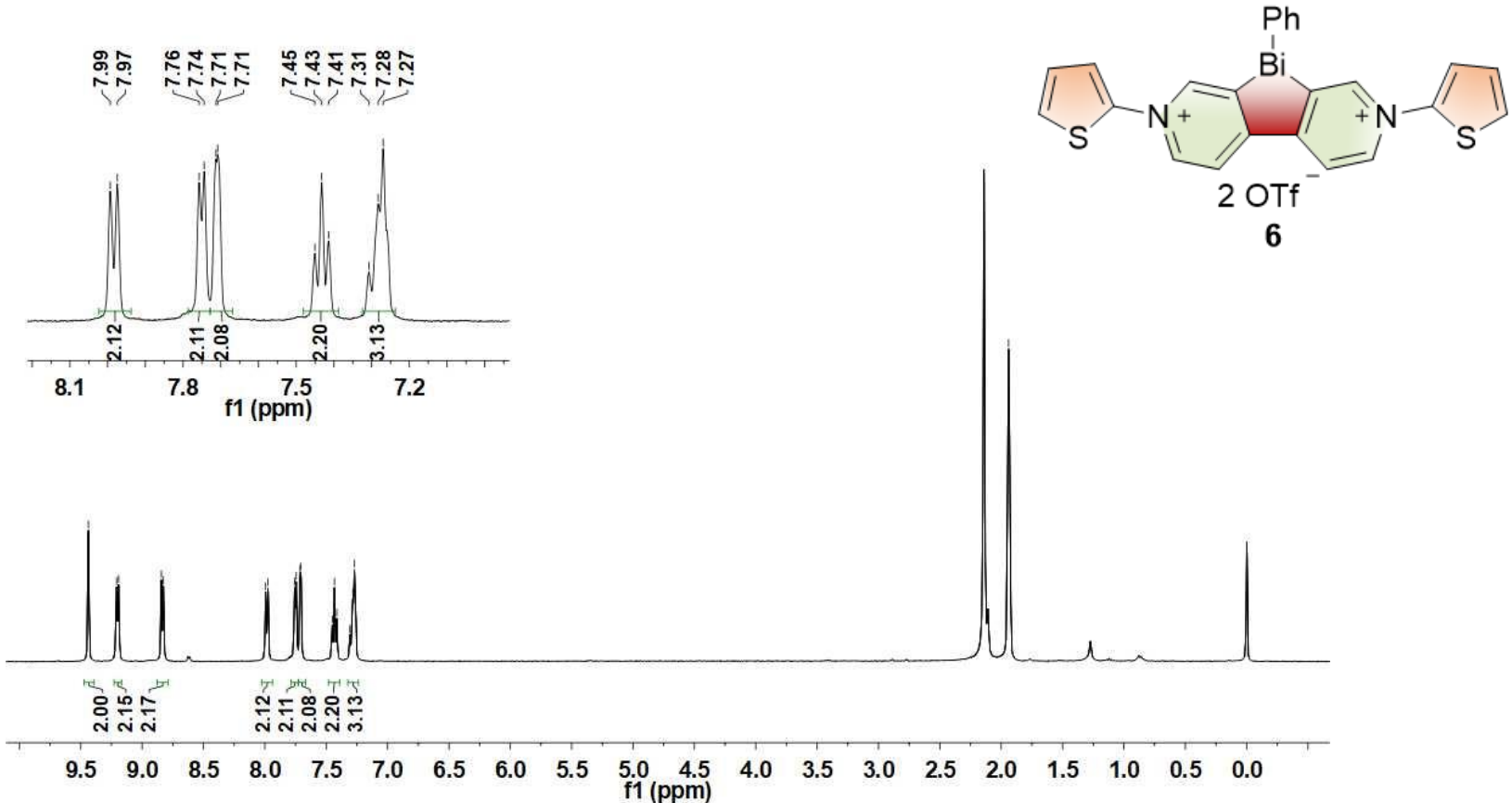

${ }^{13} \mathrm{C}$ NMR $\left(100 \mathrm{MHz}, \mathrm{CD}_{3} \mathrm{CN}-d 3\right)$ spectrum of 6.
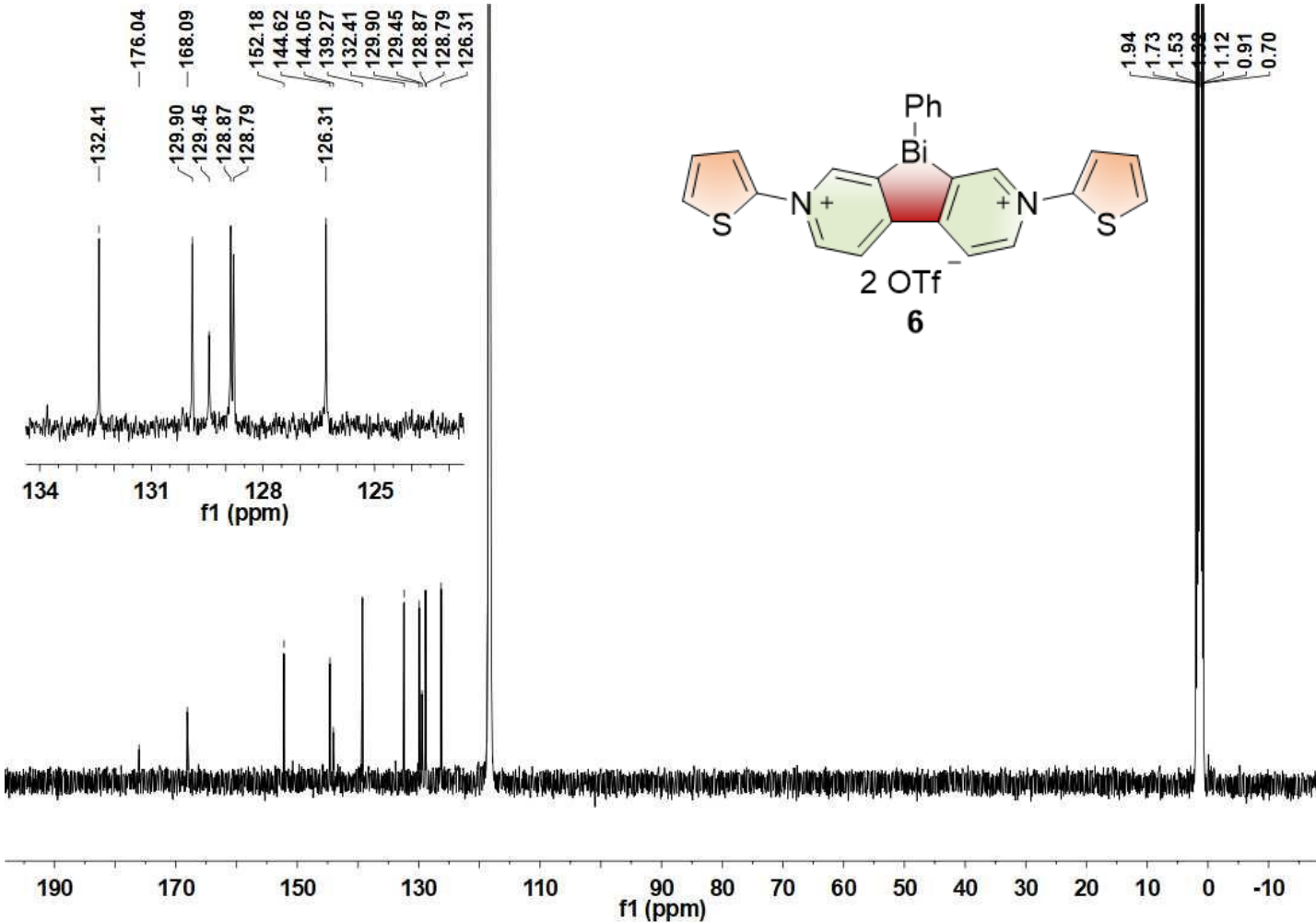
${ }^{19} \mathrm{~F} \mathrm{NMR}\left(376 \mathrm{MHz}, \mathrm{CD}_{3} \mathrm{CN}-d 3\right)$ spectrum of 6.

$\stackrel{\text { क्ष }}{i}$
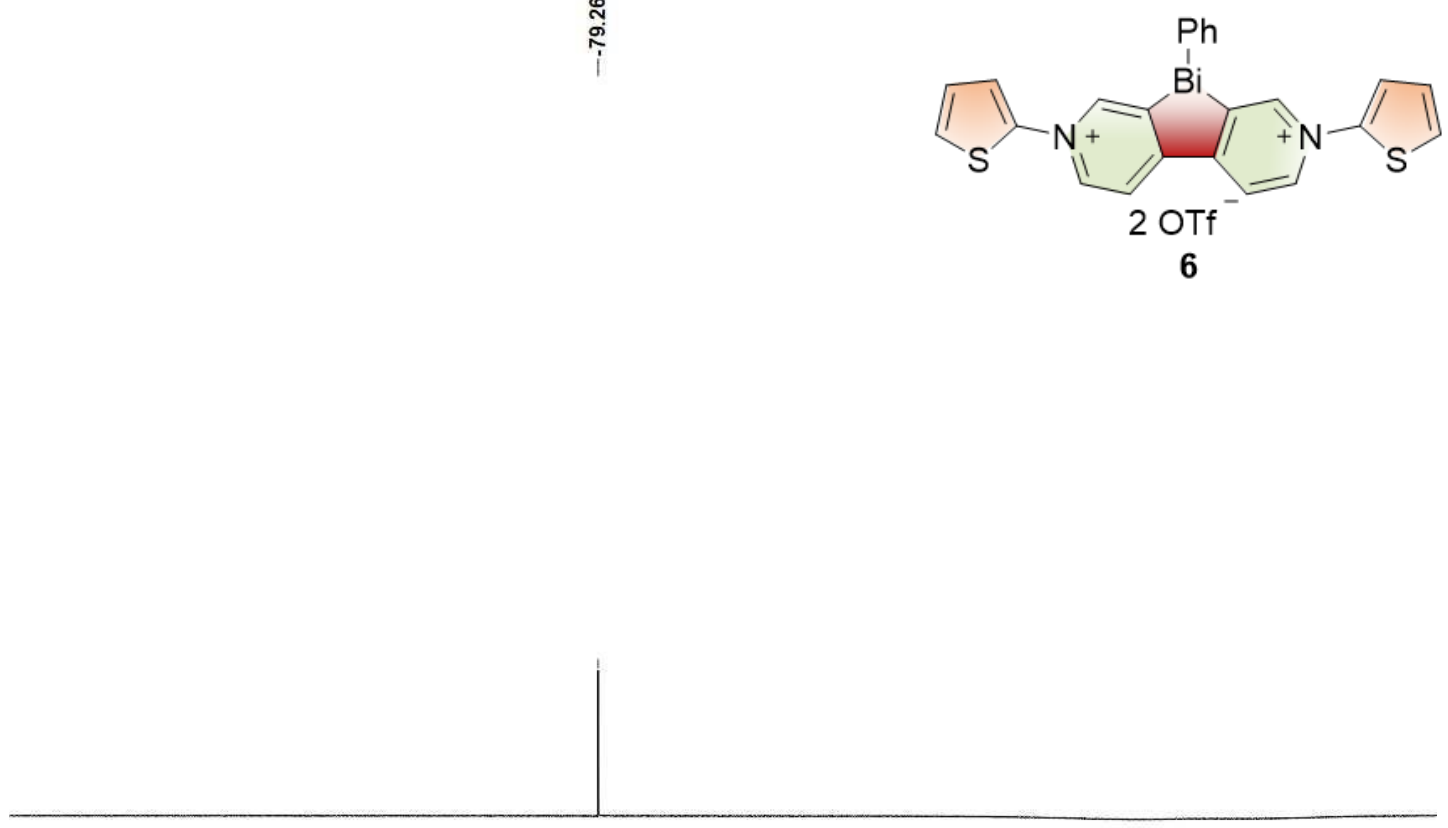

\begin{tabular}{|c|c|c|c|c|c|c|c|c|c|c|}
\hline 100 & -20 & -40 & -60 & -80 & $\begin{array}{c}-100 \\
\mathrm{f} 1(\mathrm{ppm})\end{array}$ & -120 & -140 & -160 & -180 & -200 \\
\hline
\end{tabular}




\section{References}

1. Bielawski, M.; Zhu, M.; Olofsson, B., Efficient and General One-Pot Synthesis of Diaryliodonium Triflates: Optimization, Scope and Limitations. Adv. Synth. Catal. 2007, 349, 2610-2618.

2. Zhu, M.; Jalalian, N.; Olofsson, B., One-Pot Synthesis of Diaryliodonium Salts Using Toluenesulfonic Acid: A Fast Entry to Electron-Rich Diaryliodonium Tosylates and Triflates. Synlett 2008, 4, 592-596.

3. Parke, S. M.; Hupf, E.; Matharu, G. K.; de Aguiar, I.; Xu, L.; Yu, H.; Boone, M. P.; de Souza, G. L. C.; McDonald, R.; Ferguson, M. J.; He, G.; Brown, A.; Rivard, E., Aerobic Solid State Red Phosphorescence from Benzobismole Monomers and Patternable Self-Assembled Block Copolymers. Angew. Chem. Int. Ed. 2018, 57, 14841-14846.

4. Hari, D. P.; König, B., Eosin Y Catalyzed Visible Light Oxidative C-C and C-P bond Formation. Org. Lett. 2011, 13, 3852-3855.

5. Tomasi, J.; Mennucci, B.; Cammi, R., Quantum Mechanical Continuum Solvation Models. Chem. Rev. 2005, 105, 2999-3093.

6. Stephens, P. J.; Devlin, F. J., Ab Initio Calculation of Vibrational Absorption and Circular Dichroism Spectra Using Density Functional Force Fields. J. Phys. Chem. 1994, 98, 11623-11627.

7. Check, C. E.; Faust, T. O.; John M. Bailey; Wright, B. J.; Gilbert, T. M.; Sunderlin, L. S., Addition of Polarization and Diffuse Functions to the LANL2DZ Basis Set for P-Block Elements. J. Phys. Chem. A 2001, 105, 8111 8116.

8. Frisch, M. J.; Trucks, G. W.; Schlegel, H. B.; Scuseria, G. E.; Robb, M. A.; Cheeseman, J. R.; Scalmani, G.; Barone, V.; B.Mennucci; Petersson, G. A.; Nakatsuji, H.; Caricato, M.; Li, X.; Hratchian, H. P.; Izmaylov, A. F.; Bloino, J.; Zheng, G.; L.Sonnenberg, J.; Hada, M.; Ehara, M.; Toyota, K.; Fukuda, R.; Hasegawa, J.; Ishida, M.; Nakajima, T.; Honda, Y.; Kitao, O.; Nakai, H.; Vreven, T.; J. A. Montgomery, J.; Peralta, J. E.; Ogliaro, F.; Bearpark, M.; Heyd, J. J.; Brothers, E.; Kudin, K. N.; Staroverov, V. N.; Kobayashi, R.; Normand, J.; Raghavachari, K.; Rendell, A.; Burant, J. C.; Iyengar, S. S.; Tomasi, J.; Cossi, M.; Rega, N.; Millam, J. M.; Klene, M.; Knox, J. E.; Cross, J. B.; Bakken, V.; Adamo, C.; Jaramillo, J.; Gomperts, R.; Stratmann, R. E.; Yazyev, O.; Austin, A. J.; Cammi, R.; Pomelli, C.; Ochterski, J. W.; Martin, R. L.; Morokuma, K.; Zakrzewski, V. G.; Voth, G. A.; Salvador, P.; Dannenberg, J. J.; Dapprich, S.; Daniels, A. D.; Farkas, Ö.; Foresman, J. B.; Ortiz, J. V.; Cioslowski, J.; Fox, D. J., Gaussian09, Revision A.02, Gaussian, Inc.: Wallingford CT. 2009.

9. Stolar, M.; Borau-Garcia, J.; Toonen, M.; Baumgartner, T., Synthesis and Tunability of Highly Electron-Accepting, N-Benzylated "Phosphaviologens". J. Am. Chem. Soc. 2015, 137, 3366-3371.

10. Durben, S.; Baumgartner, T., 3,7-Diazadibenzophosphole Oxide: A Phosphorus-Bridged Viologen Analogue with Significantly Lowered Reduction Threshold. Angew. Chem. Int. Ed. 2011, 50, 7948-7952.

11. Wang, X. Z.; Meng, Q. Y.; Zhong, J. J.; Gao, X. W.; Lei, T.; Zhao, L. M.; Li, Z. J.; Chen, B.; Tung, C. H.; Wu, L. Z., The Singlet Excited State of BODIPY Promoted Aerobic Cross-Dehydrogenative-Coupling Reactions under Visible Light. Chem. Commun. 2015, 51, 11256-11259.

12. Cismesia, M. A.; Yoon, T. P., Characterizing Chain Processes in Visible Light Photoredox Catalysis. Chem. Sci. 2015, 6, 5426-5434.

13. Murov, S. L.; Carmichael, I.; Hug, G. L., Handbook of photochemistry 2nd ed., Marcel Dekker, New York,. 1993, 303. 